\title{
The Human Capital Legacy of a Trade Embargo
}

DOI:

10.1093/jeea/jvaa052

\section{Document Version}

Accepted author manuscript

Link to publication record in Manchester Research Explorer

\section{Citation for published version (APA):}

Chakravarty, A., Wright, G., \& Parey, M. (2020). The Human Capital Legacy of a Trade Embargo. Journal of the European Economic Association, 0, 0. https://doi.org/10.1093/jeea/jvaa052

\section{Published in:}

Journal of the European Economic Association

\section{Citing this paper}

Please note that where the full-text provided on Manchester Research Explorer is the Author Accepted Manuscript or Proof version this may differ from the final Published version. If citing, it is advised that you check and use the publisher's definitive version.

\section{General rights}

Copyright and moral rights for the publications made accessible in the Research Explorer are retained by the authors and/or other copyright owners and it is a condition of accessing publications that users recognise and abide by the legal requirements associated with these rights.

\section{Takedown policy}

If you believe that this document breaches copyright please refer to the University of Manchester's Takedown Procedures [http://man.ac.uk/04Y6Bo] or contact uml.scholarlycommunications@manchester.ac.uk providing relevant details, so we can investigate your claim.

\section{OPEN ACCESS}




\title{
The Human Capital Legacy of A TRADE EMBARgo *
}

\author{
Abhishek Chakravarty ${ }^{\dagger}$ Matthias Parey $y^{\ddagger}$ and Greg C. Wright ${ }^{\S}$
}

June 1, 2020

\begin{abstract}
We estimate the effects of in-utero exposure to a trade embargo on survival and human capital in an import-dependent developing country. Using a regression discontinuity design, we find that a nearly comprehensive embargo imposed by India on Nepal in 1989 led to a large decline in reported live births, and increased early life mortality. The decline in births is concentrated in poorer, more remote districts, and is sharper for female births than male births, consistent with documented gender discrimination. Women survivors of exposure are more educated in adulthood than unexposed cohorts.
\end{abstract}

Key Words: In-utero, trade embargo, long-term health

JEL Codes: I15, O11, O15

${ }^{*}$ We thank the editor Claudio Michelacci and two anonymous referees for very helpful comments and suggestions. We thank Shiva Raj Adhikari for help with the NLSS data, and Alexandra Marr for excellent research assistance. We further thank Alan Barreca, Sonia Bhalotra, Justin Cook, Adeline Delavande, Lakshmi Iyer, Robert Jensen, Eliana La Ferrara, Giovanni Mastrobuoni, Jon Robinson, Peter Schott, and numerous seminar and conference participants for their comments. All remaining errors are our own.

${ }^{\dagger}$ Chakravarty: The University of Manchester, Oxford Road, Manchester M13 9PL, U.K.

${ }^{\ddagger}$ Parey: University of Surrey, School of Economics, Guildford, Surrey GU2 7XH, U.K.

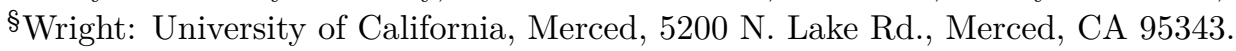




\section{Introduction}

Scant rigorous evidence exists regarding the impact of trade embargoes on health and economic outcomes of individuals in embargoed countries. ${ }^{1}$ This is somewhat surprising, as trade embargoes have historically been employed often and widely as a tool of coercion, ${ }^{2}$ and continue to be a frequently used policy instrument today. The U.S. alone has full embargoes in place on six countries as of the end of $2019 .{ }^{3}$ Importantly, in recent years embargoed countries have frequently been poor and import-dependent and thus vulnerable to trade shocks. While estimates of the impact of embargoes have been reported across academic disciplines, ${ }^{4}$ these often do not disentangle the effects of the embargoes from other circumstances, such as conflict during the embargo period. ${ }^{5}$ In this paper we examine an unanticipated, 15-month-long embargo of Nepal by India beginning in 1989 that placed Nepal and its 17.6 million citizens in a state of virtual autarky. We use the Nepal Demographic and Health Survey (DHS) and the Nepal Living Standards Measurement Survey (NLSS) and implement a sharp regression discontinuity design (RDD) to provide quasi-experimental impact estimates of in-utero exposure to the embargo on reported births, early-life mortality, and on the height, education, and earned income of adult survivors.

We begin by showing that the embargo reduced the number of reported live births by as much as 27 percent shortly after it began. Our subsequent analyses focus both on exploring the causes of this stark decline, as well as investigating its long-run implications. We find that family composition plays an important role. Specifically we show that among mothers without a previous child (also called 'nulliparous' mothers) at the time of the embargo, miscarriages increased by around 4 percentage points due to the shock. In addition, male infant mortality in these households rose by more than 8 percentage points, compared with no rise in the female infant mortality rate, a finding that is consistent with the higher health fragility of newborn boys (e.g., see Waldron, 1983; Naeye et al., 1971). However, mothers with at least one child experienced no such increases in miscarriages or child mortality after the embargo begins. We discuss possible explanations for these findings, such as obstetric risks and the availability of household resources.

The more recent cross-sections of the DHS also allow us to compare long-run educational attainment for cohorts born around the introduction of the embargo. We find significant increases of 0.7-0.9 years in completed education for women exposed in-utero. For men, the DHS sample is much smaller and we find substantial variation in the estimates across specifications. Finally, we complement our long-run analyses with estimates

\footnotetext{
${ }^{1}$ We refer to legal trade restrictions rather than military blockades that rely on naval or armed forces.

${ }^{2}$ Historical examples include the U.S. Embargo Act of 1807 imposed on all naval trade during the Napoleonic wars, or the 1935 League of Nations embargo of Italy imposed after Italy invaded Abyssinia.

${ }^{3}$ The targets are Iran, North Korea, Syria, Sudan, Cuba, and Venezuela.

${ }^{4}$ E.g. see Ali and Shah (2000) for estimates of embargo impacts on child mortality in Iraq, and Garfield and Santana (1997) on the effects of the tightening of the long-running U.S. embargo on Cuba in 1992.

${ }^{5}$ For instance, the U.N. Security Council imposed a complete embargo on Iraq in 1990 that lasted until 2003, and the war in Iraq that followed soon after had significant repercussions that likely contributed to welfare declines during the embargo period.
} 
of the embargo impact on adult income using the NLSS, finding some evidence that adult men who survived in-utero exposure may have had higher adult income relative to unexposed cohorts.

We investigate embargo impacts further by exploiting heterogeneity in households' exposure to the shock, which we argue is in part a function of their effective proximity to international markets. We begin by outlining a conceptual framework (described more formally in Appendix D) in which a region's relative remoteness from global markets has an ambiguous effect on the relative severity of embargo exposure. On the one hand, due to Nepal's poor infrastructure and mountainous terrain, more remote regions may be effectively insulated from international trade shocks; that is, high transport costs within the country may mitigate the effects of external shocks. On the other hand, more remote regions are much poorer, in part as a consequence of the domestic trade frictions that they face. As a result, they may be relatively vulnerable to a trade shock, ${ }^{6}$ particularly when key subsistence goods such as fuel, salt and pharmaceuticals are imported, as they were in Nepal in 1989.

Investigating this in the DHS data, we show that the decline in live births is concentrated in the poorer, more remote districts, establishing the importance of household access to markets during the embargo. Further, the decline in female births exceeds the decline in male births in these districts, despite the greater fragility of boys in early life. This is consistent with parental discrimination against daughters in these regions during the embargo, in line with strong son preference. This preference has historically led to sex selective abortion and subsequent male-biased sex ratios at birth (Pradhan et al., 2019; Valente, 2014), and post-natal neglect of daughters, particularly in remote hilly districts (Koolwal, 2007; Puri and Tamang, 2015). We also examine long-run outcomes, which reveal that women that were exposed to the embargo in-utero in more remote districts are about 2-3 centimetres taller than unexposed cohorts. ${ }^{7}$ This is consistent with positive "selection" of the survivors of the embargo, which would have increased early-life death among weaker children (Bozzoli et al., 2009; Almond, 2006). At the same time, it is also consistent with positive selection at birth of women into less discriminatory households, which would have invested more to ensure daughters' survival. In contrast, women survivors of exposure that were born in closer, wealthier districts are about 3 centimetres shorter, pointing to a less harsh "scarring" effect in these regions where early-life survival was better insured (Bozzoli et al., 2009; Almond, 2006), and where we observe a much smaller decline in live births relative to remote districts.

The context of the Nepalese economy and society is key to interpreting our findings. In particular, it is unlikely that most Nepalese households had savings or stocks of essential goods to smooth the adverse impact of the embargo - i.e., most households were likely living at subsistence income levels. This is also evidenced by the high child labour rate

\footnotetext{
${ }^{6}$ This also applies to exposure to different shocks. For example, in different circumstances, the earthquake in Nepal in April, 2015 had dire consequences in part because relatively poor, remote regions were shut off from both internal and international markets.

${ }^{7}$ We present results on the height of women only, as the heights of surveyed men are not measured.
} 
in the country at the time. ${ }^{8}$ Both the empirical and theoretical literatures indicate that the decision to send children into the labour force, rather than to school, is driven by the inability to meet subsistence levels of consumption without the child's income (see e.g. Basu and Van, 1998; Baland and Robinson, 2000; Ravallion and Wodon, 2000). Given this, the consequences of the embargo were likely felt quickly and harshly by most Nepalese households, which is consistent with news reports at the time that reported shortages of essential goods just days into the embargo. ${ }^{9}$

An oft-cited concern is that lost pregnancies and infant deaths are underreported in developing countries by as much as 20-40\% (WHO, 2006; Sullivan et al., 1994). ${ }^{10}$ This phenomenon has been attributed in part to the fact that over half of all births in developing countries take place at home rather than at a medical facility, and thus may not be reported. It has also been attributed to the resulting social stigma and trauma for mothers who lose late-term pregnancies or young infants (Sullivan et al., 1994; Darmstadt et al., 2009; Stanton et al., 2006; Heazell et al., 2016). Our results are consistent with these channels. Specifically, the large decrease in reported live births that occurs at the start of the embargo is not matched by an equivalent increase in reported child deaths, stillbirths, or miscarriages in the DHS data. Given this likelihood of significant underreporting of births, the long-run estimates noted above provide additional evidence of lasting embargo effects. Since the long-run data are collected from more recent survey respondents who were in the womb in (or close to) March 1989, the respondents are different from the women (mothers) who provided the information on pregnancy outcomes around March 1989, and the information on long-run outcomes is therefore not subject to the stigma or reporting challenges associated with pregnancy.

Our work relates to existing studies that examine the health effects of in-utero exposure to economic shocks. For example, van den Berg, Lindeboom, and Portrait (2006) find that children born during economic downturns in the Netherlands have shorter lifespans. In contrast, Cutler, Miller, and Norton (2007) find no effects on the long term health of children born during the American dust bowl era. One advantage of our study is that the embargo that we examine constituted a large economic shock with a clearly defined start and end date, allowing us to accurately identify cohorts that were exposed in-utero, and to compute sharply identified quasi-experimental estimates of exposure on live births and human capital using data at the level of individual pregnancies. ${ }^{11}$

\footnotetext{
${ }^{8}$ Over 40 percent of children aged 5-14 are estimated to have participated in the labour force in 1996 according to a large national study conducted by the International Labour Organisation (Suwal et al., 1997).

${ }^{9}$ For example, three weeks into the embargo the LA Times (April 10, 1989) reported that "Women and children [...] said they hadn't eaten a cooked meal in a week". Six weeks into the embargo the NY Times reported that traffic across the main border crossing in Birgunj "is a trickle compared with the level before March 23".

${ }^{10}$ Lawn et al. (2011) estimates the number of miscarriages and stillbirths in the developing world to be 2.08-3.79 million per year. $98 \%$ of the stillbirths worldwide are estimated to take place in developing countries.

${ }^{11}$ Adhvaryu et al. (2018) uses individual-level data in Ghana to show that in-utero exposure to adverse cocoa price shocks increases the risk of mental health problems in later life in cocoa-growing regions.
} 
Another prominent feature of the literature on the welfare effects of in-utero exposure to shocks is a reliance on natural phenomena such as rainfall shocks to identify causal impacts. In contrast, our paper examines the impact of a policy instrument, one that affects the welfare of significant numbers of people who are typically economically vulnerable. Given the poverty and the landlocked nature of Nepal, our estimates likely represent upper-bound effects. At the same time, there are 32 landlocked developing countries recognized as such by the U.N. (UNCTAD, 2020), with an aggregate population of over 450 million citizens.

The effects of sudden and extreme shocks to market access have been explored in several papers, primarily in a historical context. Juhász (2018) explores the effect of the Napoleonic Blockade on long-term economic development. Similarly, Feyrer (2009) exploits the closing of the Suez Canal in 1967 and its reopening in 1975 to estimate the impact of trade cost shocks on income. Berhofen and Brown (2005) evaluate the aggregate welfare gains from Japan's opening to global trade after 200 years of near autarky, finding a rise in welfare equal to eight or nine percent of Gross National Product. Frankel (1982) finds that the U.S. self-imposed embargo of 1807-1809 effectively put Britain in a state of autarky, leading to a large rise in relative prices in Britain. Irwin (2005) also explores this historical event but from the U.S. perspective, finding that the embargo cost the U.S. approximately five percent of its Gross National Product in 1808. Redding and Sturm (2008) exploit the division and reunification of Germany to estimate the impact of market access on the population growth of West German cities, exploring the role that regional differences in market access play in their outcomes.

The remainder of the paper is organized as follows. Section 2 provides background on the embargo and discusses the literature on early-life health shocks and the effects of trade embargoes. Section 3 describes the data we use for the analysis. Section 4 summarizes the estimation methods we use to analyze the impact of in-utero exposure to the embargo. Section 5 presents the empirical findings. Section 6 concludes with a discussion of the implications of our findings.

\section{Background and Conceptual Framework}

\subsection{The 1989 Embargo}

On March 23, 1989, treaties on trade and transit between India and Nepal were allowed to expire, at which point India closed all but two entry points into landlocked Nepal. ${ }^{12}$ Historically, the treaties had been renewed as a matter of course, and the embargo clearly took the Nepalese authorities by surprise; for instance, as late as February 6 the Nepal Foreign Minister dismissed reports that India may not renew the treaties as misleading, describing the relationship with India as excellent (Koirala, 1990).

\footnotetext{
${ }^{12}$ The two transit points that remained open only allowed a few critical goods into Nepal, such as some medicines.
} 
Nominally the breakdown in the relationship between India and Nepal had been caused by the inability of the two countries to agree on whether trade and transit should be negotiated within a single agreement, as India desired, or whether the status quo should be maintained, in which the treaties were individually negotiated. However, the underlying impetus for the standoff was more complicated, and three factors are usually given as main causes. First, Nepal had recently agreed to arms purchases from China, India's rival. Second, in mid-1988 Nepal unilaterally imposed 55 percent tariffs on some Indian goods. Third, in 1987 Nepal began requiring work permits for non-Nepalese, a policy that was made more restrictive in 1989 (Koirala, 1990). At the time, approximately 150,000 Indians were living in Nepal and a significantly higher number of Nepalese were living in India, and required no permit to work (Koirala, 1990). To make matters worse for Nepal, on March 31 an agreement between the countries expired, in which India had agreed to transport coal and oil purchased from third countries into Nepal. Next, on June 23 a contract for warehouse space in Calcutta port - Nepal's only reliable outlet to the sea - also expired and India cancelled several million dollars of trade credits (Blanchard and Ripsman, 2013). Finally, throughout the embargo India refused to supply rail cars for shipments across the remaining two transit points and remittances from Nepalese working in India were restricted (Garver, 1991).

Given Nepal's near-total reliance on India as a conduit to the world, it is unlikely the Nepalese government sought such a schism with India, and once the embargo had begun the Nepalese government continued to state that the breakdown had been unforeseen. At the time of the border closure, Nepal had a per capita Gross National Income of $\$ 180$; fifth-lowest in the world tied with Malawi (World Bank, 1990). Blanchard and Ripsman (2013) summarize the prevailing view that "the economic consequences of the dispute were enormous".

More generally, being a landlocked nation has been found to be a major impediment to international trade. For instance, Anderson and Van Wincoop (2004) find that the median landlocked country faces transport costs that are 55 percent higher than the median coastal country, and similar results are found throughout the literature. MacKellar et al. (2000) conclude that being landlocked reduced economic growth by an average of 1.5 percent per year. Elliott (2006) argues that United Nations sanctions on Iraq during the 1990s imposed an unprecedented cost on the economy because Iraq was nearly landlocked. Faye et al. (2004) argue that it is dependence on neighbours that often leads to the relatively poor performance of landlocked countries. The case we focus on represents perhaps an extreme case, since not only was India the major trading partner of Nepal (accounting for 38 percent of its exports and 36 percent of its imports), but perhaps more importantly was also Nepal's sole source of access to international markets (very little trade went via China).

The consequences for Nepal were predictably severe. Without sufficient oil and kerosene, forests were cut down for fuel; transportation within the country slowed dramatically (NY Times, May 10, 1989). The near cessation of vehicle traffic cut vital links 
to rural areas that were dependent on shipments of medicine, food and other necessities. From the beginning of the embargo the government instituted rationing, ${ }^{13}$ which increased the prices of commodities and most imported items. Industrial output took a large hit due to its dependence on imported intermediates, while agriculture was less affected. Inflation reached up to 25 percent (Blanchard and Ripsman, 2013). Finally, in July of 1990, 15 months after the embargo began, India lifted the embargo and the countries began negotiations over new trade and transit treaties.

Figure 1(a) documents the impact of the embargo on imports from India (solid line in the Figure). Since trade between Nepal and the rest of the world almost exclusively travelled via India, we also show Nepalese imports from all countries as well (dashed line). Figure 1(b) then breaks down imports from India by sector, and Figure 1(c) charts the effect on exports, which may have had an indirect effect on outcomes. When interpreting the patterns one should keep in mind that the embargo began in March of 1989 and ended in July of 1990, such that in both years there were substantial periods in which trade relations were effectively normal.

The figures present a consistent pattern and point to a large decline in international trade due to the embargo. As expected, trade with India was disproportionately affected. In line with the anecdotal evidence, Figure 1(b) indicates that coal and petroleum imports were hit particularly hard. Indeed, coal and petroleum imports from India fell 95 percent during 1989. Food imports from India fell 45 percent and manufactures fell 49 percent. Pharmaceutical imports from India fell 13 percent, a drop that was likely mitigated by supplies via the remaining open border crossings. Finally, Figure 1(c) indicates that exports also fell, particularly exports to India, as industrial production stumbled.

\subsection{Conceptual Framework and Mechanisms}

Our primary focus is on the consequences of the embargo for birth outcomes and the implications for long-run human capital accumulation of the adult survivors of in-utero exposure. We consider our findings within the context of the literature on the health effects of early-life exposure to large economic shocks, which we discuss in detail below. These depend on the balance between scarring and selection effects within the exposed population. We explore the relevant mechanisms associated with our results by investigating heterogeneity in the effects, and linking the observed heterogeneity to related findings in the literature. For this purpose, we split our sample by gender, household composition and initial exposure to international markets, each of which has been found to be an important determinant of the responsiveness of households to shocks. We also explore the interaction of these characteristics to provide additional evidence regarding potential mechanisms.

There is substantial evidence that exposure to negative economic shocks in early life

\footnotetext{
${ }^{13}$ The government also implemented a series of policies over the embargo period intended to ease the burden on households, which we discuss further in Section 5.3.
} 
leads to worse health outcomes. In particular, the literature has found that shocks may lead to lower height in adulthood (see Almond and Currie, 2011, for a comprehensive survey of the literature). For example, children affected by the phylloxera infestation in wine-growing regions in France in the late 1800's were found to be 0.5-0.9 centimeters shorter at age 20 than unexposed cohorts (Banerjee et al., 2010). Similarly, a 10 percent increase in local district rainfall led to increases in adult female height in Indonesia of up to 0.3 centimeters (Maccini and Yang, 2009). ${ }^{14}$ Regarding in-utero health shocks and adult height, studies have found that the Chinese famine reduced height by as much as 3 centimeters among children born or conceived during the famine period (Chen and Zhou, 2007; Gorgens et al., 2012).

In some circumstances a negative economic shock may be so severe that it increases fetal, and possibly infant, mortality. ${ }^{15}$ This may be of particular concern in the high mortality environments typical of many developing countries such as Nepal. Bozzoli et al. (2009) present a theoretical framework where health is measured as adult height. This framework suggests that mortality selection can dominate scarring effects in high mortality environments, leading survivors of early-life shocks to be taller in adulthood. Almond (2006) develops a theoretical framework for mortality selection that assumes a summary measure of health is sufficient for survival to adulthood if it is above some mortality threshold. ${ }^{16}$ Valente (2015) builds on Almond (2006) and Bozzoli et al. (2009) and examines, using the same data as in our paper, how in-utero exposure to conflict during the Nepalese civil war affects fetal loss, sex ratio at birth, and neonatal health. The study finds significant increases in fetal loss and the probability of a female birth with increased exposure to conflict. However it finds no significant effects on probability of neonatal survival or newborn health, indicating that the scarring effects of exposure to conflict, which worsen health, were approximately the same magnitude as the selection effects, which improve observed health conditional on prenatal survival.

\subsubsection{Conditions at Childbirth}

The overwhelming majority of Nepalese mothers in 1989 experienced very low levels of professional support during childbirth. The 1996 wave of the DHS data ${ }^{17}$ shows that only 8 percent of births in Nepal during 1994-96 were delivered in a health facility. ${ }^{18}$ The 1996

\footnotetext{
${ }^{14}$ Adult height is a salient health outcome due to the fact that taller adults also have better cognitive, social, and economic outcomes (e.g., see Currie, 2009; Steckel, 2008), possibly because taller workers are stronger, healthier, and more productive (e.g., Strauss and Thomas, 1998). Related hypotheses argue that common inputs to height and cognitive ability mean taller workers are also smarter (Case and Paxson, 2008) and may also have better self-esteem (e.g., Young and French, 1996), be socially dominant (e.g., Hensley, 1993), and may benefit from positive discrimination (e.g., Magnusson et al., 2006).

${ }^{15}$ The Chinese famine is one such case, and the studies by Chen and Zhou (2007) and Gorgens et al. (2012) take care to deal with the resulting sample selection bias.

${ }^{16}$ Meng and Qian (2009) address the selection bias empirically by focusing on the top decile of heights, showing that stunting is most pronounced among these (likely healthiest) children, as the unhealthiest children were culled by the famine.

${ }^{17}$ We describe the data we use in detail in Section 3 below.

${ }^{18}$ The DHS data do not provide this information for births during the embargo period, but an alternative National Fertility, Family Planning, and Health Survey (NFHS) carried out in 1991 reports identical
} 
DHS data also show that only 9 percent of births were delivered with the assistance of a doctor or a trained nurse (or midwife). ${ }^{19}$ Also, 56 percent of births occurred at home with only mothers' friends and relatives to provide assistance, and 11 percent of births occurred without any assistance at all (Pradhan et al., 1997). Lack of skilled birth care is seen as a key factor leading to high neonatal mortality rates (Darmstadt et al, 2005).

Maternal stress and reduced maternal nutrition may also play a role in the effects of the embargo. Evidence on the impact of shocks, such as bereavement, on pregnant women from large samples of thousands of births show that such events can increase the risk of stillbirth by as much as 18 percent, and of preeclampsia during labour by over 50 percent (László et al., 2013a; László et al., 2013b). Importantly, these studies were undertaken in countries such as Sweden and Denmark, which are much wealthier nations than Nepal. Episodes of widespread nutrition deprivation have been shown to increase pregnancy loss due to raised maternal progesterone levels (see e.g. Wynn and Wynn (1993)). While we cannot estimate the separate impacts of these potential channels directly, they may form part of the overall impact.

In our context, it is important to keep in mind that there may be substantial underreporting of lost pregnancies in the survey data, in line with the literature on Nepal and developing countries more generally (Karki and Kittel, 2019; Paudel et al., 2018; WHO, 2006). In general, this phenomenon has been attributed to the fact that over half of all births in developing countries take place at home rather than at a medical facility, and thus may not be reported, as well as the role of social stigma or trauma for mothers who lose late-term pregnancies (Darmstadt et al., 2009; Stanton et al., 2006; Heazell et al., 2016).

\subsubsection{The Role of Gender, Family Composition, and Geography}

To identify the specific household circumstances that led to differential outcomes during and after the shock, we explore key dimensions of heterogeneity that the literature has identified as playing an important role in household responses to an economic shock.

We begin by noting that the diverse and sometimes extreme geography of Nepal implies that domestic transport costs likely played a large role in propagating or mitigating the embargo shock. In a recent paper Storeygard (2016) found that the magnitude of transport costs between sub-Saharan cities was an important determinant of the extent to which an external trade shock affected those cities. More generally, the literature indicates that Nepalese households located far from international markets would have experienced a relatively mild income shock, since domestic transport costs create a pricebuffer between local and international markets. ${ }^{20}$ On the other hand, remote households are significantly more likely to have been poor. The relationship depicted in Figure A.1

statistics, indicating that very few mothers delivered under trained medical supervision at the time of the embargo.

${ }^{19}$ Again this is very similar to 8 percent reported in the NFHS 1991 data.

${ }^{20}$ See Redding and Sturm (2008) or Atkin and Donaldson (2015) for an overview of this literature. 
implies that a household that is 100 kilometers closer to the main border crossing will on average have 20 percent higher earned income. Similarly, the Asian Development Bank recently noted that poverty is both much higher in rural Nepal and has also been rising in recent decades, in contrast to urban areas (Asian Development Bank, 2017). As a result remote households may have been more vulnerable to negative shocks to the extent that their subsistence needs were only just being met prior to the embargo.

In Appendix D we present an illustrative model that formally highlights this tension. In the model, more remote households have lower real incomes, all else equal. This is due to the fact that domestic transport costs create a wedge between local and international prices, such that the price that remote households get for their exports is relatively low and the price they pay for their imports is relatively high. We assume that individuals have Stone-Geary preferences, which imply that household subsistence needs must be met prior to consuming other goods. Combining these features, we show that a sharp rise in external (international) barriers to trade - such as occurred due to the embargo - has an ambiguous relative impact on households ${ }^{21}$ such that it is not clear whether households facing higher domestic transport costs will be more or less harmed by the embargo relative to less remote households, since the answer depends on model parameters. For instance, we show the intuitive result that the welfare consequences of the embargo will be relatively worse for remote regions when the required expenditure on subsistence goods is large.

With this framework in mind, we explore the health and human capital outcomes in aggregate, and then accounting for whether a household is above the median distance to the main border crossing (far) or below the median (close). We also split the sample by gender throughout the analysis, an approach that is motivated by the greater health fragility of newborn boys (e.g. see Waldron, 1983; Naeye et al., 1971), and also by high prevailing parental son preference in Nepal that manifests in a male-biased sex ratio at birth and postnatal neglect of girls, particularly in remote, hilly districts (see Pradhan et al., 2019; Koolwal, 2007; Puri and Tamang, 2015). Sex-selective abortion and neglect of daughters in China and India, which border Nepal and have high societal son preference, have been shown to determine the later-life welfare outcomes of surviving girls born in less discriminatory households. The introduction of ultrasound technology in these countries increased sex-selective abortion, but also reduced the child mortality rate amongst surviving girls, narrowed the male child advantage in breastfeeding duration and immunisation rates, and reduced rates of wasting and undernutrition of girls at later ages $(\mathrm{Hu}$ and Schlosser, 2015; Anukriti et al., 2016; Lin et al., 2014).

Figure 2 provides some initial evidence from the DHS survey data on the interaction between gender and a household's relative access to international markets, showing the pre-embargo pattern of relative birth outcomes by gender as a function of the distance of a household from the border with India (a proxy for distance to international markets). ${ }^{22}$

\footnotetext{
${ }^{21}$ Note that the effect of the embargo is negative for all households - i.e., the embargo reduces absolute welfare for all households.

${ }^{22}$ We can only use the 2006, 2011, and 2016 waves of the DHS survey data to examine heterogeneity by distance from the border, as district identifier information is not available for the previous waves. See
} 
In Figure 2(a), we see that the sex ratio at birth among cohorts born before the 1989 embargo is marginally biased towards boys, and this bias slightly increases with distance to the border, even though this difference across terciles is not statistically significant. In Figures 2(b) and 2(c), we also see that both female and male postnatal infant mortality increase with distance to the border, but male mortality always exceeds female mortality; a reflection of boys' greater postnatal fragility, even in the presence of parental son preference. Hence, the interaction of gender and geography may be an important channel through which the embargo affects in-utero and infant outcomes.

Building on Figure 2, Figure 3 documents additional pre-embargo evidence on education and health outcomes for adult women. ${ }^{23}$ Figures 3(a) and 3(b) show that adult women in the most remote districts had lower educational attainment and weight than women residing closer to the border, indicating greater relative poverty and worse access to nutrition. Interestingly, Figure 3(c) shows that adult women in the most remote districts were taller than those in districts closer to the border, despite being poorer. There could be several explanations for this, but we note that it is consistent with a channel in which higher risk of early-life mortality due to poverty and greater gender discrimination in remote areas causes overall positive health "selection" of women survivors.

An additional source of heterogeneity that we exploit is in the size of the household and, more specifically, whether this is the mother's first child. There are two main reasons this could be important. First, nulliparous mothers in developing countries including Nepal have a well-documented higher obstetric risks that impact child survival (e.g. see Lee et al., 2011; Kupka et al., 2009). Such complications could have occurred with greater incidence, or been more difficult to medically treat when the embargo was imposed due to its consequent hardships, particularly as the majority of births in Nepal took place at home without skilled medical care at this time. A related concern is that nulliparous women may experience more mistreatment (Vedam et al., 2019). Second, more children may mean more household income, given the high rate of child labor in Nepal, which could buffer the adverse income effects of the embargo (a "portfolio" effect). It is not possible for us to separately identify which of these channels may drive heterogeneity in embargo impacts by child birth order, but we investigate whether such heterogeneity exists nevertheless.

\section{Data}

We use the 1996, 2001, 2006, 2011, and 2016 waves of the Demographic and Health Survey (DHS) data from Nepal in our analysis of birth and health outcomes. The Nepal DHS survey collects detailed information from women aged 15-49 on their entire history

\footnotetext{
below in Section 3 for our definition of distance to the border.

${ }^{23} \mathrm{Men}$ are not interviewed in all DHS survey rounds, and in addition sampled with lower frequency in the survey rounds where they are included. We therefore focus on women in this figure and in many of our main results.
} 
of pregnancies, recorded at a monthly level, and whether these culminated in a live birth, a stillbirth, or if the child was lost before coming to term. ${ }^{24}$ The survey also records whether children who are born alive continue to survive, and their age of death if they do not. Information on a variety of respondent characteristics such as education and health is also collected. We first examine the impact of in-utero exposure to the embargo on the number of reported live births. We also examine embargo impacts on reported miscarriages directly, but we rely on the indirect approach of measuring reported live births for the main analysis, as research using globally available data (including the DHS surveys) shows that final-trimester miscarriages are underreported by as much as 40\% (Stanton et al., 2006). This underreporting most likely reflects perinatal deaths, which include both stillbirths of fetuses past 28 weeks of gestation, and infant deaths of children within the first year of birth. We also present estimated embargo impacts on the probability of infant mortality (death aged one year or less) and miscarriage, and test for impact heterogeneity by child gender and also by whether the family already has a child.

Table 1 shows descriptive statistics on mothers and their completed pregnancies during 1985-1995, which is broadly the period from which our estimation sample is drawn. This period yields a sample of 22,022 mothers who have 57,473 completed pregnancies. The data show that Nepal was a high mortality environment during this period. The probability of a pregnancy ending in a reported miscarriage in the sample is 6.1 percent, and the infant mortality rate (death aged one year or less) is 10.1 percent. The probability of a stillborn birth is however lower at 1.9 percent. ${ }^{25}$ The other statistics show that mothers are about 24.5 years of age on average when they complete a pregnancy, have an average height of 150.6 centimeters, and have a 35 percent likelihood of belonging to one of the two dominant castes in Nepal (Brahman and Chhetri castes). Notably, mothers in this sample have very low levels of education. Only 21 percent of mothers have any education. The average years of schooling obtained by mothers is 1.25 years. Regarding the long-run outcomes, we examine the effect of in-utero exposure to the embargo on educational attainment in adulthood for women survey respondents, both at the extensive and the intensive margin. the summary statistics show that women born during 19851995 have 6.1 years of completed education, and men born during these years have 7.8 years of completed education on average. We further investigate the impact of in-utero exposure to the embargo on adult women's height, which is 151.6 centimetres on average for the same cohorts of women. ${ }^{26}$

We supplement the analysis of long-run economic outcomes with earnings data from the 2010/2011 (Wave III) wave of the Nepal Living Standards Survey (NLSS). The NLSS Wave III is a household survey of 7,020 Nepalese households and 28,689 individuals

\footnotetext{
${ }^{24}$ Miscarriages after 24 or 28 weeks of pregnancy are often technically defined as stillbirths in the medical literature. However we follow the survey methodology and define births where the child was born dead as stillbirths, and pregnancies lost before term as miscarriages.

${ }^{25}$ The reported monthly frequencies of both stillbirths and intentionally terminated pregnancies are very low, so we do not report estimation results on these.

${ }^{26}$ Men's heights are not recorded in any of the DHS survey rounds.
} 
(both men and women). The survey covers 71 of Nepal's 75 districts and is stratified geographically across 14 regions. ${ }^{27}$ These data are recorded at the annual level and as a consequence the embargo treatment is measured at the annual cohort level, starting with the 1989 cohort (we discuss shortcomings and implications of this in Section 4 below). Table 2 provides some descriptive statistics for the NLSS sample, where we see that the majority is female. Regarding income, we focus exclusively on wage income, thus excluding non-wage income such as in-kind payments and rental income in our analysis. ${ }^{28}$ Overall, wage income is quite low in Nepal, with a mean monthly wage income of 8,743 Rupees in 2010/2011, the equivalent of about 87 US dollars in $2011 .^{29}$ The use of 2010/2011 NLSS data ensures that those exposed in-utero to the 1989 embargo (which lasted through 1990) will be 20-22 years of age, and will therefore (mostly) have finished school.

We also exploit information on the district of birth of an individual, which allows us to exploit heterogeneity in the relative remoteness of households. Specifically, we calculate the distance from each district's headquarter to Nepal's main border crossing in Birgunj, referred to as the "Gateway to Nepal". ${ }^{30}$ The vast bulk of trade with India goes via Birgunj, as Birgunj hosts the only rail-connected multi-modal clearance depot (i.e., transportation hub) in Nepal. ${ }^{31}$ Particularly in the years prior to the embargo when air shipments were less common, most international trade would have travelled via Birgunj due to the fact that Nepalese trade with the rest of the world primarily went via the Port of Kolkata in India, after which it was put on rail or truck to Birgunj. Thus, the distance of a household from Birgunj in 1989-90 we believe is a reasonable proxy for the magnitude of domestic transport costs faced by households - i.e., their relative remoteness from international markets. We also note that rates of inter-district migration were reported at $8.6 \%$ and $9.6 \%$ in the 1981 (pre-embargo) and 1991 (immediately postembargo) Censuses of Nepal respectively, increasing confidence that our results based on distance to international trade networks are not driven by embargo-induced migration. We only have district identifier information in the 2006, 2011, and 2016 waves of the DHS survey data, and not for the earlier DHS survey waves, so our results on impact

\footnotetext{
${ }^{27}$ The 14 strata are: mountains, urban areas of the Kathmandu valley, other urban areas in the hills, rural Eastern hills, rural Central hills, rural Western hills, rural mid-Western hills, rural far-Western hills, urban Terai, rural Eastern Terai, rural central Terai, rural Western Terai, rural mid-Western Terai, rural far-Western Terai.

${ }^{28} \mathrm{~A}$ shortcoming of the focus on wage income is that only $37 \%$ of respondents report wage income. With this in mind we perform a McCrary (2008) test to see if the embargo affects the likelihood that respondents report wage income. We find that it does not.

${ }^{29}$ Respondents sometimes report wage income on a per day basis and at other times on a monthly basis, and we exploit survey responses on average days worked per month and average hours worked per week to convert daily income into an average monthly income for each respondent when needed.

${ }^{30}$ Formally, we split households by whether they are below or above the median distance to Nepal's main border crossing in Birgunj. This median is calculated separately for the DHS and NLSS datasets and so is somewhat different in each. But the results are qualitatively robust to adopting either datasetspecific median distance value.

${ }^{31}$ In the midst of the embargo, the NY Times in May 1989 stated that "The bridge to India [in Birgunj] is an economic lifeline for this impoverished nation of 18 million people because it has long been the main entry point by road and rail for most of Nepal's consumer and industrial goods."
} 
heterogeneity by distance to the main border crossing are estimated using data from only these waves.

\section{Estimation Methods}

We implement a standard RDD analysis to examine the impact of the embargo on pregnancies and human capital outcomes. Let calendar month be the running variable $t$, with treatment cut-off $t_{0}$ set at March 1989, when the embargo was imposed. Treated pregnancies are those that complete in $t \geq t_{0}$ (with treatment indicator $D=1$ ), while those in calendar month $t<t_{0}$ are untreated $(D=0) .{ }^{32}$ The outcome variable we first focus on is the total number of pregnancies that result in live births in a calendar month, denoted by $Y{ }^{33}$ We estimate the following parametric specification:

$$
\begin{aligned}
& Y=\alpha+\beta D+\gamma m(t) * D+\delta m(t)+\epsilon \\
& \forall t \in\left(t_{0}-h, t_{0}+h\right)
\end{aligned}
$$

where $m(t)$ is a polynomial in $t$ that is interacted with the treatment indicator $D$ to allow for differential impacts of this time-trend polynomial before and after the treatment cutoff $t_{0} ; \alpha$ is a constant; and $\epsilon$ is an idiosyncratic error term. The parameter of interest is $\beta$, which captures the change in the outcome in or after March 1989 (our designated cut-off month, $\left.t_{0}\right)$. We report results from setting $m(t)$ to be linear or quadratic in $t .^{34}$ We follow Kolesár and Rothe (2018) and report robust standard errors for our estimates in the presence of a discrete running variable.

We report estimates from (1) for different bandwidths around $t_{0}$. We use the optimal bandwidth algorithm described in Calonico et al. (2014) to determine the bandwidth $\left(h^{*}\right)$. However $h^{*}$ often exceeds 24 months by a large margin, so we under-smooth the polynomial fit on either side of the cut-off $t_{0}$ and report results from specifications using half the optimal bandwidth, and also from specifications using bandwidths of 9 months or less. This reduces the precision of the estimates, but increases confidence that the embargo impact estimates are local to the cut-off, and capture impacts only for children already in-utero during the embargo rather than those conceived during the embargo.

We also perform a density break test as outlined in McCrary (2008), which estimates the density of $Y$ as a function of the running variable $t$, and then tests for a discontinuity in the density estimator at the cut-off $t_{0}$. The parameter of interest is the $(\log )$ difference in the density at the cut-off $t_{0}$. We complement the McCrary test with another density

\footnotetext{
${ }^{32}$ This means that in the main results, we treat all pregnancies completed after March 1989 as treated. For larger bandwidth choices this may include months when the embargo has ended. In Section 5.3 we discuss the end of the embargo explicitly.

${ }^{33}$ When we investigate specific pregnancy outcomes (miscarriage and infant death), adult educational attainment, as well as the height of women survey respondents, we use individual-level data on pregnancies $i$ and mothers $j$, rather than monthly aggregates (as we do for live births). We show that the results for miscarriage and infant mortality hold for monthly averages as well in Appendix Table A.4.

${ }^{34}$ We do not use polynomials of higher order as this may bias the results (Gelman and Imbens, 2018).
} 
break test described in Cattaneo et al. (2019). This second test does not require the construction of a histogram, relying instead on local polynomial techniques to smooth the empirical distribution of $Y$. Hence it only requires the choice of bandwidth $h$, and not of any other tuning parameters. ${ }^{35}$ The test statistic, which we refer to as the CJM $t$-statistic, is asymptotically normally distributed under the null hypothesis of no density break at $t_{0} \cdot{ }^{36}$

Regarding the bandwidth for the McCrary density break test, we first specify a range in the data from which to then determine the bandwidth for the procedure, as outlined in McCrary (2008), and we refer to this as "data bandwidth" here. We set data bandwidths to be no larger than 24 months, as introducing observations from well before or after $t_{0}$ reduces comparability of treated and untreated observations. Typically this leads to a computed bandwidth of 6-7 months. The procedure to estimate the CJM $t$-statistic derives optimal bandwidths on either side of $t_{0}$ using the entire sample of pregnancies as part of the procedure.

We also use (1) to estimate embargo impacts on adult earned income in the NLSS data, by respondents' gender and distance to the main border crossing. Since these data are reported at an annual level only, we use year of birth to define in-utero exposure. We therefore define cohorts as treated if they are born in 1989 or later. We recognise that this approach reduces the precision of our estimates somewhat, as it introduces measurement error in the treatment variable, and with annual bandwidths the analysis typically includes several years around the cut-off.

The main threats to identification with this research design are: 1) the potential for household manipulation of exposure to the embargo during pregnancy and 2) other shocks besides the embargo that occur around March 1989 and that also affect our outcomes. With respect to 1), since the embargo was a sudden and unanticipated shock that affected the entire country simultaneously, it is unlikely that households could alter the exposure of their unborn children to the embargo during the third trimester. To ensure that our results on live births are not driven by non-random reporting close to March 1989, we report estimates from "donut" regression discontinuity designs that re-estimate specification (3) after dropping observations close to the cut-off, as recommended in Barreca et al. (2011). With respect to 2), since in-utero rainfall shocks have been shown to affect birth outcomes, we plot deviations from 20-year average monthly rainfall by calendar month in Figure A.2 to ensure that these are not driving our results. Reassuringly, there are no statistically significant deviations in monthly rainfall at the time of the embargo or in the months preceding. ${ }^{37}$ We further report results from various robustness checks alongside our main results in the following section to rule out competing explanations

\footnotetext{
${ }^{35}$ This method uses a data-driven bandwidth selection procedure that minimizes the mean-squared error.

${ }^{36}$ The bandwidth is chosen to be the appropriate special case of the robust bias-corrected bandwidth as outlined in Calonico et al. (2014). Further details on both the McCrary test and the density break test in Cattaneo et al. (2019) are in Appendix C.

${ }^{37} \mathrm{Nepal}$ is an earthquake-prone country, but the closest major earthquake chronologically to March 1989 was in August 1988.
} 
such as seasonality effects and imperfect recall by survey respondents as time passes since the embargo.

We follow Hsu and Shen (2018) and rely on sub-sample analyses, rather than interaction terms, in order to examine impact heterogeneity, since using interaction terms of treatment with covariates can potentially bias the estimates and over-reject the null hypothesis of no effect. In addition, we perform a Benjamini-Hochberg correction on the $p$-values of the split sample as outlined in Yekutieli and Benjamini (1999) and Benjamini et al. (2009) to adjust for potential false discovery of effects arising from multiple hypothesis testing, which would again lead to over-rejection of the null (Benjamini and Hochberg, 1995). ${ }^{38}$

\section{Results}

The impact of the embargo on live births is the first outcome that we investigate. We then estimate the impact on further outcomes and progressively allow for additional heterogeneity via sub-sample analyses. We explore the impact of the embargo on specific pregnancy outcomes (miscarriage and infant death), which we also estimate separately by birth order. We also examine the characteristics of mothers who were pregnant during the embargo in order to determine whether there was embargo-induced selection on mother characteristics into pregnancy. Finally, we explore the long-run impact of the embargo on adult educational attainment and income, as well as the adult height of women. For some of these outcomes we study heterogeneity by the household's relative remoteness from international markets during the embargo, an approach motivated by the discussion in Section 2.2.2 above, as well as by a formal model that we present in Appendix D. Specifically, we examine impact heterogeneity by distance to Nepal's main international border crossing. ${ }^{39}$

\subsection{Birth outcomes}

\subsubsection{Live Births}

Our first key result finds a sharp reduction in live births due to the embargo. Figure 4 plots the frequency of reported live births by calendar month from the DHS data. It also includes a local-linear regression plot of these frequencies and the associated $95 \%$ confidence intervals. There is a large visible drop of just over $25 \%$ in the number of live births when the embargo begins in March 1989. Table 3, Panel A, presents the live birth results from the McCrary density break test. We restrict the data bandwidth to lie within an 18-month window on either side of the first month of the embargo in March 1989. This yields an optimal bandwidth of 6.93 months for the estimates reported in

\footnotetext{
${ }^{38}$ We also present additional results that perform this $p$-value correction across outcomes, rather than across split samples.

${ }^{39}$ This measure is described in more detail in Section 3 above.
} 
column (1). ${ }^{40}$ The estimates show that the density of live births declined $27 \%$ when the embargo began, an effect that is significant at the $1 \%$ level.

However, in Figure 4 it is important to note that there is also an increase in live births in the two months preceding March 1989 that may exaggerate the observed decline after the start of the embargo, and we therefore investigate the role of these two preceding months for the finding. First, Figure 4 suggests that these two months are broadly similar to the trend in monthly live births going back as far as two years before the embargo in 1987, suggesting that the upturn in live births in these two months was not a short-run aberration. Second, Figure A.4 suggests that the decline in live births persists after dropping the data in the two months previous to the embargo. And third, Figure A.3 shows no unusual change in reported pregnancy intervals for pregnancies ending in March, 1989 compared to the month of March in other years, which would be the case if mothers were erroneously reporting births as taking place during the pre-embargo period. More formally, in Table 3 we present the results of a donut RDD to test the robustness of our results to potential non-random reporting of live births close to the cut-off. The results indicate that the estimates are robust to the exclusion of observations just around the cut-off. We also investigate this in Table 3, where we present results from a donut regression discontinuity specification that drops one month of data on either side of the cut-off (column (2)). Despite the reduced sample around the cut-off, we still find a highly statistically significant decline of $21 \%$ in live births. Column (3) goes further and drops two months of data before the cut-off, and one month of data after. Again, despite this reduction in the sample we still find a decline of $13.5 \%$, statistically significant at the $10 \%$ level. Columns (4)-(6) repeat the specifications in columns (1)-(3) for live male births, and columns (7)-(9) for live female births. Column (4) shows a highly statistically significant $27 \%$ decline in live male births in the month the embargo began, which falls to $20.5 \%$ in column (5) in the donut regression discontinuity specification, but remains significant at the $5 \%$ level. In column (6), the most severe donut regression discontinuity design strongly reduces the estimated decline in male births to $3 \%$ and no longer statistically significant. In contrast, the estimated decline in female births in the month the embargo began is consistent and statistically significant across these specifications at $23-29 \%$ in columns (4)-(6). There is no statistical difference in the estimates across genders except in the most severe donut regression specification, where there is a greater female drop in live births.

As a complement to the baseline findings in Panel A, Panel B of Table 3 reports the estimated CJM $t$-statistics (Cattaneo et al., 2019). The bandwidths on the left side $\left(h_{l}\right)$ and right side $\left(h_{r}\right)$ are computed as part of the procedure using the entire sample. Column (1) shows a $t$-statistic of -3.63 , which is statistically significant at the $1 \%$ level, and is consistent with column (1) in Panel A that points to a large decline in the number of live births in the month the embargo begins. The donut regression discontinuity specifications

\footnotetext{
${ }^{40}$ Here we use the bandwidth selection algorithm that is part of the density break test procedure in McCrary (2008).
} 
in columns (2) and (3) also yield $t$-statistics of 2.54 and 2.19 after dropping observations close to the cut-off, both statistically significant at the $5 \%$ level. Columns (4) and (5) show statistically significant declines in male births that mirror those in columns (1) and (2), with $t$-statistics of 2.71 and 2.02, respectively. Unlike the McCrary test in Panel A, the more demanding donut regression discontinuity estimation in column (6) shows a marginally significant decline in male births in Panel B, albeit with a much smaller $t$-statistic of 1.73. In columns (7)-(9) we find consistent evidence of declines in female births in the initial embargo month as in Panel A, with statistically significant $t$-statistics of $3.01,2.27$, and 1.98 .

Panel C of Table 3 shows estimates from specification (1) using an 18-month bandwidth, where the dependent variable is the log number of live births. The results are qualitatively very similar to those in Panel A, but smaller in magnitude. This might reflect the larger bandwidth in Panel C compared to Panel A. Columns (1)-(3) indicate that live births declined by $17.5 \%, 10.8 \%$, and $8.6 \%$ respectively, with estimates declining as data are dropped around the cut-off, but nevertheless all are statistically significant. Columns (4) and (5) show statistically significant estimated declines of $17.1 \%$ and $10 \%$ respectively in live male births, while in the most stringent donut regression discontinuity estimation in column (6) the estimated decline reduces to $6.2 \%$ and becomes statistically insignificant, as in Panel A. Columns (7)-(9) however show consistent, statistically significant declines in female live births as in Panels A and B of 18.0\%, 11.6\%, and 11.3\%, respectively.

We introduce sub-sample analyses in Table 4, where we present estimates of the embargo's impact on live births by child gender as well as by distance to the main border crossing with India. We classify households living less than the median distance to the border as residing "close" to international markets, and those living greater than the median distance to the border as residing "far" from international markets (see Section 2.2.2 above). Along with standard errors in parentheses, we also present $p$-values corrected using the Benjamini-Hochberg method for multiple hypothesis testing. These are in square brackets where appropriate. Columns (1) and (2) show the estimates from equation (1) (for those DHS waves where we can compute distance from the border) before separating the sample by distance from the border, estimated for bandwidths of 6 and 9 months, respectively. The results in Panel A mirror those in Table 3, showing estimated declines in live births of $15.6 \%$ in column (1) and $18.3 \%$ in column (2). However in Panels B and $\mathrm{C}$, we find notable gender differences in the decline in live births, similar to those in the more restrictive donut regression estimates in Table 3. Columns (1) and (2) in Panel B show statistically insignificant declines of $12-13 \%$ in male births, while the analogous estimates in Panel C show larger, highly significant declines of 19-24\% in female births. Columns (3) and (4) report results from the same specifications as in columns (1) and (2) for the sub-sample of children in households close to the border. We find no statistically significant impacts of the embargo on live births among these households in Panel A, and also no significant effects by child gender in Panels B and C. However, the results for 
households living far from the border in columns (5) and (6) show statistically significant declines of $25-27 \%$ in live births in Panel A. Further, the decline occurs primarily for female live births, estimated at about $35 \%$, and highly statistically significant. While the estimated decline in male live births is larger in more remote districts compared to closer districts, the decline is much smaller than that for female live births and statistically insignificant after correcting the $p$-values for multiple hypothesis testing. The adverse impact of the embargo therefore appears to have been concentrated 1) in more remote districts, and 2) among girls in these districts. This points toward substantial gender discrimination in these areas, in part because girls tend to be relatively hardy in early life compared to boys. However, a pattern of discrimination is consistent with the previous literature (see Section 2.2.2).

We conduct further robustness checks that find broadly consistent estimates. These checks include using additional bandwidths and splines (see Table A.1 and Table A.2, Panel A); testing for maternal recall bias by reporting estimates that only use data from the 1996 wave of the DHS dataset, the closest chronologically to 1989 (see Table A.2, Panel B); and falsification tests that report placebo estimates from using a cut-off month of March in other pre- and post-embargo years, to rule out seasonality as a potential driver of our results (see Table A.3). These additional specifications support our main findings, and their results are discussed in more detail in Appendix B.

Next we explore the extent to which the decline in live births manifests as a rise in miscarriages. However, it is important to note that there is also a decline in completed pregnancies (covering all outcomes) at the start of the embargo (see Figure A.5). This is consistent with under-reporting of miscarriages and stillbirths or post-natal deaths in the survey.

\subsubsection{Miscarriages and Infant Mortality}

In Table 5 we present estimates from specification (1) on impacts of in-utero exposure to the embargo on the probability of miscarriage. Panel A shows the results from the optimal bandwidth calculated using the algorithm in Calonico et al. (2014), and from half the optimal bandwidth. Panel B shows results from bandwidths of 6 and 9 months, as those in Panel A often exceed the duration of the embargo substantially. In both Panels A and $\mathrm{B}$ we find no statistically significant impacts of the embargo on miscarriages in columns (1) and (2), and the estimates are small. However in columns (3) and (4) of Panel A, we find 1.2 and 2.2 percentage point increases in miscarriages immediately following the embargo in the sub-sample of first births. The effect in column (4) remains statistically significant at the $10 \%$ level after adjusting the $p$-values for multiple hypothesis testing. Reducing the bandwidths further to 6 and 9 months in Panel B leads to larger estimated increases in miscarriages among first births of 4.4 percentage points in column (5) and 4.2 percentage points in column (6), both statistically significant at the $10 \%$ level following the $p$-value correction. The sub-sample of later-born children, however, experience no 
discernible increase in miscarriages in columns (5) and (6) in either Panel A or B. ${ }^{41}$ Altogether, this pattern of results points to increased vulnerability of pregnancies during the embargo among households without previously born children, either because mothers are more vulnerable to pregnancy and childbirth complications when having their first child, or because older children provide additional income to mitigate the embargo's adverse effects. To investigate the role of these mechanisms further, we split the sample depending on whether there is an older sibling aged at least 8 years, who might provide additional wage income to the household to smooth the shock. Appendix Table A.7 shows no strong differences in the effect by sibling age, suggesting that the income effect is unlikely to be the main factor.

Table 6 shows estimates from (1) on the effect of in-utero embargo exposure on the probability of infant death, separately for male and female children in Panels A and B respectively, and using bandwidths of 12 and 18 months. We find no discernible effect in column (1) of Panel A, but in column (2) we find a statistically significant increase of 3.1 percentage points in male infant mortality in the initial stages of the embargo. We see no increase in female infant mortality in the same columns, or any of the other columns in Panel B, consistent with male children being more fragile postnatally in early life, and with live female births possibly taking place disproportionately in less genderdiscriminatory households during the embargo. ${ }^{42}$ Columns (3) and (4) of Panel A show that the increased infant mortality among male children is again concentrated among first births as with miscarriages in Table 5, with statistically significant estimated mortality increases of 8.3 and 8.4 percentage points, respectively. In contrast, columns (5) and (6) show no similar increase in mortality among later-born boys following the embargo. ${ }^{43}$

We note that the discussion up until now has focused on pregnancies and children that were directly impacted by the embargo. However, there may also be important short- and long-run consequences for other children within the household, particularly if resources are re-allocated following the termination of a pregnancy or due to infant death - i.e., in response to changes in expected or actual family size. While the details of intra-household re-allocation are beyond the scope of this paper, in Appendix Table A.9, columns (1) and (2) we report the effect of the embargo on reported family sizes. Specifically, we restrict attention to all pregnancies ending between nine months prior and nine months after the start of the embargo (column (1)) or alternatively within a six months window (column (2)), and we exclude all families with more than one completed pregnancy reported in this period. ${ }^{44}$ We then consider as outcome the number of children reported alive at

\footnotetext{
${ }^{41}$ Table A.4, Panel A shows that the results are robust to being estimated on monthly aggregated counts of miscarriages. Table A.5, Panel A further shows that seasonality is not a likely driver of the results.

${ }^{42}$ Households that discriminate may underreport deaths of daughters.

${ }^{43}$ Table A.6 confirms that the coefficient estimates are nearly identical when estimated using smaller bandwidths of 6 and 9 months. Table A.4, Panels B and C confirm that the gender-specific results are robust to being estimated on monthly aggregated counts of infant deaths. Table A.5, Panel B again confirms that the effects for infant mortality are not driven by seasonality.

${ }^{44} \mathrm{We}$ would not be able to link a specific pregnancy to the embargo when there is more than one pregnancy.
} 
the time of the DHS interview. Since these effects may differ depending on the gender composition of the household, we also interact the embargo indicator with the share of boys among all children reported in the DHS interview. These results are reported in columns (3) and (4) for nine- and six-months windows around the embargo. Interestingly, in all cases we find no statistically significant effects, suggesting that average family sizes are not (statistically) changed by the drop in live births due to the embargo.

\subsubsection{Mother Characteristics}

The impact of the embargo on completed pregnancies and later outcomes may have, in part, been due to a change in the composition of mothers who reported. Figure 6 indicates that there is no perceptible change in the caste composition or age of mothers reporting completed pregnancies in March 1989. There are however visible declines in mothers' completed years of schooling, indicating that women who have live births once the embargo began have less education than women who have live births just before. This is noteworthy, given the significant decline in reported completed pregnancies at the same time.

Estimates for mothers' characteristics, using equation (1), are shown in Panel A of Table 7. There are no statistically significant changes in the caste composition, height, or education of women completing pregnancies once the embargo begins in March 1989 compared to those completing pregnancies in the immediately preceding months. There is a statistically significant difference in the age at birth of mothers of treated cohorts in column (8), but the magnitude of the age difference is only approximately $4-5$ months, relative to a standard deviation in age at birth of 5.6 years (Table 1). The optimal bandwidth $\left(h^{*}\right)$ calculated using the algorithm in Calonico et al. (2014) exceed 24 months on either side of the cut-off month by a large margin for each of these characteristics. In fact, under-smoothing the estimates by using observations from half the optimal bandwidth $\left(0.5 h^{*}\right)$ still yields a data window of over 24 months either side of the cut-off in each case. We therefore also present results using smaller bandwidths of 6 and 9 months either side of March 1989 in Panel B of Table 7. We still find no statistically significant effects on mothers' caste composition in columns (1) and (2) of Panel B of Table 7. The estimated age difference in column (8) of Panel B in Table 7 is again statistically significant and positive. In column (3) of Panel B of Table 7, We find a statistically significant, negative difference of 0.257 in years of schooling for mothers completing pregnancies just after the start of the embargo compared to mothers completing pregnancies just before. We also find a statistically significant negative height difference for mothers of treated cohorts of 0.790 centimetres in column (5) of Panel B, which is potentially explained by the sharp reduction in live births to taller women in poorer, remote households (see Figure 3(c) and Table 4). However, this effect is close to zero and insignificant for all other bandwidths.

The results for mothers' education are present across multiple bandwidths, suggesting that the large decline in live births following the embargo is to some extent driven by 
a disproportionate decline in reported live births by more educated mothers. This is consistent with mothers of higher socioeconomic status underreporting births at a higher rate than less educated mothers when they lose a child, particularly if it is these mothers who discriminate more against daughters and underreport their births if they do not survive, but we cannot confirm this directly in our data.

\section{$5.2 \quad$ Long-Run Effects}

In this section we explore the long-run impacts of the embargo, focusing on adult height, education and income. Collectively, the pattern of estimated effects can provide insight into the mechanisms linking the observed fall in live births to the long-run well-being of the affected cohort. In addition, in some specifications we again differentiate between households according to their relative exposure to international markets at birth using the distance between a household's district headquarters and the main border crossing between Nepal and India in Birgunj, across which the vast bulk of traded goods crossed.

\subsubsection{Height}

We first present estimated impacts of the embargo on the adult height of women exposed to the event in-utero. Table 8 presents the results from specification (1) on the impacts of in-utero exposure to the embargo on women's height in adulthood, first for the whole sample, and then by distance to the main border crossing. Panel A shows results from the optimal bandwidth and half of this bandwidth, and Panel B shows results from bandwidths of 6 and 9 months around the cut-off. Columns (1) and (2) show no significant effects of exposure to the embargo on women's height in adulthood. On the other hand, we find substantial differences by distance to international markets. Columns (3) and (4) show negative effects of embargo exposure on the adult height of women in districts that are relatively close to the border crossing, which is consistent with scarring. These are statistically insignificant in Panel A, but the estimated declines are much larger at 2.7-3.4 centimetres when estimated using smaller bandwidths in Panel B, and significant at the $5 \%$ level. In contrast, columns (5) and (6) show statistically significant increases in height for women exposed in-utero to the embargo in districts relatively far from the border crossing in both Panels A and B. The estimates are large, ranging from approximately 1.4 to 3.7 centimetres, and consistent with selection effects that dominate scarring. As Table 4 suggests that more early-life discrimination against female children took place in these poorer, more distant districts in response to the embargo, adult women survivors of exposure may also exhibit greater height in these districts because they are a selected group born into less discriminatory households that invested more in their health during infancy. 


\subsubsection{Education}

We investigate whether the increase in educational attainment occurred on the intensive or extensive margin, and how the returns to education in the labour market may help to explain the increase in earned income for affected cohorts. To start, in Figure 7 we plot women's years of schooling by their month of birth from the DHS data. We only include women who were at least 18 years of age at the time of the survey so as to more accurately capture their completed schooling in adulthood. We see a substantial increase in completed years of education by approximately 0.7-0.9 years for women respondents who were born in March 1989 or the month following compared to those born in the months just preceding, and consistent with positive selection of women survivors with stronger health endowments or into less-discriminatory households. The corresponding plot for the limited sample of men in Figure 8 shows no discernible effect of the embargo on their education, keeping in mind that the sample of interviewed men is much smaller, and regression results are also unstable and imprecisely estimated (see Appendix Table A.10).

Table 9 shows results from specification (1) for the estimated impact of women's inutero exposure to the embargo on their educational attainment in adulthood. Column (1) in Panel A shows that adult women born immediately after the embargo have 0.7 years more schooling than those born just before, an effect that is statistically significant at the $1 \%$ level, when estimated using the optimal bandwidth of about 30 months. Reestimating the specification with observations from half the optimal bandwidth increases the coefficient to about 0.9 years, and the effect remains highly statistically significant. The untreated women in the regression samples in these columns have about 5.6 years of completed education on average, so the estimated embargo impact constitutes an increase of about 12-16 percent in educational attainment. This effect is large, but the confidence intervals are also relatively wide. It is important to keep in mind that our analysis takes place in the context of rapidly rising educational attainment in Nepal at this time. ${ }^{45}$ Columns (3) and (4) report estimated embargo impacts on the binary outcome of whether adult women have any schooling at all. Both columns show statistically significant estimated increases of 8-12 percentage points in entry into education after in-utero exposure to the embargo. In Panel B, using smaller bandwidths of 6 and 9 months yields a statistically insignificant increase in adult women's schooling of 0.9 years in column (1), but a statistically significant estimated impact of identical magnitude in column (2). Columns (3) and (4) however yield statistically significant estimates of 1113 percentage point increases in women's entry into education. This extensive margin increase in entry into schooling is clearly an important factor in the increased education that women obtain on average after being exposed to the embargo. ${ }^{46}$

\footnotetext{
${ }^{45}$ In the DHS data, adult women's education increases from 2.4 years for birth cohort 1975 to 7.8 years for birth cohort 1995, which is an increase of over 6 percent per year. The annual growth rate across cohorts born during 1975-88 before the embargo is even larger at over 6.5 percent.

${ }^{46} \mathrm{We}$ also investigated whether there were changes in government investment in educa-
} 
In Table A.8 we examine the impact of the embargo on education by distance to the border. The estimates from the optimal bandwidths in Panels A indicate that women exposed to the embargo in-utero had higher education in adulthood in both close and remote districts. Smaller bandwidths of 6 and 9 months in Panel B however indicate that the increase was larger for women in remote districts, in line with the greater estimated height and selection of surviving girls we also find in these districts. ${ }^{47}$ We turn to income in the following section. ${ }^{48}$

\subsubsection{Income}

The effects of the embargo on income are imprecisely estimated and so should be interpreted with caution. The results from specification (1) in Table 10 show some evidence of a rise in earned income (of around $20 \%$ in column (1)), which is concentrated among men (column (3)), but the estimates are sensitive to the choice of bandwidth. We do not find a similar increase in earned income for females (columns (5) and (6) of Panel A). ${ }^{49}$ To the extent that a gender difference exists it may be driven by disproportionately adverse embargo impacts on men in childhood due to higher fragility, and also the greater likelihood of men realising the full labor market returns to their education as the primary wage earners in Nepal's patriarchal economy. The effects on earned income seem to be concentrated in districts close to the main border crossing with India (see column (1), Panels B and C), though this is inconclusive given the lack of statistical power, and even more so when multiple hypothesis testing is taken into account. In light of the roughly equal impacts of the embargo on education across districts, these results are consistent with a higher return to education in close, relative to far, districts. In Figure 9 we see that the return to an additional year of schooling in close districts is around 9.5 percent for women and around 6.5 percent for men, both of which exceed the return in more remote areas (6.5 and 6 percent, respectively), though the effect for men is statistically indistinguishable. ${ }^{50}$

tion that may have affected treated cohorts disproportionately relative to untreated cohorts. Using UNESCO data we see no significant change in pupil-teacher ratio or primary school enrollment at the time that the exposed cohort would have entered school (data available at https://data.worldbank.org/indicator/SE.PRM.ENRL.TC.ZS?locations=NP and https://data.worldbank.org/indicator/SE.PRM.ENRR?locations=NP).

${ }^{47}$ The estimated impact of in-utero exposure to the embargo for the small sample of men in the DHS data in Table A.10 show a similar, marginally significant increase in education to women of 0.704 years in column (1), but the estimate is not robust to reducing the optimal bandwidth or to using a quadratic rather than a linear spline.

${ }^{48}$ In Appendix Table A.11 we also present results (for both short and long-term outcomes) where we correct $p$-values for multiple testing across different outcomes rather than across sample splits.

${ }^{49} \mathrm{We}$ also perform $t$-tests of the difference in mean earnings across the years just prior to the embargo (1988), and at the start of the embargo (1989). These results indicate a statistically significant effect (at the 5 percent level) on earnings for men, equal to 0.263 , and no effect for women. However, these results should be interpreted cautiously since they do not account for trends in income before or after the introduction of the embargo.

${ }^{50}$ Our estimates of the returns to education are very close to those reported in Akanda (2010) for Nepal, who also finds higher returns to a year of education for women relative to men, and of similar magnitudes. 


\subsection{End of Embargo}

In principle, it would be possible to conduct a parallel analysis for the end of the embargo, after the embargo was lifted on July 1, 1990. Such an analysis is challenging because the timing is less clear-cut and the transition back to "normality" was likely gradual: The New York Times reported in April 1990 that an agreement to end the trade embargo had already been widely anticipated in the Spring of 1990, but was then delayed due to disagreements in the negotiation (NY Times, April 14, 1990). Furthermore, it is not clear how quickly trade flows were re-established once the embargo was lifted. The government also implemented a series of policies over the embargo period intended to ease the burden on households - including implementing energy rations, increasing export subsidies, and greatly expanding borrowing (see Blanchard and Ripsman, 2013) - but the timing of these policies and their incidence is unclear. For these reasons we focus our analysis on the start of the embargo. However, to complement our analysis, Figure A.6 in the Appendix shows the change in completed pregnancies at the end of the embargo in July 1990. After the end of the embargo, there is a slight increase in the number of completed pregnancies, and the level after the end of the embargo is similar to the numbers seen in the months shortly before the start of the embargo. We report the corresponding regression results in Table A.12, which suggest an increase in the births of girls, even though most estimates are insignificant once the corrected $p$-values are considered.

\section{Conclusion}

Our findings provide a first set of results on the human capital consequences of a trade embargo. Given the widespread use of embargoes as a policy tool, and the vast number of people affected, the lack of existing research on the welfare consequences of trade embargoes is notable. This paper begins to fill the gaps in the literature on the impact of trade embargoes by providing estimates of the short-run (live births and miscarriage rates) and long-run (educational attainment and income) consequences of a 15-monthlong embargo.

We find a substantial decline in reported live births shortly after the embargo began. The largest decline in births takes place in poorer, remote districts, suggesting that the impact of the embargo is harsher on households in these districts. The number of live female births declines more steeply than the number of male births in these districts in spite of greater male early-life fragility, suggesting a sharpening of parental discrimination against daughters during the embargo. We also find that women survivors of in-utero exposure to the embargo seem to have substantially more education than untreated cohorts born shortly before March 1989. In households with no previous child, we find a significant increase in reported miscarriages and in male infant mortality immediately following the imposition of the embargo. In contrast, we find no similar increases in child mortality in households with a previous child. Importantly, the large decrease in 
reported live births is not matched by an equivalent increase in reported child deaths, stillbirths, or miscarriages. This suggests that there may be substantial underreporting of miscarriages, stillbirths or infant deaths, as has been found for developing countries more generally.

Adult women survivors of in-utero embargo exposure are 1.6-3.7 centimetres taller than unexposed cohorts in remote, poorer districts located farther away from international markets, due possibly to positive selection of survivors on health endowments at birth, and also their selection at birth into less discriminatory parental households. Women survivors in closer, wealthier districts that experienced smaller declines in live births are 2.7-3.3 shorter than unexposed cohorts, consistent with scarring effects of the embargo. Women survivors in both close and far districts also have more educational attainment than unexposed cohorts, but the gains are again larger in remote districts. Finally, we find some evidence that in-utero exposure to the embargo may have raised adult wage income for male survivors of exposure, effects that may have been concentrated in areas close to international markets.

Our results by distance to trade networks are a new contribution to the literature on within-country variation in access to trade and and its effects on poverty, which has focused largely on increased exposure to market competition and international price volatility, rather than remoteness from trade (e.g., see Topalova, 2010; McCaig, 2011; Kovak, 2013). Recent political instability in North Africa and the Middle-East has led to a renewed focus on the societal impacts of trade shocks to imported necessities, as these regions are highly dependent on food imports, and sharp increases in international prices of food following the start of the global recession in 2007 have been linked to the unrest that followed (e.g., see Bellemare, 2015; Ianchovichina et al., 2014). Our findings contribute to this literature on the intersection of economic forces and political phenomena.

Finally, the estimates that we present likely represent upper-bound effects since Nepal is landlocked and poor. At the same time, there is a significant number of landlocked developing countries. This suggests that our findings have wide-ranging policy relevance, especially so when we consider the additional set of countries that are heavily reliant on international trade, but not landlocked, and are currently embargoed or at risk of being embargoed in the future.

\section{References}

Adhvaryu, A., Fenske J., \& Nyshadham, A. (2018) Early Life Circumstance and Adult Mental Health. Forthcoming, Journal of Political Economy.

Akanda, Md. A. S. (2010). Returns to Education in Nepal: Evidence from Living Standard Survey (July 1, 2010). Dhaka University Journal of Science, 58(2): 257-264, 2010. 
Ali, M. M. \& Shah, I. H. (2000). Sanctions and Child Mortality in Iraq. The Lancet 355: 1851-57.

Almond, D. (2006). Is the 1918 Influenza Epidemic Over? Long-Term Effects of inutero Influenza Exposure in the Post-1940 U.S. Population. Journal of Political Economy, 114(4), 672-712.

Almond, D., \& Currie, J. (2011). Killing Me Softly: The Fetal Origins Hypothesis. The Journal of Economic Perspectives, 25(3), 153-172.

Anderson, J. E., \& Van Wincoop, E. (2004). Trade costs. Journal of Economic literature, $42(3), 691-751$.

Anukriti, S., Bhalotra, S., \& Tam, H. (2016). On the Quantity and Quality of Girls: New Evidence on Abortion, Fertility, and Parental Investments. IZA Discussion Paper No. 10271

Asian Development Bank (2017). Country Partnership Strategy: Nepal, 2013-2017, Report.

Atkin, D., \& Donaldson, D. (2015). Who's Getting Globalized? The Size and Implications of Intra-national Trade Costs (No. w21439). National Bureau of Economic Research.

Baland, J. M., \& Robinson, J. A. (2000). Is Child labour Inefficient?. Journal of Political Economy, 108(4), 663-679.

Banerjee, A., Duflo, E., Postel-Vinay, G., \& Watts, T. (2010). Long-Run Health Impacts of Income Shocks: Wine and Phylloxera in Nineteenth-Century France. Review of Economics and Statistics, 92(4), 714-728.

Barreca, A. I., Guldi, M., Lindo, J. M., \& Waddell, G. R. (2011). Saving Babies? Revisiting the Effect of Very Low Birth Weight Classification. The Quarterly Journal of Economics, 126(4), 2117-2123.

Basu, K., \& Van, P. H. (1998). The Economics of Child labour. American Economic Review, 88(3), 412-427.

Becker, G.S. (1991). A Treatise on the Family. Enlarged edition. Harvard University Press.

Bellemare, M. F. (2015). Rising Food Prices, Food Price Volatility, and Social Unrest. American Journal of Agricultural Economics, 97(1): 1-21.

Benjamini, Y., \& Hochberg, Y. (1995). Controlling the False Discovery Rate: A Practical and Powerful Approach to Multiple Testing. Journal of the Royal Statistical Society. Series B (Methodological), 57(1), 289-300. 
Benjamini, Y., Heller, R., \& Yekutieli, D. (2009). Selective Inference in Complex Research. Philosophical Transactions of the Royal Society A, 367, 4255-4271.

Bernhofen, D. \& Brown, J. (2005). An Empirical Assessment of the Comparative Advantage Gains from Trade: Evidence from Japan. American Economic Review, 95(1), $208-225$.

Blanchard, J. M. F., \& Ripsman, N. M. (2013). Economic statecraft and foreign policy: Sanctions, incentives, and target state calculations. Routledge.

Bozzoli, C., Deaton, A., \& Quintana-Domeque, C. (2009). Child Mortality, Income, and Adult Height. Demography, 647-669.

Calonico, S., Cattaneo, M., \& Titiunik, R. (2014). Robust Nonparametric Confidence Intervals for Regression-Discontinuity Designs. Econometrica, 82(6), 2295-2326.

Case, A., \& Paxson, C. (2008). Stature and Status: Height, Ability, and labour Market Outcomes. Journal of Political Economy, 116 (3), 499-532.

Cattaneo, M. D., Jansson, M., \& Ma, X. (2019). Simple local polynomial density estimators. Journal of the American Statistical Association, 1-11.

Chen, Y., \& Zhou, J. (2007). The Long-Term Health and Economic Consequences of the 1959-1961 Famine in China. Journal of Health Economics. 26(4):659-81.

Cutler, D. M., Miller, G. \& Norton, D. M. (2007). Evidence on early-life income and late-life health from America's Dust Bowl era. PNAS, 104 (33), 13244-13249.

Currie, J. (2009). Healthy, Wealthy, and Wise: Socioeconomic Status, Poor Health in Childhood, and Human Capital Development. Journal of Economic Literature. 47(1), $87-122$.

Darmstadt, G. L., Bhutta, Z. A., Cousens, S., Adam, T., Walker, N., De Bernis, L., \& Lancet Neonatal Survival Steering Team. (2005). Evidence-based, cost-effective interventions: how many newborn babies can we save?. The Lancet, 365(9463), 977-988.

Darmstadt, G.L., Lee, A.C., Cousens, S., Sibley, L., Bhutta, Z.A., Donnay, F., Osrin, D., Bang, A., Kumar, V., Wall, S.N. and Baqui, A. (2009). 60 Million Non-Facility Births: Who Can Deliver in Community Settings to Reduce Intrapartum-Related Deaths?. International Journal of Gynecology \& Obstetrics 107: S89-S112.

Elliott, K.A. (2006). Economic Sanctions and Threats in Foreign and Commercial Policy. Chapter 4 in 'C. Fred Bergsten and the World Economy,' edited by Michael Mussa. Peterson Institute for International Economics.

Faye, M. L., McArthur, J. W., Sachs, J. D., \& Snow, T. (2004). The challenges facing landlocked developing countries. Journal of Human Development, 5(1): 31-68. 
Feyrer, J. (2009). Distance, Trade, and Income - The 1967 to 1975 Closing of the Suez Canal as a Natural Experiment, NBER working paper 15557. National Bureau of Economic Research.

Frankel, J. (1982). The 1807-1809 Embargo Against Great Britain. Journal of Economic History, 42(2), 291-308.

Garfield, R. and Santana, S. (1997). The Impact of the Economic Crisis and the US Embargo on Health in Cuba. American Journal of Public Health 87(1): 15-20.

Garver, J. (1991). China-India Rivalry in Nepal: The Clash Over Chinese Arms Sales, Asian Survey 31(10): 956-975.

Gelman, A. \& Imbens, G. (2018). Why High-Order Polynomials Should Not Be Used in Regression Discontinuity Designs. Journal of Business \& Economic Statistics.

Gorgens, T., Meng, X., \& Vaithianathan, R. (2012). Stunting and Selection Effects of Famine: A Case Study of the Great Chinese Famine. Journal of Development Economics, 97(1), 99-111.

Heazell, A.E., Siassakos, D., Blencowe, H., Burden, C., Bhutta, Z.A., Cacciatore, J., Dang, N., Das, J., Flenady, V., Gold, K.J. and Mensah, O.K. (2016). Stillbirths: Economic and Psychosocial Consequences. The Lancet 387(10018):P604-616.

Hensley, W. (1993). Height as a Measure of Success in Academe. Psychology: Journal of Human Behavior, 30(1), 40-46.

Hsu, Y. C., \& Shen, S. (2018). Testing Treatment Effect Heterogeneity in Regression Discontinuity Designs. Forthcoming, Journal of Econometrics.

Hu, L., \& Schlosser, A. (2015). Prenatal Sex Selection and Girls' Well-Being: Evidence from India. The Economic Journal, 125(587), 1227-1261.

Ianchovichina, E. I., Loening, J. L., \& Wood, C. A. (2014). How Vulnerable are Arab Countries to Global Food Price Shocks? The Journal of Development Studies 50(9): 1302-1319.

Irwin, D. (2005). The Welfare Costs of Autarky: Evidence from the Jeffersonian Trade Embargo, 1807-09. Review of International Economics, 13(4), 631-645.

Juhász, R. (2018). Temporary Protection and Technology Adoption: Evidence from the Napoleonic Blockade. American Economic Review, 108 (11): 3339-76.

Karki, B. K., \& Kittel G. (2019). Neonatal Mortality and Child Health in a Remote Rural Area in Nepal: A Mixed Methods Study. BMJ Paediatrics Open 2019;3:e000519.

Koirala, N. (1990). 1989: A Difficult Year, Asian Survey, 30(2), 136-143. 
Kolesár, M. \& Rothe, C. (2018). Inference in Regression Discontinuity Designs with a Discrete Running Variable. American Economic Review, 108(8), 2277-2304.

Koolwal, Gayatri B. "Son Preference and Child Labor in Nepal: The Household Impact of Sending Girls to Work." World Development 35.5 (2007): 881-903.

Kovak, B. K. (2013). Regional Effects of Trade Reform: What Is the Correct Measure of Liberalization?. American Economic Review 103(5): 1960-1976.

Kupka, R., Kassaye, T., Saathoff, E., Hertzmark, E., Msamanga, G. I., \& Fawzi, W. W. (2009). Predictors of Stillbirth Among HIV-infected Tanzanian Women. Acta Obstetricia Et Gynecologica Scandinavica, 88(5), 584-592.

LA Times (1989). Trade Embargo Wreaks Havoc: Nepal Is Paying the Price for Standing Up to India. April 10, 1989.

László, K.D., Liu, X.Q., Svensson, T., Wikström, A.K., Li, J., Olsen, J., Obel, C., Vestergaard, M. \& Cnattingius, S. (2013a). Psychosocial Stress Related to the Loss of a Close Relative the Year Before or During Pregnancy and Risk of Preeclampsia Novelty and Significance. Hypertension 62(1): 183-189.

László, K. D., Svensson, T., Li, J., Obel, C., Vestergaard, M., Olsen, J., \& Cnattingius, S. (2013b). Maternal Bereavement During Pregnancy and the Risk of Stillbirth: a Nationwide Cohort Study in Sweden. American Journal of Epidemiology, 177(3):219-27.

Lawn, J.E., Blencowe, H., Pattinson, R., Cousens, S., Kumar, R., Ibiebele, I., Gardosi, J., Day, L.T. and Stanton, C., (2011). Stillbirths: Where? When? Why? How to Make the Data Count?. The Lancet 377(9775): 1448-1463.

Lee, A.C., Mullany, L.C., Tielsch, J.M., Katz, J., Khatry, S.K., LeClerq, S.C., Adhikari, R.K. \& Darmstadt, G.L. (2011). Community-Based Stillbirth Rates and Risk Factors in Rural Sarlahi, Nepal. International Journal of Gynecology \& Obstetrics, 113(3), 199-204.

Lin, M. J., Liu, J. T., \& Qian, N. (2014). More Missing Women, Fewer Dying Girls: The Impact of Sex-Selective Abortion on Sex at Birth and Relative Female Mortality in Taiwan. Journal of the European Economic Association, 12(4), 899-926.

Maccini, S., \& Yang, D. (2009). Under the Weather: Health, Schooling, and Economic Consequences of Early-Life Rainfall. American Economic Review, 99 (3): 1006-26.

MacKellar, L., Wörgötter, A., \& Wörz, J. (2000). Economic Development Problems of Landlocked Countries. Transition Economics Series, 14. Institute for Advanced Studies, Vienna.

Magnusson, P., Rasmussen, F., \& Gyllensten, U. (2006). Height at Age 18 Years is a Strong Predictor of Attained Education Later in Life: Cohort Study of over 950,000 Swedish Men. International Journal of Epidemiology, 35(3), 658-63. 
McCaig, B. (2011). Exporting Out of Poverty: Provincial Poverty in Vietnam and US Market Access. Journal of International Economics 85(1): 102-113.

McCrary, J. (2008). Manipulation of the Running Variable in the Regression Discontinuity Design: A Density Test. Journal of Econometrics 142(2), 698-714.

Meng, X., \& Qian, N. (2009). The Long Term Consequences of Famine on Survivors: Evidence from China's Great famine. NBER Working Paper 14917.

Naeye, R. L., Burt, L. S., Wright, D. L., Blanc, W. A., \& Tatter, D. (1971). Neonatal Mortality, the Male Disadvantage. Pediatrics, 48(6), 902-906.

New York Times (1989). India Presses, And Nepalese Feel the Pinch. May 10, 1989.

New York Times (1990). India-Nepal Accord on Ending Trade Dispute Is Near Collapse. April 14, 1990.

Paudel, M., Javanparast, S., Dasvarma, G., \& Newman, L. (2018). Religio-cultural Factors Contributing to Perinatal Mortality and Morbidity in Mountain Villages of Nepal: Implications for Future Healthcare Provision. PloS one, 13(3), e0194328.

Pradhan, A., Hari Aryal, R., Regmi, G., Ban, B., \& Govindasamy, P. (1997). Nepal Family Health Survey 1996. Kathmandu, Nepal and Calverton, Maryland: Ministry of Health [Nepal], New ERA, and Macro International Inc.

Pradhan, E., Pearson, E., Puri, M., Maharjan, M., Maharjan, D. C., \& Shah, I. (2019). Determinants of Imbalanced Sex Ratio at Birth in Nepal: Evidence from Secondary Analysis of a Large Hospital-Based Study and Nationally-Representative Survey Data. BMJ open, 9(1), e023021.

Puri, M., \& Tamang, A. (2015). Understanding Factors Influencing Adverse Sex Ratios at Birth and Exploring What Works to Achieve Balance: The Situation in Selected Districts of Nepal. Kathmandu: CREHPA

Ravallion, M., \& Wodon, Q. (2000). Does Child Labour Displace Schooling? Evidence on Behavioural Responses to an Enrollment Subsidy. The Economic Journal, 110(462), 158-175.

Redding, S., \& Sturm, D. (2008). The Costs of Remoteness: Evidence from German Division and Reunification. The American Economic Review, 98 (5), 1766-1797.

Stanton, C., Lawn, J. E., Rahman, H., Wilczynska-Ketende, K., \& Hill, K. (2006). Stillbirth Rates: Delivering Estimates in 190 Countries. The Lancet 367(9521): 14871494.

Steckel, R. (2008). Biological Measures of the Standard of Living. The Journal of Economic Perspectives, 22 (1), 129-152. 
Storeygard, A. (2016). Farther on down the Road: Transport Costs, Trade and Urban Growth in Sub-Saharan Africa. The Review of Economic Studies, 83(3), 1263-1295.

Strauss, J., \& Thomas, D. (1998). Health, Nutrition, and Economic Development. The Journal of Economic Literature, 36(2), 766-817.

Sullivan, J. M., Rutstein, S. O., \& Bicego, G. T. (1994). Infant and Child mortality (No. 15). Calverton, Maryland: Macro International.

Suwal, B. R., \& KC, B. K. \& Adhikari, K. P. (1997). Child labour situation in Nepal. Report from Migration and Employment Survey, 1995/96. International Labour Organisation.

Topalova, P. (2010). Factor Immobility and Regional Impacts of Trade Liberalization: Evidence on Poverty From India. American Economic Journal: Applied Economics 2(4): $1-41$.

UNCTAD (2020). List of land-locked developing countries. United Nations Conference on Trade and Development. https://unctad.org/en/pages/aldc/Landlocked\% 20Developing\%20Countries/List-of-land-locked-developing-countries .aspx.

Valente, C. (2014). Access to abortion, investments in neonatal health, and sex-selection: Evidence from Nepal. Journal of Development Economics 107: 225-243.

Valente, C. (2015). Civil Conflict, Gender-Specific Fetal Loss, and Selection: A New Test of the Trivers-Willard Hypothesis. Journal of Health Economics 39: 31-50.

van den Berg, G. J., M. Lindeboom \& F. Portrait. 2006. Economic Conditions Early in Life and Individual Mortality. American Economic Review, 96(1), 290-302.

Vedam, S., Stoll, K., Taiwo, T.K., Rubashkin, N., Cheyney, M., Strauss, N., McLemore, M., Cadena, M., Nethery, E., Rushton, E. and Schummers, L. 2019. The Giving Voice to Mothers Study: Inequity and Mistreatment During Pregnancy and Childbirth in the United States. Reproductive Health, 16: 77.

Waldron, I. (1983). Sex Differences in Illness Incidence, Prognosis and Mortality: Issues and Evidence. Social Science \& Medicine, 17(16): 1107-1123.

World Health Organization. (2006). Neonatal and Perinatal Mortality: Country, Regional and Global Estimates.

World Bank (1990). World Development Report 1990: Poverty. New York: Oxford University Press.

Wynn, A., \& Wynn, M. (1993). The Effects of Food Shortage on Human Reproduction. Nutrition and Health 9(1): 43-52. 
Yekutieli, D., \& Benjamini, Y. (1999). Resampling-Based False Discovery Rate Controlling Multiple Test Procedures for Correlated Test Statistics, Journal of Statistical Planning and Inference, 82, 171-196.

Young, T., \& French, L. (1996). Height and Perceived Competence of U.S. Presidents. Perceptual and Motor Skills, 82(3), 1002. 
Figure 1: Nepalese Foreign Trade During the Embargo

(a) Nepalese Imports

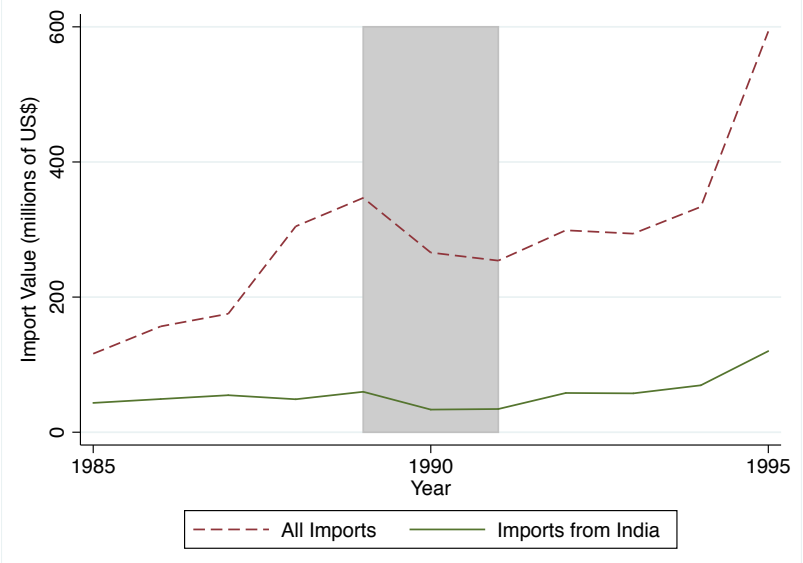

(b) Nepalese Imports by Sector

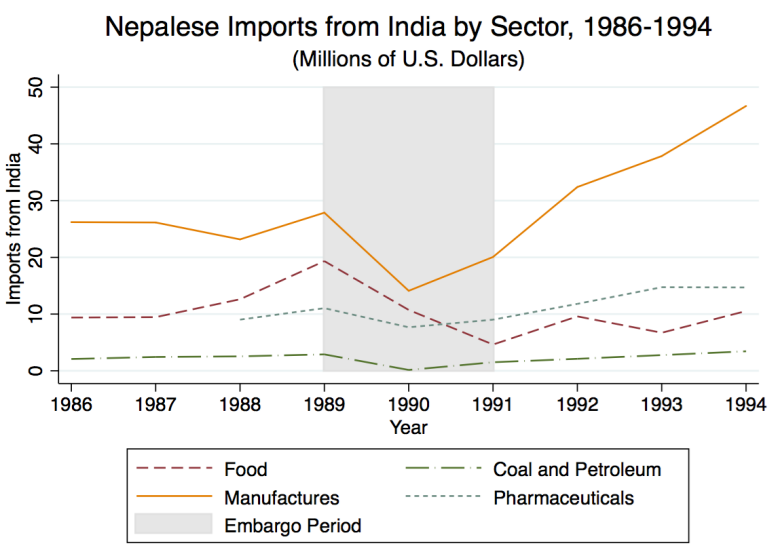

(c) Nepalese Exports

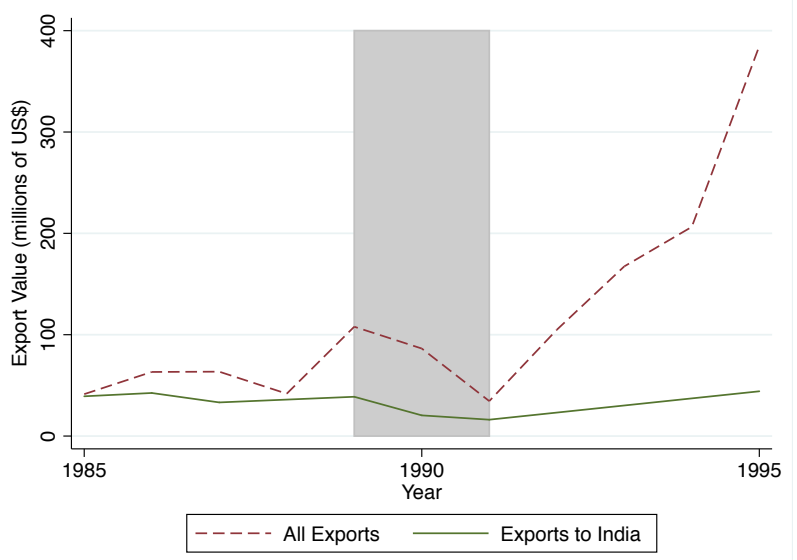

Notes: The figures show the value of annual Nepalese total imports, annual Nepalese imports by sector, and annual Nepalese exports in millions of US dollars from India and from all countries. The grey shaded area indicates the years the embargo was in effect, though it is important to note that the embargo was not in place for some portion of the first and final years (it began in March 1989 and ended in July 1990). Source: United Nations Comtrade. 
Figure 2: Pre-Embargo Mortality and Sex Ratio at Birth by Distance to Main Border Crossing

(a) Sex Ratio at Birth

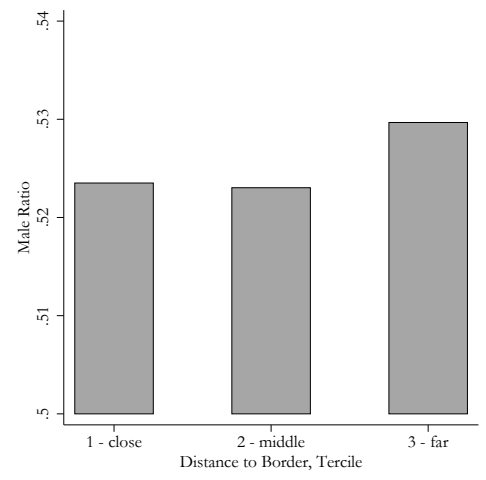

(b) Female Infant Mortality

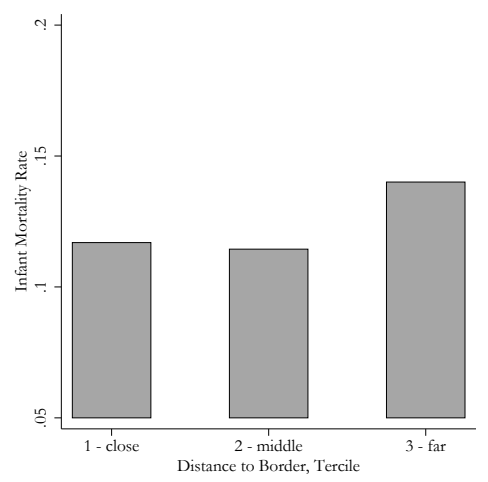

(c) Male Infant Mortality

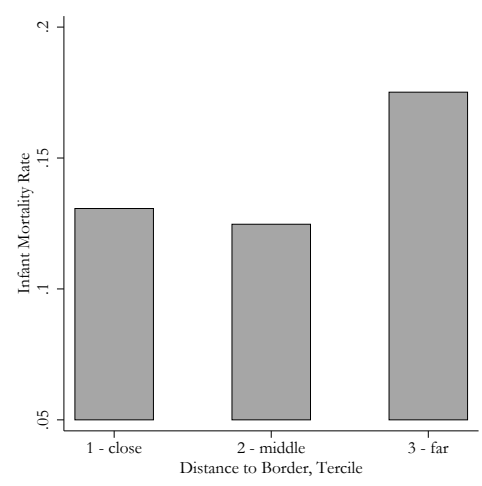

Notes: Figure (a) shows the share of male births in total births taking place before 1989 in our sample by tercile of distance to the main border crossing with India. Figure (b) shows the infant mortality rate for female children, and Figure (c) shows the infant mortality rate for male children in our sample born before 1989 by tercile of distance to the main border crossing.

Figure 3: Education and Health Outcomes for Women Born before the Embargo by Distance to Main Border Crossing

(a) Schooling

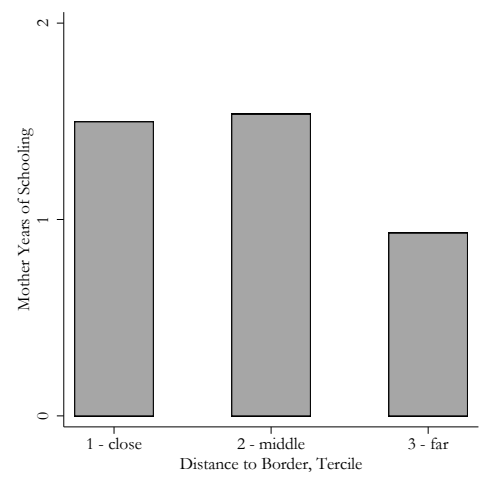

(b) Weight

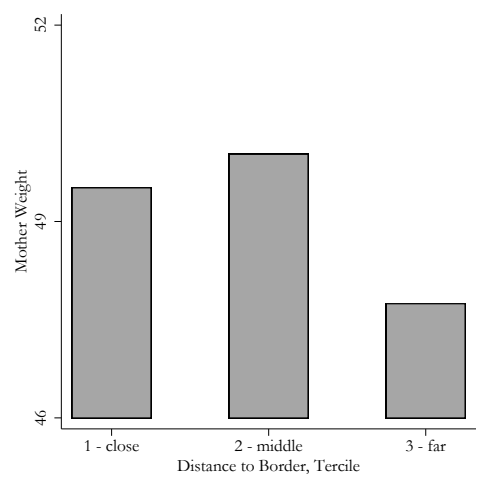

(c) Height

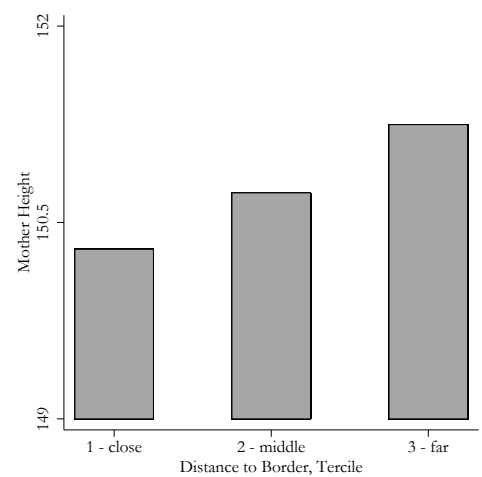

Notes: Figure (a) shows the years of schooling for women born at least 18 years before 1989 by tercile of distance to the main border crossing with India. Figure (b) shows the weight of women, and Figure (c) shows the height of women born at least 18 years before 1989 by tercile of distance to the main border crossing. 
Figure 4: Live Births

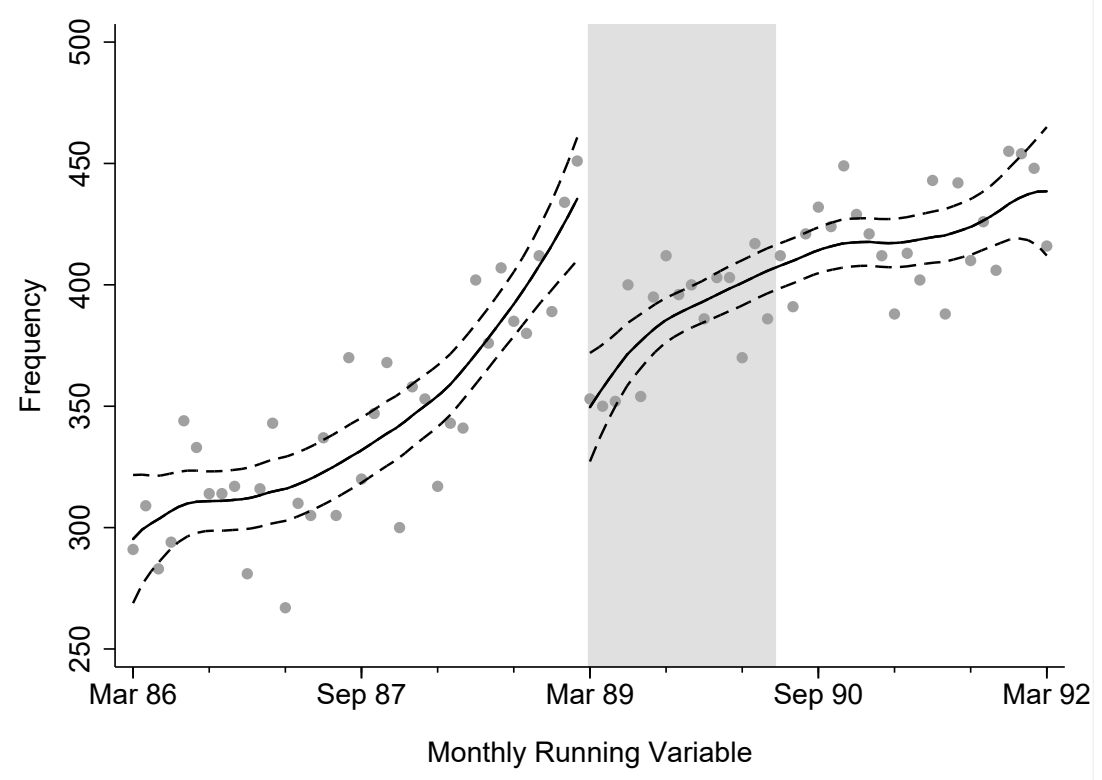

Notes: The graph shows the number of live births by month. The black curves are local linear regression plots of live births with a a triangular kernel.

Figure 5: Miscarriages

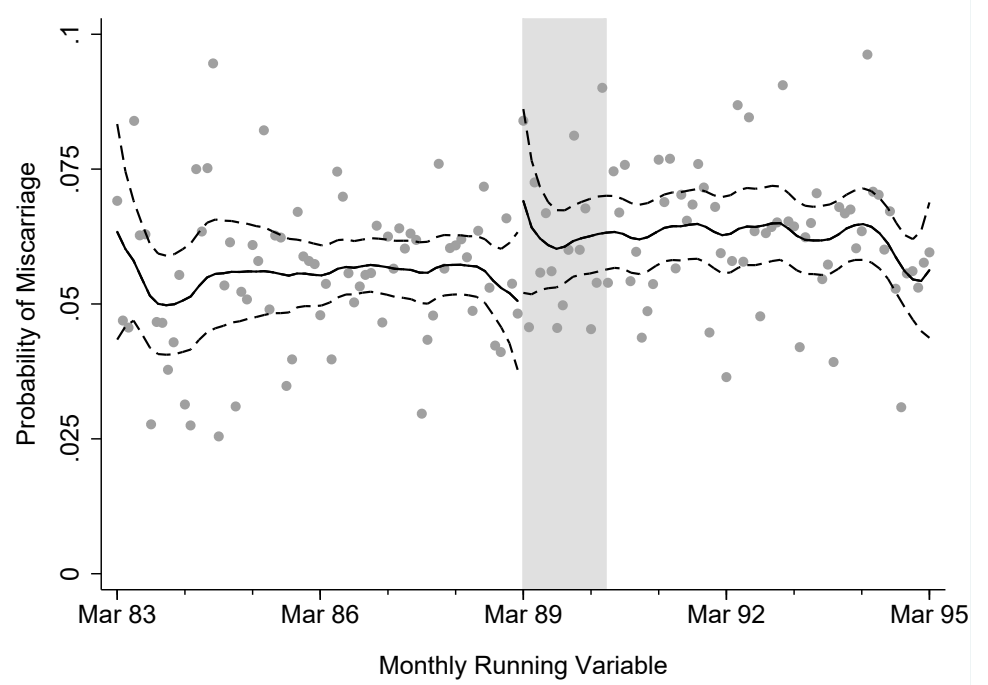

Notes: The graph shows the fraction of monthly completed births ending in miscarriage, and local linear regression plots with a triangular kernal. The grey shaded area indicates the embargo period. The dashed lines show the $95 \%$ confidence intervals around the local linear estimates. 
Figure 6: Mother Characteristics

(a) Caste

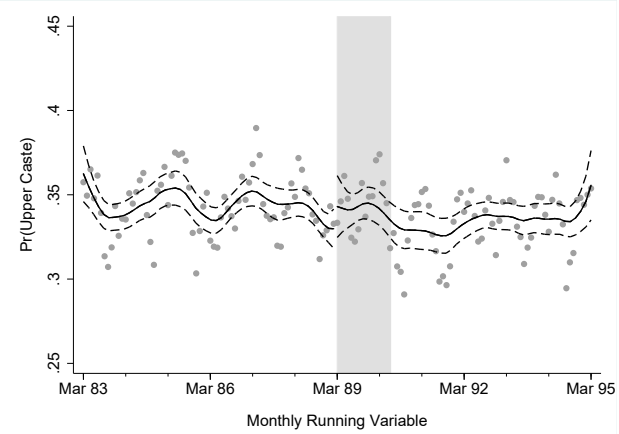

(c) Height

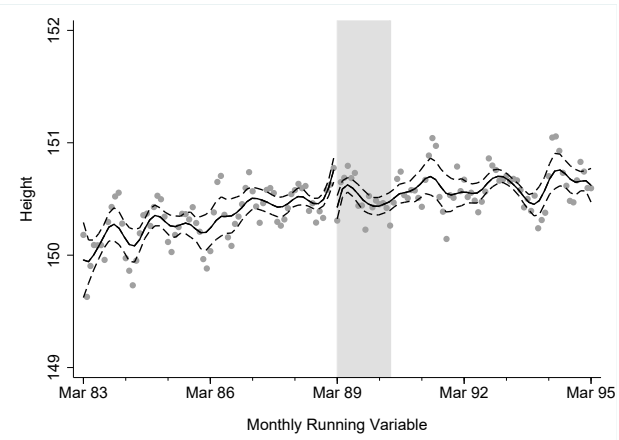

(b) Education

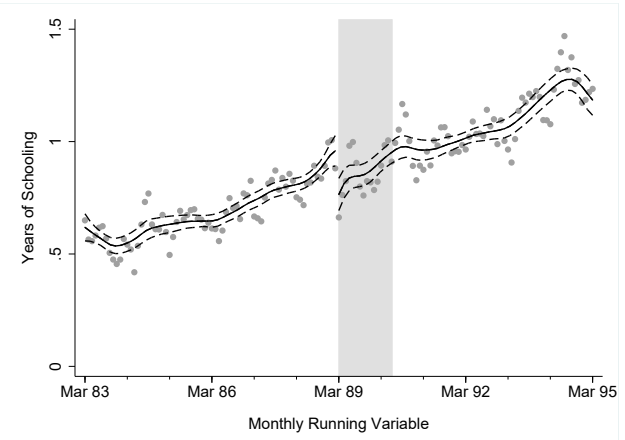

(d) Age at Birth

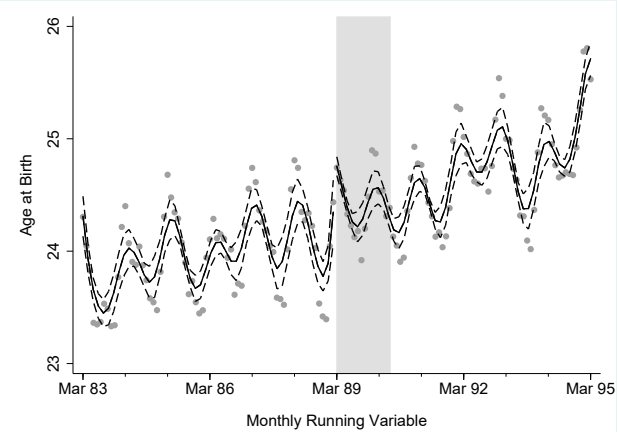

Notes: The graphs show 3-month smoothed averages of mother characteristics by child month of birth, and local linear regression plots with a triangular kernel on either side of March 1989. The gray shaded region indicates the embargo period.

Figure 7: Long-Run Years of Schooling: Women

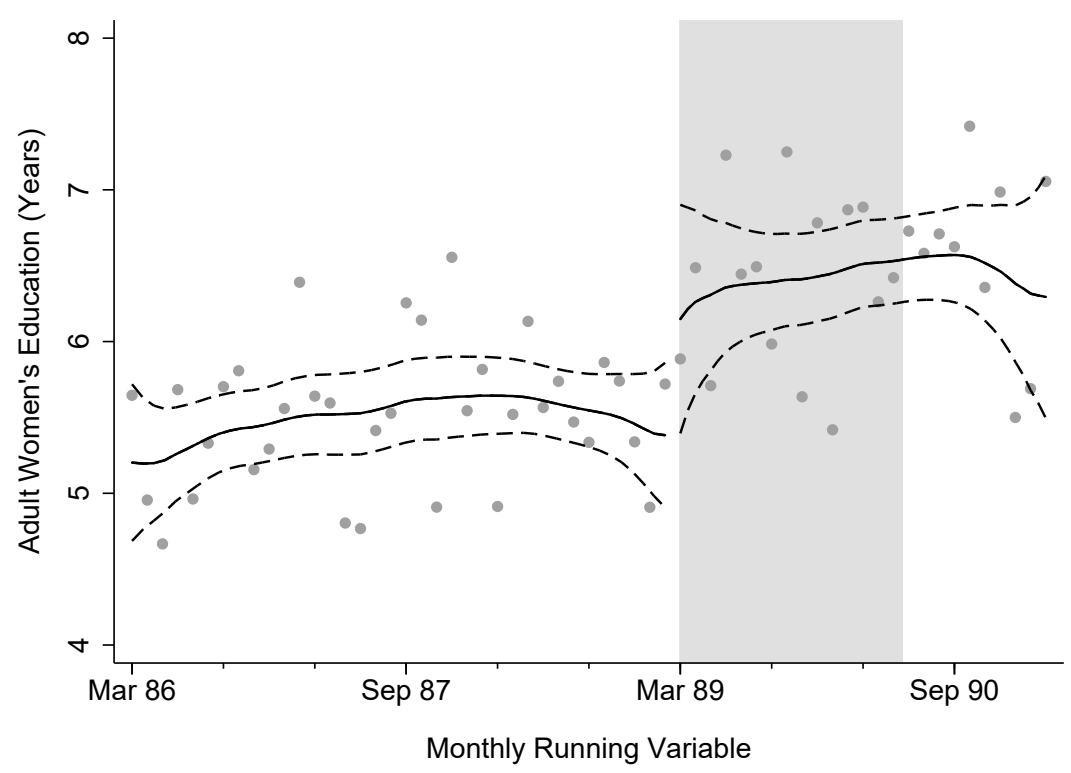

Notes: The graph shows averages of DHS survey respondents' years of completed schooling by month of birth, and local linear regression plots with a triangular kernel. The shaded region indicates the embargo months. The dashed lines show the $95 \%$ confidence intervals around the local linear estimates. The sample includes only women who were aged at least 18 years at the time of the survey. 
Figure 8: Long-Run Years of Schooling: Men

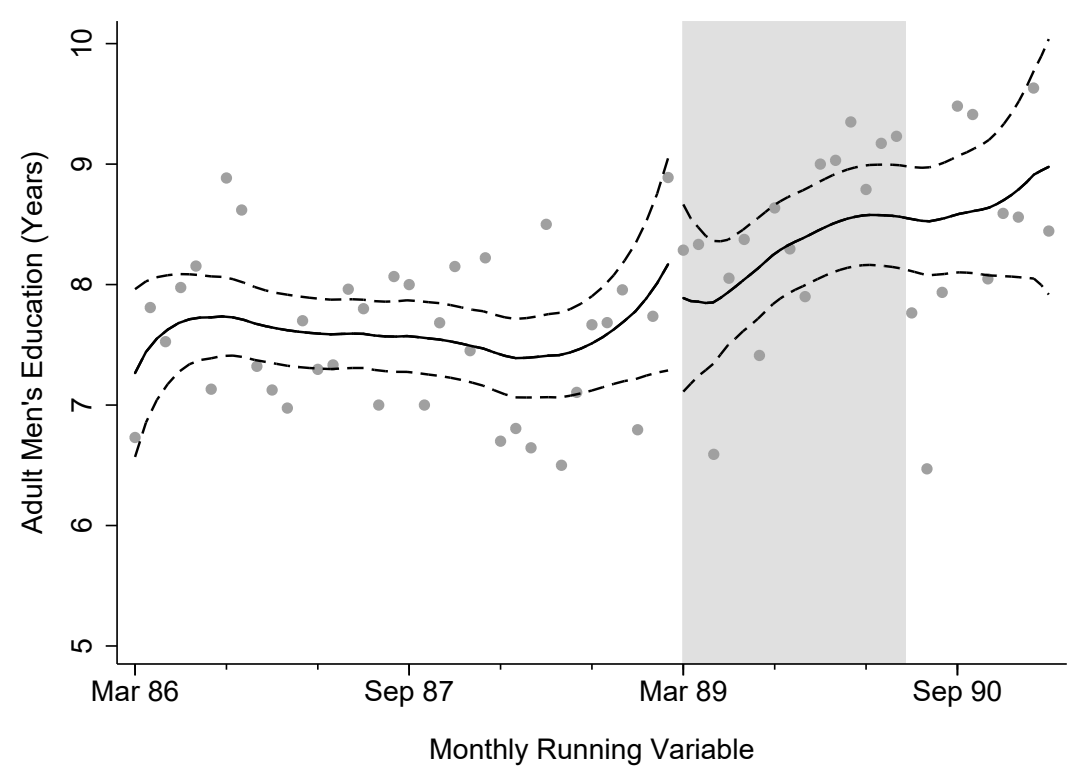

Notes: The graph shows averages of male DHS survey respondents' years of completed schooling by month of birth, and local linear regression plots with a triangular kernel. The shaded region indicates the embargo months. The dashed lines show the $95 \%$ confidence intervals around the local linear estimates. The sample includes only men who were aged at least 18 years at the time of the survey. 
Figure 9: Log Earned Income Returns to Education, NLSS Data

(a) Women, 15-49 years old

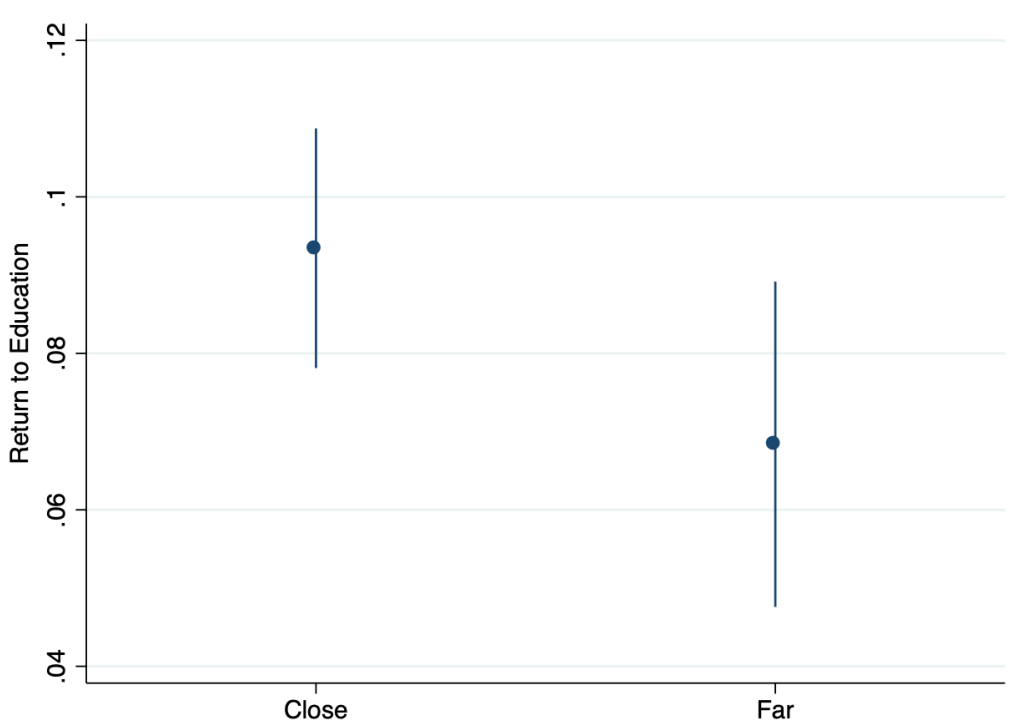

(b) Men, 15-49 years old

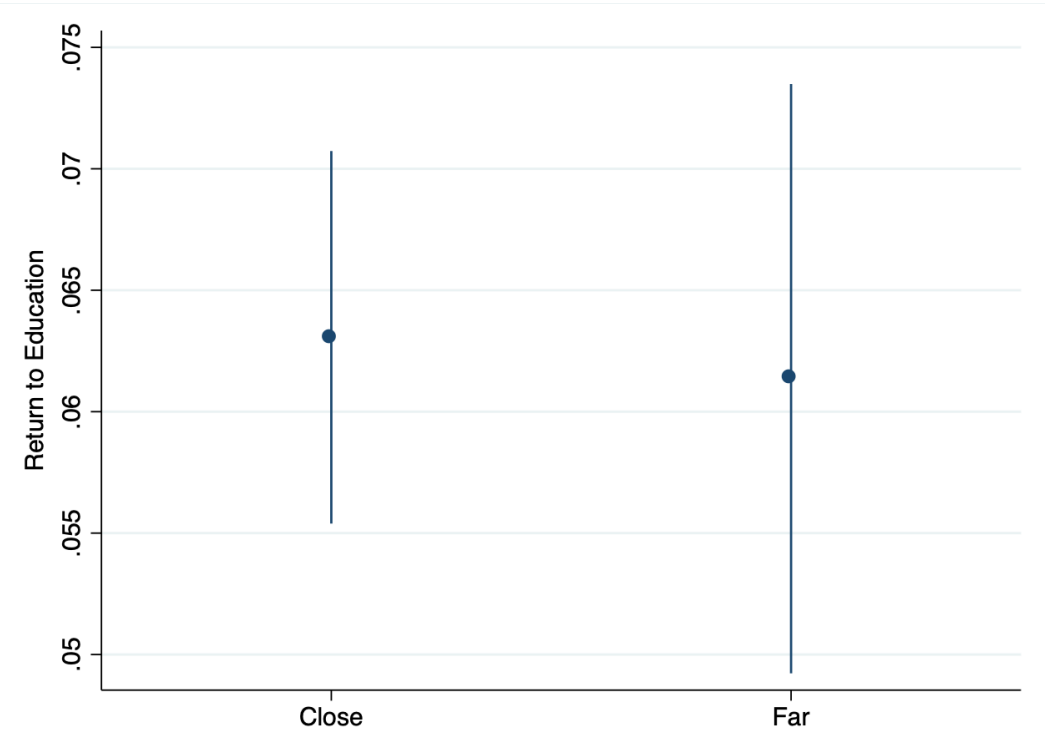

Notes: The graphs show the estimated log earned income returns to a year of education from an OLS regression, conditional on district fixed effects and linear and quadratic terms in age. The spikes indicate the $95 \%$ confidence intervals around the estimates. We restrict the sample to the pre-embargo (1989) period and to those 15 to 49 years old in line with the age range of the workers in our long run DHS sample. 
Table 1: DHS Summary Statistics

\begin{tabular}{lccccc}
\hline Variables & $(1)$ & $(2)$ & $(3)$ & $(4)$ & $(5)$ \\
\hline & Mean & S.D. & Min & Max & Observations \\
\hline Miscarriage & 0.061 & - & 0 & 1 & 57,435 \\
Stillborn & 0.019 & - & 0 & 1 & 57,435 \\
Infant Death & 0.101 & - & 0 & 1 & 52,873 \\
Mother Age at Birth & 24.48 & 5.612 & 10 & 48 & 57,473 \\
\hline Mother Height & 150.6 & 5.463 & 105.9 & 192.6 & 16,320 \\
Mother Upper Caste & 0.345 & - & 0 & 1 & 22,022 \\
Mother Has Some Education & 0.210 & - & 0 & 1 & 22,020 \\
Mother Years of Education & 1.246 & 2.815 & 0 & 14 & 22,020 \\
\hline Years of Education (Women) & 6.126 & 4.008 & 0 & 14 & 13,211 \\
Years of Education (Men) & 7.781 & 3.058 & 0 & 13 & 4,150 \\
Height (Women) & 151.6 & 5.649 & 105.3 & 182.8 & 8,069 \\
\hline
\end{tabular}

Notes: The table shows summary statistics for children's health outcomes and maternal age (top panel, at pregnancy level) for pregnancies ending 1985-1995, corresponding maternal characteristics (middle panel, at mother level), and educational outcomes and height in adulthood (bottom panel) for individuals born 1985-1995. Source: Pooled DHS data.

Table 2: NLSS Summary Statistics

\begin{tabular}{lccccc}
\hline Variables & $(1)$ & $(2)$ & $(3)$ & $(4)$ & $(5)$ \\
\hline & Mean & S.D. & Min & Max & Observations \\
\hline Male & 0.427 & - & 0 & 1 & 6,394 \\
Age & 19.79 & 3.49 & 15 & 26 & 6,394 \\
Monthly Earned Income, Men & 11,133 & 15,554 & 0 & 134,550 & 910 \\
Monthly Earned Income, Women & 6,042 & 10,726 & 0 & 147,500 & 676 \\
\hline
\end{tabular}

Notes: The table shows summary statistics for earned income and demographic characteristics from the NLSS Wave III (2010/11) for individuals born during 1985-1995. Note that reported income excludes those whose wage income is missing in the data. 
Table 3: Live Births

\begin{tabular}{|c|c|c|c|c|c|c|c|c|c|}
\hline \multirow[b]{3}{*}{ Month Trim } & \multicolumn{9}{|c|}{ Live Births } \\
\hline & \multicolumn{3}{|c|}{ All Children } & \multicolumn{3}{|c|}{ Male Children } & \multicolumn{3}{|c|}{ Female Children } \\
\hline & $(0,0)$ & $(1,1)$ & $(2,1)$ & $(0,0)$ & $(1,1)$ & $(2,1)$ & $(0,0)$ & $(1,1)$ & $(2,1)$ \\
\hline \multirow[t]{2}{*}{ Panel $A$} & \multicolumn{9}{|c|}{$M c C R A R Y T E S T$} \\
\hline & $(1)$ & $(2)$ & $(3)$ & $(4)$ & $(5)$ & $(6)$ & $(7)$ & $(8)$ & $(9)$ \\
\hline Log-Diff & $\begin{array}{c}-0.270^{* * *} \\
(0.060)\end{array}$ & $\begin{array}{c}-0.210^{* * *} \\
(0.064)\end{array}$ & $\begin{array}{c}-0.135^{*} \\
(0.071)\end{array}$ & $\begin{array}{c}-0.274^{* * *} \\
(0.085)\end{array}$ & $\begin{array}{c}-0.205^{* *} \\
(0.089)\end{array}$ & $\begin{array}{l}-0.030 \\
(0.087)\end{array}$ & $\begin{array}{c}-0.285^{* * *} \\
(0.086)\end{array}$ & $\begin{array}{c}-0.232^{* *} \\
(0.103)\end{array}$ & $\begin{array}{c}-0.265^{* *} \\
(0.110)\end{array}$ \\
\hline Estimated BW & 6.93 & 6.19 & 5.15 & 6.20 & 5.55 & 6.41 & 7.38 & 5.40 & 4.77 \\
\hline Data BW & 18 & 18 & 18 & 18 & 18 & 18 & 18 & 18 & 18 \\
\hline Panel B & \multicolumn{9}{|c|}{ CJM TEST } \\
\hline$t$-statistic & $-3.626^{* * *}$ & $-2.544^{* *}$ & $-2.185^{* *}$ & $-2.709^{* * *}$ & $-2.017^{* *}$ & $-1.732^{*}$ & $-3.005^{* * *}$ & $-2.274^{* *}$ & $-1.980^{* *}$ \\
\hline $\begin{array}{l}\text { Observations } \\
h_{l}, h_{r}\end{array}$ & $\begin{array}{c}137,103 \\
27.30,25.85\end{array}$ & $\begin{array}{c}136,299 \\
26.80,26.15\end{array}$ & $\begin{array}{c}135,865 \\
26.50,26.49\end{array}$ & $\begin{array}{c}70,202 \\
34.58,31.75\end{array}$ & $\begin{array}{c}69,780 \\
33.62,32.20\end{array}$ & $\begin{array}{c}69,535 \\
32.98,32.82\end{array}$ & $\begin{array}{c}66,901 \\
30.52,30.52\end{array}$ & $\begin{array}{c}66,519 \\
30.79,30.39\end{array}$ & $\begin{array}{c}66,330 \\
30.92,30.27\end{array}$ \\
\hline Panel $C$ & \multicolumn{9}{|c|}{ PARAMETRIC TEST } \\
\hline Treated & $\begin{array}{c}-0.175^{* * *} \\
(0.034)\end{array}$ & $\begin{array}{c}-0.108^{* * *} \\
(0.036)\end{array}$ & $\begin{array}{c}-0.086^{* *} \\
(0.035)\end{array}$ & $\begin{array}{c}-0.171^{* * *} \\
(0.047)\end{array}$ & $\begin{array}{c}-0.100^{*} \\
(0.050)\end{array}$ & $\begin{array}{l}-0.062 \\
(0.041)\end{array}$ & $\begin{array}{c}-0.180^{* * *} \\
(0.049)\end{array}$ & $\begin{array}{c}-0.116^{* *} \\
(0.054)\end{array}$ & $\begin{array}{c}-0.113^{* *} \\
(0.055)\end{array}$ \\
\hline Bandwidth & 18 & 18 & 18 & 18 & 18 & 18 & 18 & 18 & 18 \\
\hline
\end{tabular}

Notes: Panel A shows results from McCrary (2008) tests. Standard errors are in parentheses. The data bandwidths around the March 1989 cut-off in Panel A are restrictions placed on the sample before estimating the default bandwidth. Panel B shows results from density break tests as described in Cattaneo, Jansson, and Ma (2017). Panel C shows estimates from a parametric OLS regression with linear splines, with standard errors clustered by the running variable in parentheses. Dependent variable is log number of live births. In the row 'Month Trim' at the top of the table, $(a, b)$ indicates $a$ months trimmed before, and $b$ months trimmed after the cut-off. ${ }^{* * *} p<0.01 ;{ }^{* *} p<0.05 ;{ }^{*} p<0.10$. 
Table 4: Live Births by Distance to Main Border Crossing

\begin{tabular}{|c|c|c|c|c|c|c|}
\hline \multirow[b]{3}{*}{ Panel A: All Children } & \multicolumn{6}{|c|}{ Live Births } \\
\hline & \multicolumn{2}{|c|}{ All } & \multicolumn{2}{|c|}{ Close } & \multicolumn{2}{|c|}{ Far } \\
\hline & (1) & $(2)$ & (3) & (4) & (5) & (6) \\
\hline Treated & $\begin{array}{c}-0.156 \\
(0.049)^{* *}\end{array}$ & $\begin{array}{c}-0.183 \\
(0.052)^{* * *}\end{array}$ & $\begin{array}{l}-0.073 \\
(0.154) \\
{[0.646]}\end{array}$ & $\begin{array}{l}-0.133 \\
(0.122) \\
{[0.294]}\end{array}$ & $\begin{array}{c}-0.272 \\
(0.113)^{* *} \\
{[0.080]^{*}}\end{array}$ & $\begin{array}{c}-0.254 \\
(0.092)^{* *} \\
{[0.028]^{* *}}\end{array}$ \\
\hline Bandwidth & 6 & 9 & 6 & 9 & 6 & 9 \\
\hline Panel B: Male Children & (1) & $(2)$ & (3) & $(4)$ & $(5)$ & (6) \\
\hline Treated & $\begin{array}{l}-0.123 \\
(0.100) \\
{[0.251]}\end{array}$ & $\begin{array}{l}-0.133 \\
(0.089) \\
{[0.155]}\end{array}$ & $\begin{array}{l}-0.072 \\
(0.211) \\
{[0.741]}\end{array}$ & $\begin{array}{l}-0.114 \\
(0.168) \\
{[0.507]}\end{array}$ & $\begin{array}{c}-0.201 \\
(0.109)^{*} \\
{[0.198]}\end{array}$ & $\begin{array}{l}-0.172 \\
(0.100) \\
{[0.212]}\end{array}$ \\
\hline Bandwidth & 6 & 9 & 6 & 9 & 6 & 9 \\
\hline Panel C: Female Children & (1) & $(2)$ & (3) & (4) & (5) & (6) \\
\hline Treated & $\begin{array}{c}-0.193 \\
(0.024)^{* * *} \\
{[0.000]^{* * *}}\end{array}$ & $\begin{array}{c}-0.235 \\
(0.041)^{* * *} \\
{[0.000]^{* * *}}\end{array}$ & $\begin{array}{l}-0.067 \\
(0.143) \\
{[0.741]} \\
\end{array}$ & $\begin{array}{l}-0.149 \\
(0.108) \\
{[0.251]} \\
\end{array}$ & $\begin{array}{c}-0.352 \\
(0.149)^{* *} \\
{[0.168]}\end{array}$ & $\begin{array}{c}-0.346 \\
(0.117)^{* * *} \\
{[0.040]^{* *}}\end{array}$ \\
\hline Bandwidth & 6 & 9 & 6 & 9 & 6 & 9 \\
\hline \multicolumn{7}{|c|}{$\begin{array}{l}\text { Notes: The table shows results from parametric OLS regressions with a linear spline. Panel A reports results for all } \\
\text { children, Panel B reports results for male children, and Panel C reports results for female children. The estimation } \\
\text { samples are from the } 2006,2011 \text {, and } 2016 \text { waves of the DHS survey data, for which we have district identifiers and can } \\
\text { calculate distance to the main border crossing. Robust standard errors are in parentheses, and Benjamini-Hochberg } \\
\text { corrected } p \text {-values are reported in brackets. Families of corrected } p \text {-values: 1. Panel A columns (3), (5); 2. Panel A } \\
\text { columns }(4),(6) ; 3 \text {. Panel B column (1), Panel C column (1); 4. Panel B column }(2) \text {, Panel C column }(2) ; \mathbf{5} \text {. Panel B } \\
\text { columns }(3),(5), \text { Panel C columns }(3),(5) ; 6 \text {. Panel B columns }(4),(6) \text {, Panel C columns }(4),(6) . *^{* * *} p<0.01 ; * * \\
p<0.05 ; * p<0.10 \text {. }\end{array}$} \\
\hline
\end{tabular}

Table 5: Miscarriage

\begin{tabular}{|c|c|c|c|c|c|c|}
\hline \multirow[b]{3}{*}{ Panel A: Optimal Bandwidth } & \multicolumn{6}{|c|}{ Miscarriage } \\
\hline & \multicolumn{2}{|c|}{ All Children } & \multicolumn{2}{|c|}{ First Birth } & \multicolumn{2}{|c|}{ Later Birth } \\
\hline & (1) & $(2)$ & (3) & $(4)$ & (5) & (6) \\
\hline & $h^{*}$ & $0.5 h^{*}$ & $h^{*}$ & $0.5 h^{*}$ & $h^{*}$ & $0.5 h^{*}$ \\
\hline Treated & $\begin{array}{c}0.005 \\
(0.004)\end{array}$ & $\begin{array}{c}0.006 \\
(0.006)\end{array}$ & $\begin{array}{c}0.012 \\
(0.007)^{*} \\
{[0.176]}\end{array}$ & $\begin{array}{c}0.022 \\
(0.010)^{* *} \\
{[0.064]^{*}}\end{array}$ & $\begin{array}{c}0.004 \\
(0.005) \\
{[0.396]}\end{array}$ & $\begin{array}{c}0.001 \\
(0.006) \\
{[0.827]}\end{array}$ \\
\hline Observations & 52,258 & 26,494 & 15,426 & 7,814 & 42,222 & 21,332 \\
\hline Bandwidth & 64 & 32 & 73 & 36 & 70 & 35 \\
\hline Panel B: Other Bandwidths & (1) & $(2)$ & (3) & (4) & (5) & (6) \\
\hline Treated & $\begin{array}{c}0.018 \\
(0.013)\end{array}$ & $\begin{array}{c}0.014 \\
(0.011)\end{array}$ & $\begin{array}{c}0.044 \\
(0.022)^{* *} \\
{[0.092]^{*}}\end{array}$ & $\begin{array}{c}0.042 \\
(0.019)^{* *} \\
{[0.052]^{*}}\end{array}$ & $\begin{array}{c}0.008 \\
(0.016) \\
{[0.610]}\end{array}$ & $\begin{array}{c}0.003 \\
(0.013) \\
{[0.817]}\end{array}$ \\
\hline Observations & 5,455 & 8,027 & 1,474 & 2,163 & 3,981 & 5,864 \\
\hline Bandwidth & 6 & 9 & 6 & 9 & 6 & 9 \\
\hline
\end{tabular}

Notes: The table shows results from parametric OLS regressions with a linear spline. Panel A reports results from optimal bandwidths, and Panel B reports results from smaller bandwidths. Robust Standard errors are in parentheses, and Benjamini-Hochberg corrected $p$-values are reported in brackets. Families of corrected $p$-values: 1. Panel A columns (3), (5); 2. Panel A columns (4), (6); 3. Panel B columns (3), (5); 4. Panel B columns (4), (6). ${ }^{* * *} p<0.01 ;{ }^{* *} p<0.05 ;{ }^{*} p<0.10$. 
Table 6: Infant Death

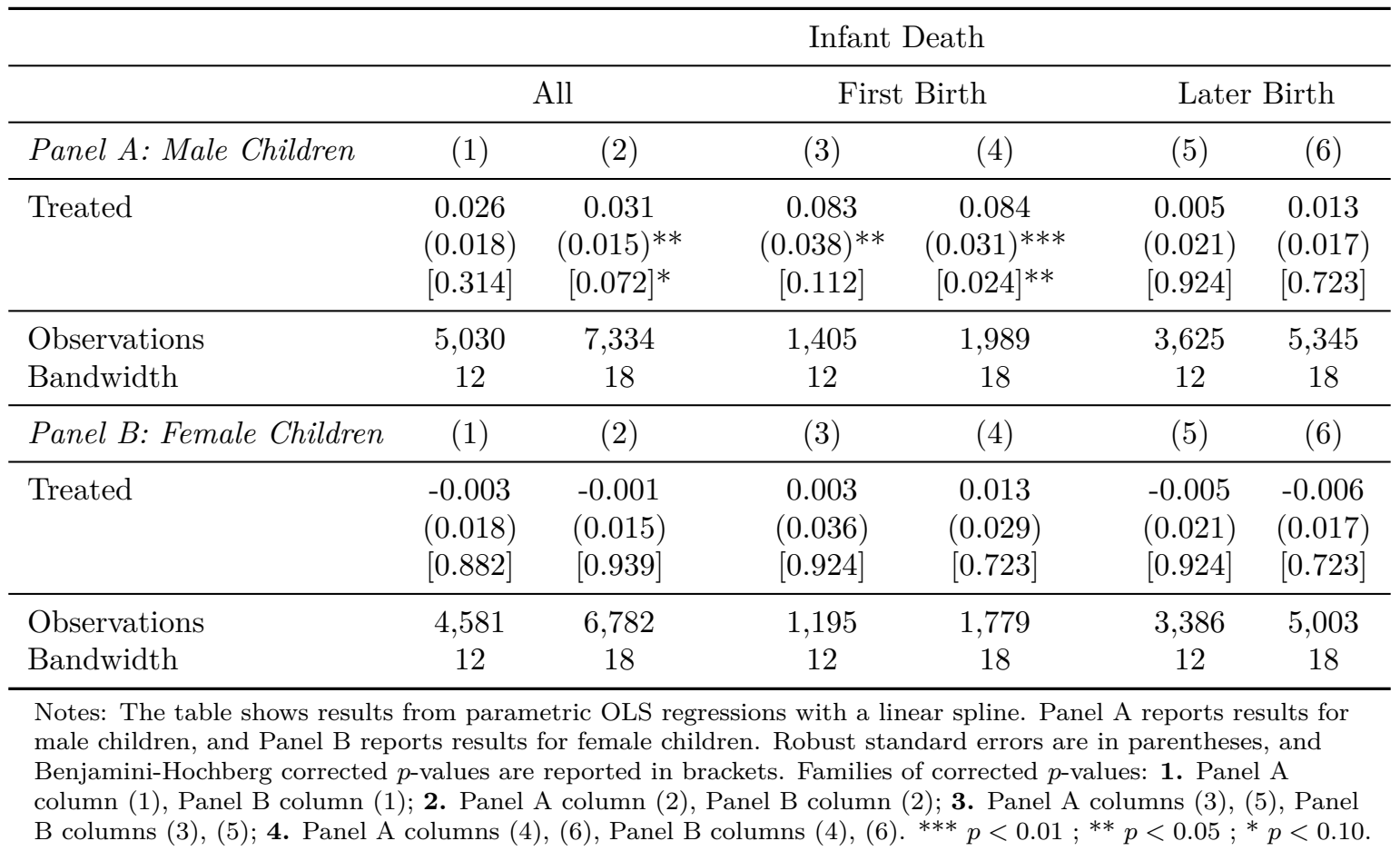

Table 7: Mother Characteristics

\begin{tabular}{lcccccccc}
\hline & \multicolumn{1}{c}{ Mother Characteristics } & & Age at Birth \\
\hline & \multicolumn{2}{c}{ Caste } & \multicolumn{2}{c}{ Education } & \multicolumn{2}{c}{ Height } & \multicolumn{2}{c}{ Ag } \\
\hline Panel A: Optimal BW & $(1)$ & $(2)$ & $(3)$ & $(4)$ & $(5)$ & $(6)$ & $(7)$ & $(8)$ \\
\hline & $h^{*}$ & $0.5 h^{*}$ & $h^{*}$ & $0.5 h^{*}$ & $h^{*}$ & $0.5 h^{*}$ & $h^{*}$ & $0.5 h^{*}$ \\
\hline Treated & 0.000 & 0.012 & -0.061 & $-0.107^{*}$ & -0.071 & -0.072 & 0.137 & $0.373^{* *}$ \\
& $(0.009)$ & $(0.013)$ & $(0.043)$ & $(0.060)$ & $(0.107)$ & $(0.148)$ & $(0.103)$ & $(0.146)$ \\
\hline Observations & 42,576 & 21,672 & 46,688 & 23,221 & 42,999 & 21,620 & 45,122 & 22,454 \\
Bandwidth & 52 & 26 & 57 & 28 & 70 & 35 & 55 & 27 \\
\hline Panel B: Other $B W$ & $(1)$ & $(2)$ & $(3)$ & $(4)$ & $(5)$ & $(6)$ & $(7)$ & $(8)$ \\
\hline Treated & 0.009 & 0.005 & $-0.257^{* *}$ & -0.139 & $-0.790^{* *}$ & -0.350 & -0.064 & $0.669^{* * *}$ \\
& $(0.026)$ & $(0.021)$ & $(0.122)$ & $(0.102)$ & $(0.351)$ & $(0.287)$ & $(0.307)$ & $(0.250)$ \\
\hline Observations & 5,459 & 8,031 & 5,458 & 8,030 & 4,079 & 5,994 & 5,459 & 8,031 \\
Bandwidth & 6 & 9 & 6 & 9 & 6 & 9 & 6 & 9 \\
\hline
\end{tabular}

Notes: The table shows results from parametric OLS regressions with a linear spline. BW refers to bandwidth. Robust standard errors are in parentheses. ${ }^{* * *} p<0.01 ;{ }^{* *} p<0.05 ;{ }^{*} p<0.10$. 
Table 8: Adult Women's Height, Distance to Main Border Crossing

\begin{tabular}{lcccccc}
\hline \multicolumn{2}{c}{ All } & \multicolumn{2}{c}{ Close } & \multicolumn{2}{c}{ Far } \\
\hline Panel A: Optimal $B W$ & $(1)$ & $(2)$ & $(3)$ & $(4)$ & $(5)$ & $(6)$ \\
\hline & $h^{*}$ & $0.5 h^{*}$ & $h^{*}$ & $0.5 h^{*}$ & $h^{*}$ & $0.5 h^{*}$ \\
\hline Treated & 0.518 & 0.534 & -0.944 & -1.353 & 1.447 & 2.229 \\
& $(0.422)$ & $(0.618)$ & $(0.598)$ & $(0.849)$ & $(0.557)^{* * *}$ & $(0.810)^{* * *}$ \\
& & & {$[0.115]$} & {$[0.111]$} & {$[0.018]^{* *}$} & {$[0.012]^{* *}$} \\
\hline Observations & 3,208 & 1,540 & 1,624 & 799 & 1,747 & 849 \\
Bandwidth & 29 & 14 & 30 & 15 & 31 & 15 \\
\hline Panel B: Other BW & $(1)$ & $(2)$ & $(3)$ & $(4)$ & $(5)$ & $(6)$ \\
\hline Treated & 0.227 & -0.062 & -3.392 & -2.691 & 3.696 & 2.309 \\
& $(1.058)$ & $(0.803)$ & $(1.472)^{* *}$ & $(1.136)^{* *}$ & $(1.453)^{* *}$ & $(1.095)^{* *}$ \\
& & & {$[0.022]^{* *}$} & {$[0.036]^{* *}$} & {$[0.022]^{* *}$} & {$[0.035]^{* *}$} \\
\hline Observations & 621 & 989 & 301 & 476 & 320 & 513 \\
\hline Bandwidth & 6 & 9 & 6 & 9 & 6 & 9 \\
\hline
\end{tabular}

Notes: The table shows results from parametric OLS regressions with a linear spline. The sample includes women who were at least 18 years old at the time of the survey. BW refers to bandwidth. Source: DHS data. Robust standard errors are in parentheses, and Benjamini-Hochberg corrected $p$-values are reported in brackets. Families of corrected $p$-values: 1. Panel A columns (3), (5); 2. Panel A columns (4), (6); 3. Panel B columns (3), (5); 4. Panel B columns (4), (6). ${ }^{* * *} p<0.01 ;{ }^{* *} p<0.05 ;{ }^{*} p<0.10$.

Table 9: Adult Women's Education

\begin{tabular}{lcccc}
\hline \multicolumn{5}{c}{ Education } \\
\hline Years of Schooling & \multicolumn{2}{c}{ Any Schooling } \\
\hline Panel A: Optimal $B W$ & $(1)$ & $(2)$ & $(3)$ & $(4)$ \\
\hline Treated & $h^{*}$ & $0.5 h^{*}$ & $h^{*}$ & $0.5 h^{*}$ \\
\hline Observations & $0.702^{* * *}$ & $0.935^{* * *}$ & $0.081^{* * *}$ & $0.120^{* *}$ \\
Bandwidth & $(0.227)$ & $(0.325)$ & $(0.031)$ & $(0.047)$ \\
\hline Panel B: Other $B W$ & 5,608 & 2,857 & 3,234 & 1,539 \\
\hline Treated & 30 & 15 & 17 & 8 \\
\hline Observations & $(1)$ & $(2)$ & $(3)$ & $(4)$ \\
Bandwidth & 0.876 & $0.879^{* *}$ & $0.132^{* *}$ & $0.107^{* *}$ \\
\hline
\end{tabular}

Notes: The table shows results from OLS regressions with linear splines. The sample includes women who were at least 18 years old at the time of the survey. BW refers to bandwidth. Robust standard errors are in parentheses. ${ }^{* * *} p<0.01$; ** $p<0.05 ; * p<0.10$. 
Table 10: Long-Run Earned Income, Distance to Border Crossing

\begin{tabular}{|c|c|c|c|c|c|c|}
\hline & \multicolumn{2}{|c|}{ All Workers } & \multicolumn{2}{|c|}{ Male Workers } & \multicolumn{2}{|c|}{ Female Workers } \\
\hline & (1) & $(2)$ & $(3)$ & (4) & $(5)$ & (6) \\
\hline Panel $A$ & & & All Nepal & istricts & & \\
\hline Treated & $\begin{array}{c}0.204 \\
(0.122)^{*}\end{array}$ & $\begin{array}{l}0.0747 \\
(0.196)\end{array}$ & $\begin{array}{c}0.262 \\
(0.149)^{*} \\
{[0.162]}\end{array}$ & $\begin{array}{l}0.0493 \\
(0.244) \\
{[1.000]}\end{array}$ & $\begin{array}{c}0.0529 \\
(0.188) \\
{[0.935]}\end{array}$ & $\begin{array}{r}-0.0242 \\
(0.298) \\
{[0.935]}\end{array}$ \\
\hline Observations & 1,201 & 660 & 692 & 383 & 509 & 277 \\
\hline Bandwidth & 4 & 2 & 4 & 2 & 4 & 2 \\
\hline Panel B & & & Close D & tricts & & \\
\hline Treated & $\begin{array}{c}0.289 \\
(0.159)^{*} \\
{[0.140]}\end{array}$ & $\begin{array}{c}0.186 \\
(0.243) \\
{[0.320]} \\
\end{array}$ & $\begin{array}{c}0.315 \\
(0.202) \\
{[0.247]}\end{array}$ & $\begin{array}{c}0.225 \\
(0.309) \\
{[0.388]}\end{array}$ & $\begin{array}{c}0.259 \\
(0.235) \\
{[0.247]}\end{array}$ & $\begin{array}{c}0.0278 \\
(0.361) \\
{[0.388]} \\
\end{array}$ \\
\hline $\begin{array}{l}\text { Observations } \\
\text { Bandwidth }\end{array}$ & $\begin{array}{c}649 \\
4\end{array}$ & $\begin{array}{c}370 \\
2\end{array}$ & $\begin{array}{c}371 \\
4\end{array}$ & $\begin{array}{c}209 \\
2\end{array}$ & $\begin{array}{c}278 \\
4\end{array}$ & $\begin{array}{c}161 \\
2\end{array}$ \\
\hline Panel $C$ & & & Far Di & ricts & & \\
\hline Treated & $\begin{array}{c}0.124 \\
(0.168) \\
{[0.462]}\end{array}$ & $\begin{array}{c}-0.287 \\
(0.291) \\
{[0.320]}\end{array}$ & $\begin{array}{c}0.264 \\
(0.199) \\
{[0.247]}\end{array}$ & $\begin{array}{l}-0.389 \\
(0.380) \\
{[0.388]}\end{array}$ & $\begin{array}{c}-0.228 \\
(0.248) \\
{[0.360]}\end{array}$ & $\begin{array}{c}-0.348 \\
(0.402) \\
{[0.388]}\end{array}$ \\
\hline $\begin{array}{l}\text { Observations } \\
\text { Bandwidth }\end{array}$ & $\begin{array}{c}552 \\
4\end{array}$ & $\begin{array}{c}290 \\
2\end{array}$ & $\begin{array}{c}321 \\
4\end{array}$ & $\begin{array}{c}174 \\
2\end{array}$ & $\begin{array}{c}231 \\
4\end{array}$ & $\begin{array}{c}116 \\
2\end{array}$ \\
\hline
\end{tabular}

Notes: The table shows results from parametric OLS regressions with a linear spline. Data are from the 2010/2011 National Living Standards Survey. Distance is the distance to the main border crossing with India in Birgunj. Robust Standard errors are in parentheses, and Benjamini-Hochberg corrected $p$-values are reported in brackets. Families of corrected $p$-values: 1. Panel A columns (3), (5); 2. Panels B and C columns (1), (2); 3. Panel A columns (4), (6); 4. Panels B and C columns (3), (5); 5. Panels B and C columns (4), (6). *** $p<0.01 ;$ *** $^{*}<0.05 ; * p<0.10$. 


\section{Appendix}

\section{A Additional Figures and Tables}

Figure A.1: Log Earned Income and Distance to Main Border Crossing

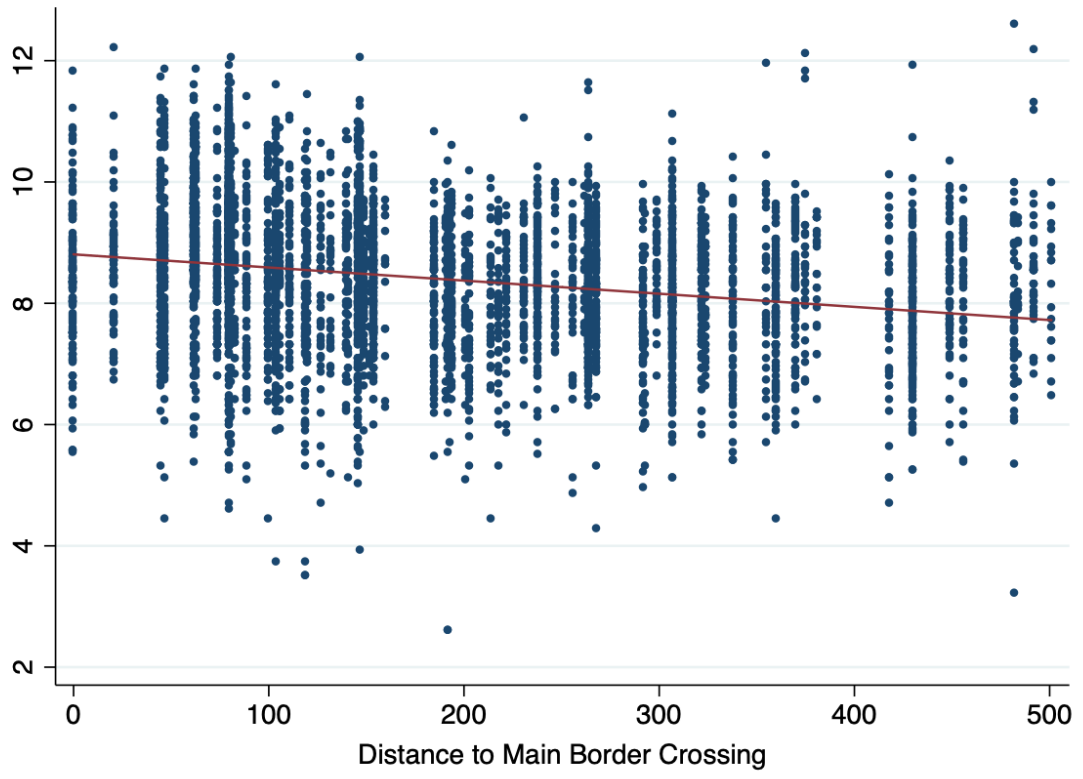

Notes: The graph plots log earned income versus distance to the main border crossing in Birgunj for all observations in the 2010/11 wave of the NLSS. Note that the coefficient of a linear regression is -0.002 with a t-statistic of 17.5 .

Figure A.2: Rainfall Shocks

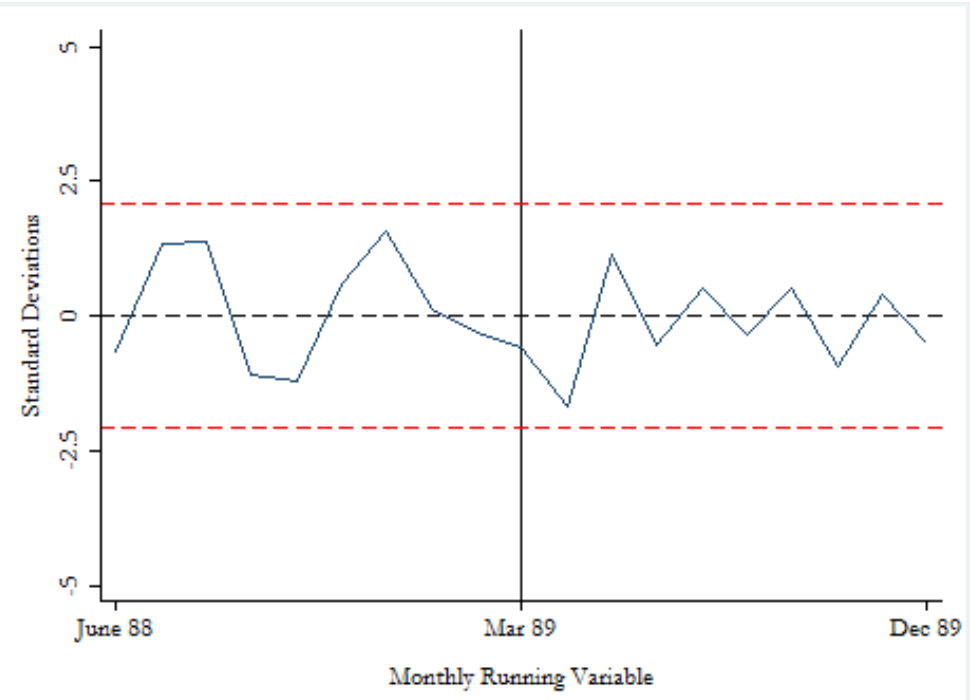

Notes: The graph shows monthly rainfall shocks, measured in standard deviations from the average rainfall in that month over the past 20 years. The red dashed lines show the $95 \%$ confidence interval. 
Figure A.3: Pregnancy Intervals

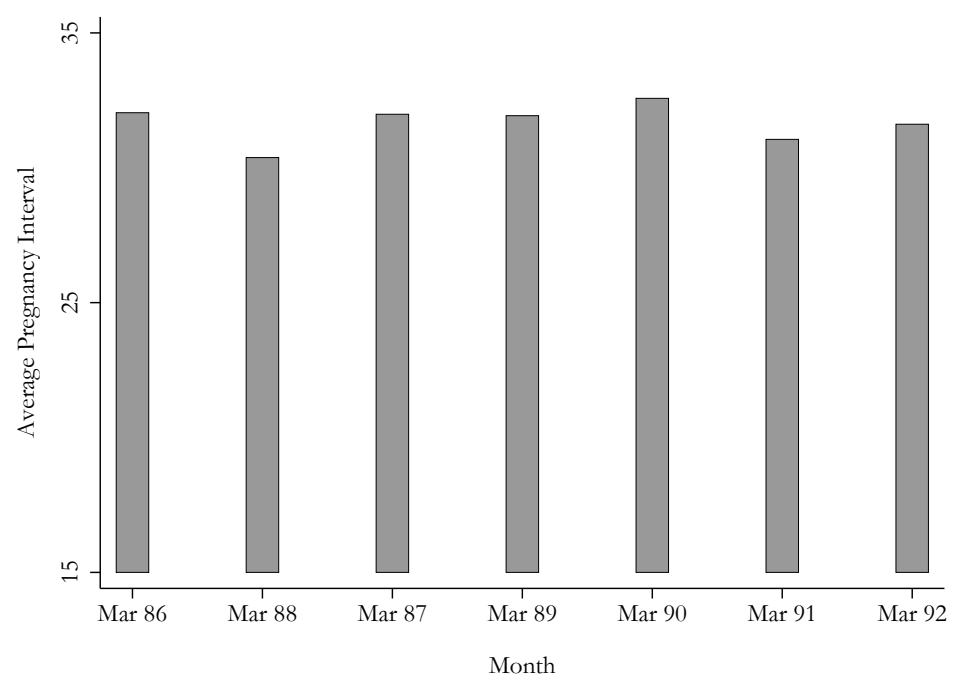

Notes: The graph shows the average interval in months from the previous pregnancy for pregnancies ending in March. Mothers' first pregnancies are not included in the sample.

Figure A.4: Live Births without Jan and Feb 1989

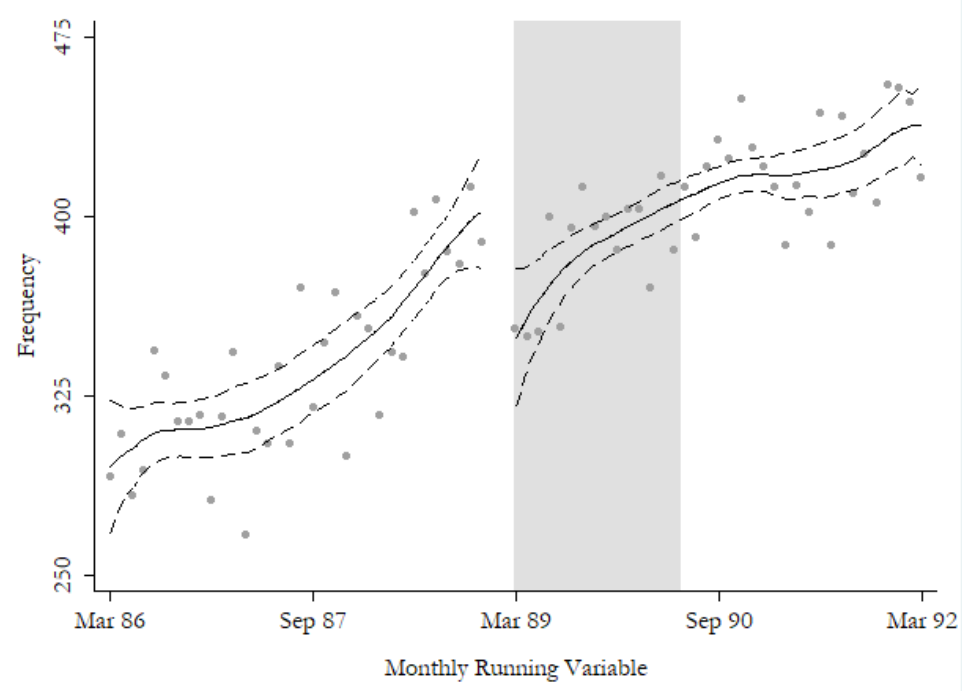

Notes: The graph shows the number of live births by month, and local linear regression plots with a triangular kernel. The dashed lines show the 95\% confidence intervals around the local linear estimates. 
Figure A.5: Completed Pregnancies

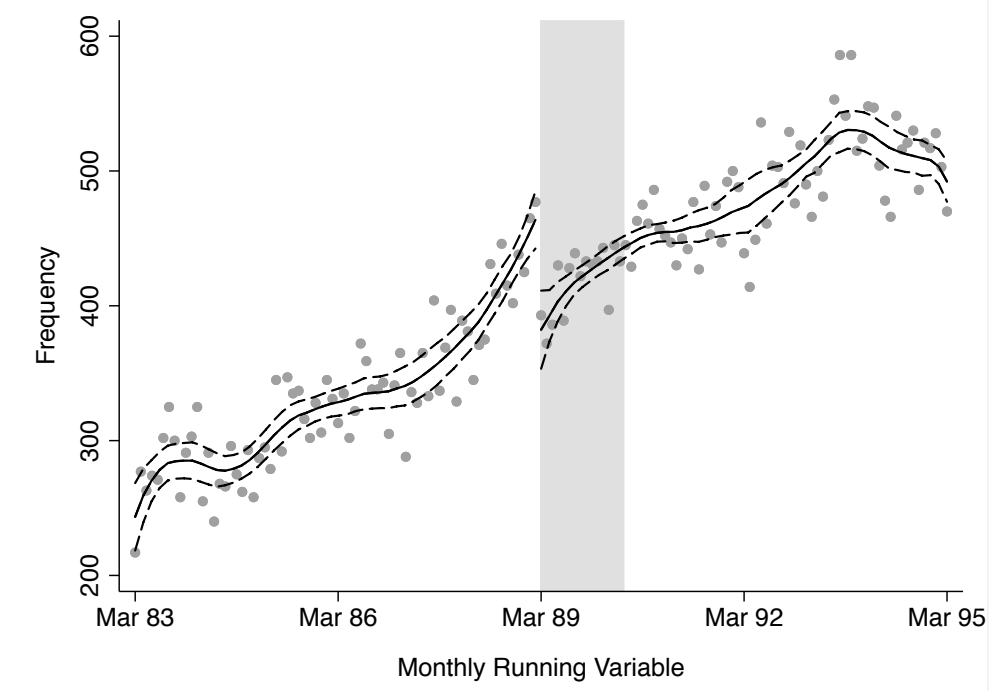

Notes: The graph shows the number of completed pregnancies by monthly bin, and local linear regression plots of completed pregnancies with a triangular kernel. The shaded region indicates the embargo months. The dashed lines show the $95 \%$ confidence intervals around the local linear estimates.

Figure A.6: Completed Pregnancies: Comparing Start and End of Embargo

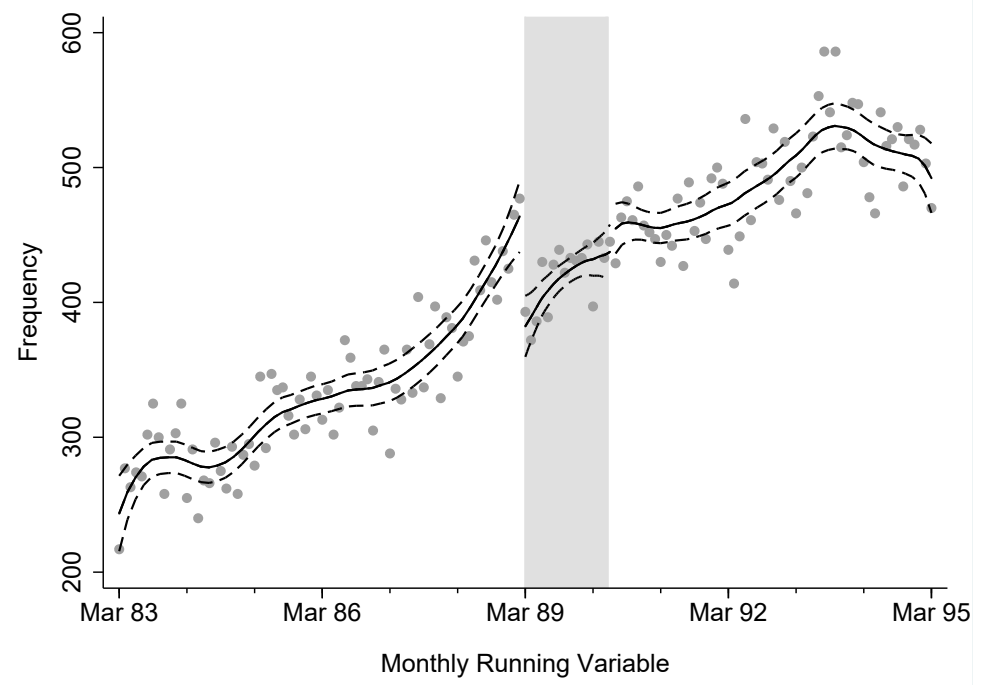

Notes: The graph shows the number of completed pregnancies by monthly bin, and local linear regression plots of completed pregnancies with a triangular kernel. The shaded region indicates the embargo months. The dashed lines show the $95 \%$ confidence intervals around the local linear estimates. The kernel bandwidth is set to 10 months, with a pilot bandwidth for the standard error calculation of 15 months. Source: DHS data. 
Table A.1: Live Births, 24-Month Bandwidth

\begin{tabular}{|c|c|c|c|c|c|c|c|c|c|}
\hline \multirow[b]{3}{*}{ Month Trim } & \multicolumn{9}{|c|}{ Live Births } \\
\hline & \multicolumn{3}{|c|}{ All Children } & \multicolumn{3}{|c|}{ Male Children } & \multicolumn{3}{|c|}{ Female Children } \\
\hline & $(0,0)$ & $(1,1)$ & $(2,1)$ & $(0,0)$ & $(1,1)$ & $(2,1)$ & $(0,0)$ & $(1,1)$ & $(-2,-1)$ \\
\hline \multirow[t]{2}{*}{ Panel $A$} & \multicolumn{9}{|c|}{$M c C R A R Y T E S T$} \\
\hline & (1) & $(2)$ & $(3)$ & (4) & $(5)$ & (6) & $(7)$ & (8) & (9) \\
\hline Log-Diff & $\begin{array}{c}-0.270^{* * *} \\
(0.060)\end{array}$ & $\begin{array}{c}-0.175^{* * *} \\
(0.047)\end{array}$ & $\begin{array}{c}-0.133^{* * *} \\
(0.046)\end{array}$ & $\begin{array}{c}-0.246^{* * *} \\
(0.075)\end{array}$ & $\begin{array}{c}-0.168^{* *} \\
(0.076)\end{array}$ & $\begin{array}{c}-0.076 \\
(0.060)\end{array}$ & $\begin{array}{c}-0.276^{* * *} \\
(0.092)\end{array}$ & $\begin{array}{c}-0.225^{* * *} \\
(0.086)\end{array}$ & $\begin{array}{c}-0.223^{* * *} \\
(0.073)\end{array}$ \\
\hline Estimated BW & 6.86 & 11.20 & 11.89 & 8.025 & 7.88 & 13.48 & 6.37 & 7.71 & 10.06 \\
\hline Data BW & 24 & 24 & 24 & 24 & 24 & 24 & 24 & 24 & 24 \\
\hline Panel B & \multicolumn{9}{|c|}{ PARAMETRIC TEST } \\
\hline Treated & $\begin{array}{c}-0.156^{* * *} \\
(0.032)\end{array}$ & $\begin{array}{c}-0.092^{* * *} \\
(0.034)\end{array}$ & $\begin{array}{c}-0.064^{*} \\
(0.033)\end{array}$ & $\begin{array}{c}-0.161^{* * *} \\
(0.042)\end{array}$ & $\begin{array}{c}-0.102^{* *} \\
(0.044)\end{array}$ & $\begin{array}{c}-0.062 \\
(0.039)\end{array}$ & $\begin{array}{c}-0.150^{* * *} \\
(0.045)\end{array}$ & $\begin{array}{l}-0.082 \\
(0.050)\end{array}$ & $\begin{array}{l}-0.068 \\
(0.051)\end{array}$ \\
\hline Bandwidth & 24 & 24 & 24 & 24 & 24 & 24 & 24 & 24 & 24 \\
\hline
\end{tabular}

Notes: Panel A shows results from McCrary tests implemented as described in McCrary (2008). Standard errors are in parentheses. The data bandwidths around the March 1989 cut-off in Panel A are restrictions on the sample placed by the authors before estimating the default

bandwidth. Panel B shows estimates from a parametric OLS regression with linear splines, with robust standard errors in parentheses. Dependent

variable is $\log$ number of live births. In the row 'Month Trim' at the top of the table, $(a, b)$ indicates $a$ months trimmed before, and $b$ months

trimmed after the cut-off. $* * * p<0.01 ; * * p<0.05 ; * p<0.10$. 
Table A.2: Live Births, Alternate Specifications

\begin{tabular}{|c|c|c|c|c|}
\hline & \multicolumn{4}{|c|}{ Live Births } \\
\hline & (1) & (2) & (3) & (4) \\
\hline Panel $A$ & \multicolumn{2}{|c|}{ Linear Spline } & \multicolumn{2}{|c|}{ Quadratic Spline } \\
\hline Treated & $\begin{array}{c}-0.086^{* * *} \\
(0.032)\end{array}$ & $\begin{array}{c}-0.180^{* * *} \\
(0.039)\end{array}$ & $\begin{array}{c}-0.248^{* * *} \\
(0.040)\end{array}$ & $\begin{array}{c}-0.211^{* * *} \\
(0.045)\end{array}$ \\
\hline Bandwidth & 33 & 16 & 18 & 24 \\
\hline \multirow[t]{2}{*}{ Panel B } & \multicolumn{4}{|c|}{1996 DHS Wave (Linear Spline) } \\
\hline & (1) & (2) & (3) & (4) \\
\hline Treated & $\begin{array}{c}-0.346^{* * *} \\
(0.057)\end{array}$ & $\begin{array}{c}-0.183^{* *} \\
(0.075)\end{array}$ & $\begin{array}{c}-0.135 * * \\
(0.065)\end{array}$ & $\begin{array}{c}-0.088 \\
(0.058)\end{array}$ \\
\hline Bandwidth & 6 & 12 & 18 & 24 \\
\hline
\end{tabular}

Table A.3: Live Births, Seasonality Tests

\begin{tabular}{lccccccc}
\hline \multicolumn{7}{c}{ Live Births } \\
\hline & 1992 & 1991 & 1990 & 1989 & 1988 & 1987 & 1986 \\
\hline Panel $A$ & $(1)$ & $(2)$ & $(3)$ & $(4)$ & $(5)$ & $(6)$ & $(7)$ \\
\hline Treated & -0.040 & $-0.060^{* *}$ & 0.027 & $-0.175^{* * *}$ & 0.038 & -0.075 & -0.060 \\
& $(0.043)$ & $(0.028)$ & $(0.030)$ & $(0.034)$ & $(0.053)$ & $(0.047)$ & $(0.037)$ \\
\hline Bandwidth & 18 & 18 & 18 & 18 & 18 & 18 & 18 \\
\hline Panel B & $(1)$ & $(2)$ & $(3)$ & $(4)$ & $(5)$ & $(6)$ & $(7)$ \\
\hline Treated & -0.037 & $-0.070^{* * *}$ & -0.011 & $-0.156^{* * *}$ & 0.064 & -0.064 & -0.058 \\
& $(0.037)$ & $(0.026)$ & $(0.030)$ & $(0.032)$ & $(0.047)$ & $(0.045)$ & $(0.036)$ \\
\hline Bandwidth & 24 & 24 & 24 & 24 & 24 & 24 & 24 \\
\hline
\end{tabular}

Notes: All estimates are from a parametric OLS regression with linear splines, with robust standard errors in parentheses. *** $p<0.01 ; * * p<0.05 ; * p<0.10$. 
Table A.4: Child Mortality, Monthly Averages

Child Mortality

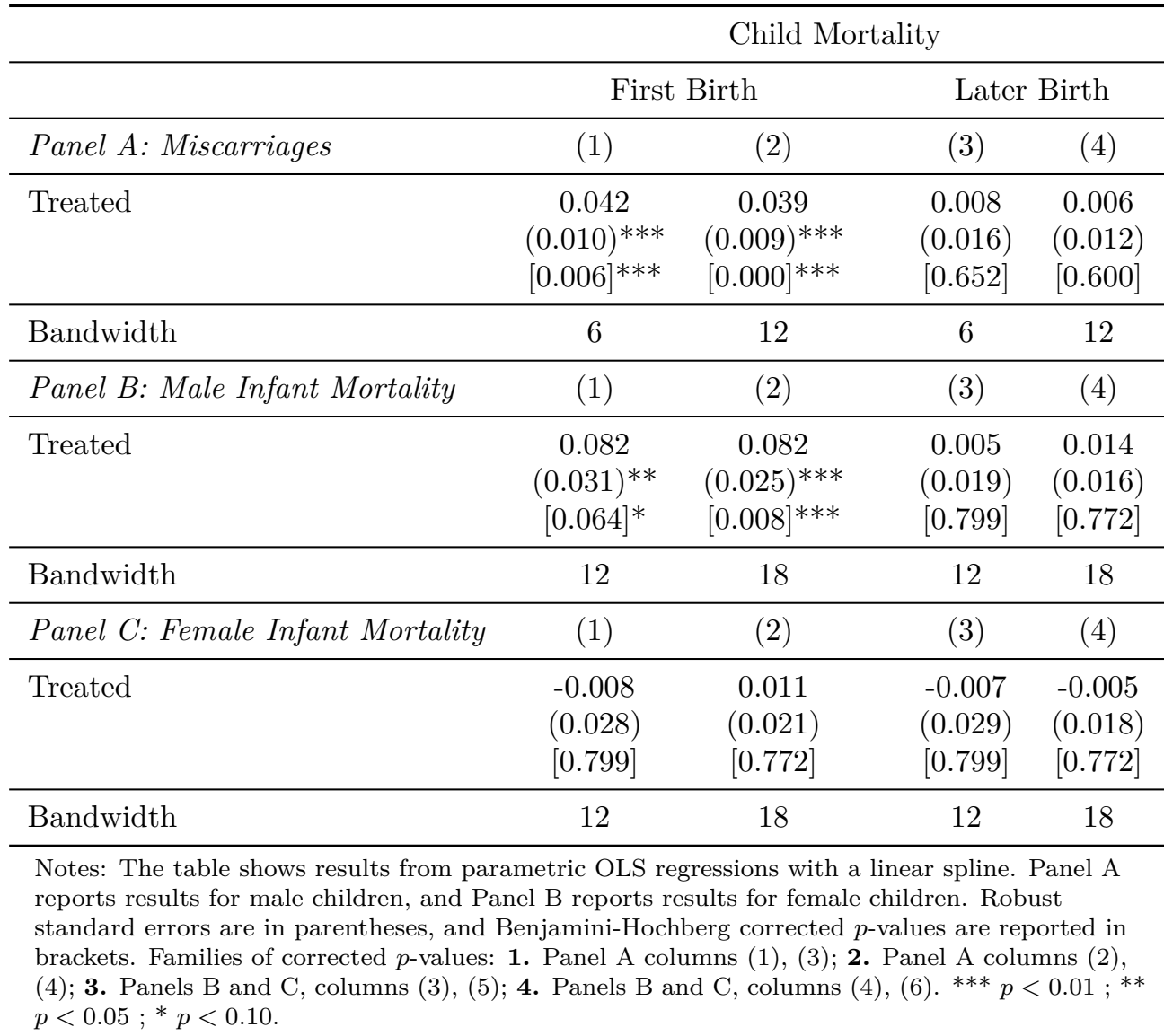

Table A.5: First Child Survival, Seasonality Tests

\begin{tabular}{lccccccc}
\hline \multicolumn{1}{c}{ 1992 } & 1991 & 1990 & 1989 & 1988 & 1987 & 1986 \\
\hline Panel $A$ & $(1)$ & $(2)$ & $(3)$ & $(4)$ & $(5)$ & $(6)$ & $(7)$ \\
\hline Treated & 0.029 & 0.026 & -0.011 & $0.044^{* *}$ & 0.003 & 0.028 & 0.030 \\
& $(0.025)$ & $(0.025)$ & $(0.024)$ & $(0.022)$ & $(0.026)$ & $(0.028)$ & $(0.025)$ \\
\hline Observations & 1,468 & 1,549 & 1,467 & 1,474 & 1,346 & 1,132 & 1,215 \\
Bandwidth & 6 & 6 & 6 & 6 & 6 & 6 & 6 \\
\hline Panel B & \multicolumn{7}{c}{ Miscarriage } \\
\hline & $(1)$ & $(2)$ & $(3)$ & $(4)$ & $(5)$ & $(6)$ & $(7)$ \\
\hline Treated & -0.036 & 0.025 & 0.025 & $0.083^{* *}$ & -0.019 & 0.069 & 0.030 \\
& $(0.033)$ & $(0.033)$ & $(0.035)$ & $(0.038)$ & $(0.046)$ & $(0.046)$ & $(0.040)$ \\
\hline Observations & 1,345 & 1,376 & 1,361 & 1,405 & 1,247 & 1,065 & 1,061 \\
Bandwidth & 12 & 12 & 12 & 12 & 12 & 12 & 12 \\
\hline
\end{tabular}

Notes: All estimates are from a parametric OLS regression with linear splines. Robust standard errors are in parentheses. ${ }^{* * *} p<0.01 ;{ }^{* *} p<0.05 ;{ }^{*} p<0.10$. 
Table A.6: Infant Death, Smaller Bandwidths

\begin{tabular}{lcccccc}
\hline & \multicolumn{7}{c}{ Infant Death } \\
\hline & \multicolumn{2}{c}{ All } & \multicolumn{2}{c}{ First Birth } & \multicolumn{2}{c}{ Later Birth } \\
\hline Panel A: Male Children & $(1)$ & $(2)$ & $(3)$ & $(4)$ & $(5)$ & $(6)$ \\
\hline Treated & 0.004 & 0.012 & 0.080 & $0.074^{*}$ & -0.023 & -0.011 \\
& $(0.025)$ & $(0.021)$ & $(0.052)$ & $(0.043)$ & $(0.029)$ & $(0.024)$ \\
\hline Observations & 2,633 & 3,856 & 730 & 1,057 & 1,903 & 2,799 \\
Bandwidth & 6 & 9 & 6 & 9 & 6 & 9 \\
\hline Panel B: Female Children & $(1)$ & $(2)$ & $(3)$ & $(4)$ & $(5)$ & $(6)$ \\
\hline Treated & 0.029 & 0.024 & 0.024 & 0.033 & 0.032 & 0.022 \\
& $(0.025)$ & $(0.021)$ & $(0.050)$ & $(0.041)$ & $(0.028)$ & $(0.024)$ \\
\hline Observations & 2,434 & 3,578 & 642 & 947 & 1,792 & 2,631 \\
Bandwidth & 6 & 9 & 6 & 9 & 6 & 9 \\
\hline
\end{tabular}

Notes: The table shows results from parametric OLS regressions with a linear spline. Panel A reports results for male children, and Panel B reports results for female children. Robust standard errors are in parentheses. *** $p<0.01 ; * * p<0.05 ; * p<0.10$.

Table A.7: Miscarriage by Presence of Older Sibling

\begin{tabular}{lcccc}
\hline & \multicolumn{4}{c}{ Miscarriage } \\
\hline & No Sibling & Aged $\geq 8$ & \multicolumn{2}{c}{ Sibling Aged $\geq 8$} \\
\hline Panel A: Optimal Bandwidth & $(1)$ & $(2)$ & $(3)$ & $(4)$ \\
\hline Treated & $h^{*}$ & $0.5 h^{*}$ & $h^{*}$ & $0.5 h^{*}$ \\
& 0.007 & 0.007 & -0.003 & -0.009 \\
& $(0.005)$ & $(0.008)$ & $(0.009)$ & $(0.012)$ \\
& {$[0.440]$} & {$[0.686]$} & {$[0.745]$} & {$[0.445]$} \\
\hline Observations & 29,766 & 15,139 & 13,550 & 6,581 \\
Bandwidth & 76 & 38 & 65 & 32 \\
\hline Treated : Other Bandwidths & $(1)$ & $(2)$ & $(3)$ & $(4)$ \\
\hline Observations & 0.002 & 0.002 & 0.020 & 0.004 \\
Bandwidth & $(0.020)$ & $(0.016)$ & $(0.026)$ & $(0.022)$ \\
\hline
\end{tabular}

Notes: The table shows results from parametric OLS regressions with a linear spline.

Panel A reports results from optimal bandwidths, and Panel B reports results from

smaller bandwidths. Robust Standard errors are in parentheses, and

Benjamini-Hochberg corrected $p$-values are reported in brackets. Families of corrected

p-values: 1. Panel A columns (1), (3); 2. Panel A columns (2), (4); 3. Panel B columns

(1), (3); 4. Panel B columns (2), (4). ${ }^{* * *} p<0.01 ;{ }^{* *} p<0.05 ;{ }^{*} p<0.10$. 
Table A.8: Adult Women's Education by Distance to Main Border Crossing

\begin{tabular}{lcccccc}
\hline & \multicolumn{3}{c}{ Years of Schooling } \\
\hline & \multicolumn{2}{c}{ All } & \multicolumn{2}{c}{ Close } & \multicolumn{2}{c}{ Far } \\
\hline Panel A: Optimal Bandwidths & $h^{*}$ & $0.5 h^{*}$ & $h^{*}$ & $0.5 h^{*}$ & $h^{*}$ & $0.5 h^{*}$ \\
\hline & $(1)$ & $(2)$ & $(3)$ & $(4)$ & $(5)$ & $(6)$ \\
\hline Treated & 0.702 & 0.935 & 0.717 & 0.847 & 0.594 & 0.814 \\
& $(0.227)^{* * *}$ & $(0.325)^{* * *}$ & $(0.280)^{* *}$ & $(0.399)^{* *}$ & $(0.317)^{*}$ & $(0.469)^{*}$ \\
& & & {$[0.020]^{* *}$} & {$[0.068]^{*}$} & {$[0.061]^{*}$} & {$[0.083]^{*}$} \\
\hline Observations & 5,608 & 2,857 & 3,826 & 1,931 & 2,774 & 1,388 \\
Bandwidth & 30 & 15 & 42 & 21 & 29 & 14 \\
\hline Panel B: Other Bandwidths & $(1)$ & $(2)$ & $(3)$ & $(4)$ & $(5)$ & $(6)$ \\
\hline Treated & 0.876 & 0.879 & 0.305 & 0.700 & 1.559 & 1.106 \\
& $(0.541)$ & $(0.426)^{* *}$ & $(0.763)$ & $(0.619)$ & $(0.764)^{* *}$ & $(0.588)^{*}$ \\
& & & {$[0.689]$} & {$[0.259]$} & {$[0.084]^{*}$} & {$[0.120]$} \\
\hline Observations & 1,128 & 1,753 & 549 & 834 & 579 & 919 \\
Bandwidth & 6 & 9 & 6 & 9 & 6 & 9 \\
\hline
\end{tabular}

Notes: The table shows results from parametric OLS regressions with a linear spline. The sample includes women who were at least 18 years old at the time of the survey. Robust standard errors are in parentheses, and Benjamini-Hochberg corrected $p$-values are reported in brackets. Families of corrected $p$-values: 1. Panel A columns (3), (5); 2. Panel A columns (4), (6); 3. Panel B columns (3), (5); 4. Panel B columns (4), (6). ${ }^{* * *} p<0.01 ;{ }^{* *} p<0.05 ;{ }^{*} p<0.10$.

Table A.9: Number of Surviving Children, DHS Data

\begin{tabular}{lcccc}
\hline \multicolumn{5}{c}{ Number of Surviving Children } \\
\hline & $(1)$ & $(2)$ & $(3)$ & $(4)$ \\
\hline Treated & 0.036 & 0.074 & -0.040 & 0.081 \\
& $(0.097)$ & $(0.081)$ & $(0.204)$ & $(0.169)$ \\
Treated x Fraction Male & & & 0.031 & -0.176 \\
& & & $(0.334)$ & $(0.277)$ \\
Fraction Male & & & $-1.004^{* * *}$ & $-0.918^{* * *}$ \\
& & & $(0.193)$ & $(0.160)$ \\
\hline Observations & 5264 & 7299 & 5245 & 7276 \\
Bandwidth & 6 & 9 & 6 & 9 \\
\hline
\end{tabular}

Notes: The table shows results from parametric OLS regressions. Robust standard errors are in parentheses. ${ }^{* * *} p<0.01 ;{ }^{* *} p<0.05 ;{ }^{*} p<0.10$. 
Table A.10: Adult Men's Education, DHS Data

\begin{tabular}{lcccc}
\hline \multicolumn{4}{c}{ Years of Schooling } \\
\hline & \multicolumn{2}{c}{ Linear Spline } & \multicolumn{2}{c}{ Quadratic Spline } \\
\hline Treated & $0.708^{*}$ & -0.405 & -0.081 & -0.143 \\
& $(0.361)$ & $(0.550)$ & $(0.575)$ & $(0.927)$ \\
\hline Observations & 1,394 & 676 & 1,394 & 676 \\
Bandwidth & 25 & 12 & 25 & 12 \\
\hline
\end{tabular}

Notes: The table shows results from parametric OLS regressions. Robust standard errors are in parentheses. ${ }^{* * *} p<0.01$; ** $p<0.05$; ${ }^{*} p<0.10$.

Table A.11: Alternative Benjamini-Hochberg Corrections

\begin{tabular}{lcccccc}
\hline Panel $A$ & \multicolumn{7}{c}{ Child Outcomes } \\
\hline & \multicolumn{2}{c}{ Live Births } & \multicolumn{2}{c}{ Miscarriage } & \multicolumn{2}{c}{ Infant Death } \\
\hline Treated & -0.221 & -0.175 & 0.018 & 0.014 & 0.012 & 0.016 \\
& $(0.038)^{* * *}$ & $(0.034)^{* * *}$ & $(0.013)$ & $(0.011)$ & $(0.013)$ & $(0.011)$ \\
& {$[0.000]^{* * *}$} & {$[0.000]^{* * *}$} & {$[0.236]$} & {$[0.183]$} & {$[0.340]$} & {$[0.183]$} \\
\hline Observations & 25 & 37 & 5,455 & 8,027 & 9,611 & 14,116 \\
Bandwidth & 12 & 18 & 6 & 9 & 12 & 18 \\
\hline Panel B & \multicolumn{7}{c}{ Height } & & Ydult Outcomes & & \\
\hline & $(1)$ & $(2)$ & $(3)$ & $(4)$ & $(5)$ & $(6)$ \\
\hline Treated & 0.227 & -0.062 & 0.876 & 0.879 & 0.075 & 0.204 \\
& $(1.058)$ & $(0.803)$ & $(0.541)$ & $(0.426)^{* *}$ & $(0.196)$ & $(0.122)^{*}$ \\
& {$[0.830]$} & {$[0.938]$} & {$[0.318]$} & {$[0.117]$} & {$[0.830]$} & {$[0.143]$} \\
\hline Observations & 621 & 989 & 1,128 & 1,753 & 660 & 1,201 \\
\hline Bandwidth & 6 & 9 & 6 & 9 & 2 & 4 \\
\hline
\end{tabular}

Notes: The table shows results from parametric OLS regressions with a linear spline. Robust standard errors are in parentheses, and Benjamini-Hochberg corrected $p$-values are reported in brackets. Families of corrected $p$-values: 1. Panel A columns (1), (3), (5); 2. Panel A columns (2), (4), (6); 3. Panel B columns (1), (3), (5); 4. Panel B columns (2), (4), (6);. *** $p<0.01$; ${ }^{* *} p<0.05$ ${ }^{*} p<0.10$. 
Table A.12: End of the Embargo: Live Births by Distance to Main Border Crossing

\begin{tabular}{lcccccc}
\hline & \multicolumn{7}{c}{ Live Births } \\
\hline & \multicolumn{2}{c}{ All } & \multicolumn{2}{c}{ Close } & Far \\
\hline Panel A: All children & $(1)$ & $(2)$ & $(3)$ & $(4)$ & $(5)$ & $(6)$ \\
\hline Treated (end of embargo) & 0.082 & 0.092 & 0.077 & 0.160 & 0.087 & 0.018 \\
& $(0.067)$ & $(0.060)$ & $(0.059)$ & $(0.057)^{* *}$ & $(0.083)$ & $(0.083)$ \\
& & & {$[0.318]$} & {$[0.028]^{* *}$} & {$[0.318]$} & {$[0.827]$} \\
\hline Bandwidth & 6 & 9 & 6 & 9 & 6 & 9 \\
\hline Panel B: Male children & $(1)$ & $(2)$ & $(3)$ & $(4)$ & $(5)$ & $(6)$ \\
\hline Treated (end of embargo) & -0.070 & -0.045 & 0.048 & 0.114 & -0.192 & -0.213 \\
& $(0.102)$ & $(0.096)$ & $(0.123)$ & $(0.105)$ & $(0.176)$ & $(0.160)$ \\
& {$[0.513]$} & {$[0.648]$} & {$[0.705]$} & {$[0.298]$} & {$[0.606]$} & {$[0.272]$} \\
\hline Bandwidth & 6 & 9 & 6 & 9 & 6 & 9 \\
\hline Panel C: Female children & $(1)$ & $(2)$ & $(3)$ & $(4)$ & $(5)$ & $(6)$ \\
\hline Treated (end of embargo) & 0.217 & 0.222 & 0.102 & 0.213 & 0.320 & 0.223 \\
& $(0.114)^{*}$ & $(0.091)^{* *}$ & $(0.139)$ & $(0.125)$ & $(0.138)^{* *}$ & $(0.111)^{*}$ \\
& {$[0.176]$} & {$[0.054]^{*}$} & {$[0.641]$} & {$[0.220]$} & {$[0.184]$} & {$[0.220]$} \\
\hline Bandwidth & 6 & 9 & 6 & 9 & 6 & 9 \\
\hline
\end{tabular}

Notes: The table shows results from parametric OLS regressions with a linear spline. Panel A reports results for all children, Panel B reports results for male children, and Panel C reports results for female children. Robust standard errors are in parentheses, and Benjamini-Hochberg corrected $p$-values are reported in brackets. Families of corrected $p$-values: 1. Panel A columns (3), (5); 2. Panel A columns (4), (6); 3. Panel B column (1), Panel C column (1); 4. Panel B column (2), Panel C column (2); 5. Panel B columns (3), (5), Panel C columns (3), (5); 6. Panel B columns (4), (6), Panel C columns (4), (6). ${ }^{* * *} p<0.01 ;{ }^{* *} p<0.05 ;{ }^{*} p<0.10$. 


\section{B Additional Robustness Results}

In this section we report robustness exercises associated with our live birth findings in Section 5.1.1.

First, we re-estimate the specifications in Panels A and $\mathrm{C}$ of Table 3 using a somewhat larger bandwidth ${ }^{51}$, and find very similar results, reported in Appendix Table A.1. We also estimate specification (1) using the optimal bandwidth choice of the algorithm in Calonico et al. (2014), shown in column (1) of Appendix Table A.2. Column (2) of that table presents results using approximately half of that bandwidth. Column (1) yields an estimated decline in live births of $8.6 \%$ with an optimal bandwidth of 33 months, and column (2) an estimated decline of $18.0 \%$ with a bandwidth of 16 months, both statistically significant at the $1 \%$ level. Columns (3) and (4) of Appendix Table A.2 show results from (1) using bandwidths of 18 and 24 months, but with quadratic rather than linear splines. The results are very similar to those in columns (1) and (2) of Table 3, showing estimated declines in live births of $24.8 \%$ and $21.1 \%$, respectively.

To address concerns of maternal recall bias driving the results, we re-estimate specification (1) using only data from the 1996 wave of DHS data, which is the closest chronologically to the imposition of the embargo in 1989. The results in Panel B of Appendix Table A.2 show that the results are again very similar to the corresponding Panel $\mathrm{C}$ in Table 3 and (with the exception of column (4) in Panel B of Table A.2) statistically significant. The estimated declines in live births become much larger when we use smaller bandwidths of 6 and 12 months in columns (1) and (2).

As a falsification check, we also re-estimate specification (1) for the full sample of live births after redefining the cut-off month to be March in the three pre-embargo years of 1986-88, and the three post-embargo years 1990-92 to confirm that we are capturing embargo impacts beginning in March 1989 rather than a seasonal effect. The results of these six placebo tests are in Appendix Table A.3, estimated with bandwidths of 18 and 24 months in Panels $\mathrm{A}$ and $\mathrm{B}$, respectively. We find statistically significant estimates in column (2) for 1991, but these have a magnitude of at most one-third of the estimated effect of the actual embargo. The other estimates are also much smaller than the estimated embargo effect and statistically insignificant, lending confidence that the effect we capture is not a seasonal phenomenon.

\footnotetext{
${ }^{51}$ This uses a data bandwidth of 24 months in Panel A, and a bandwidth of 24 months in Panel C, instead of 18 months as in Tabel 3 .
} 


\section{Density Break Tests}

The parameter of interest $\theta$ in the McCrary density break test is estimated as:

$$
\begin{aligned}
& \hat{\theta}= \ln \lim _{t \downarrow t_{0}} \hat{f}(t)-\ln \lim _{t \uparrow t_{0}} \hat{f}(t) \\
&=\ln \left\{\sum_{X_{j}>t_{0}} K\left(\frac{X_{j}-t_{0}}{h}\right) \frac{S_{n, 2}^{+}-S_{n, 1}^{+}\left(X_{j}-t_{0}\right)}{S_{n, 2}^{+} S_{n, 0}^{+}-\left(S_{n, 1}^{+}\right)^{2}} Y_{j}\right\} \\
& \quad-\ln \left\{\sum_{X_{j}<t_{0}} K\left(\frac{X_{j}-t_{0}}{h}\right) \frac{S_{n, 2}^{-}-S_{n, 1}^{-}\left(X_{j}-t_{0}\right)}{S_{n, 2}^{-} S_{n, 0}^{-}-\left(S_{n, 1}^{-}\right)^{2}} Y_{j}\right\}
\end{aligned}
$$

where $S_{n, k}^{+}=\sum_{X_{j}>t_{0}} K\left(\frac{X_{j}-t_{0}}{h}\right)\left(X_{j}-t_{0}\right)^{k}$ and $S_{n, k}^{-}=\sum_{X_{j}<t_{0}} K\left(\frac{X_{j}-t_{0}}{h}\right)\left(X_{j}-t_{0}\right)^{k}$. The bandwidth $h$ determines the number of observations included in the local-linear regression, and is computed using an automated procedure after fitting a fourth-order global polynomial separately on each side of the cut-off $t_{0}$. Under standard non-parametric regularity conditions, $\hat{\theta}$ is consistent and asymptotically normal with approximate standard error $\hat{\sigma}_{\theta}=\sqrt{\frac{1}{n h} \frac{24}{5}\left(\frac{1}{\hat{f}^{+}}+\frac{1}{\hat{f}^{-}}\right)}$, where $\hat{f}^{+}=\lim _{t \downarrow t_{0}} \hat{f}(t)$ and $\hat{f}^{-}=\lim _{t \uparrow t_{0}} \hat{f}(t)$.

The density break test in Cattaneo et al. (2019) begins with the empirical cumulative density function (c.d.f) estimator for $Y$, given by $\tilde{F}(t)=\frac{1}{n} \sum_{j=1}^{n} \mathbf{1}\left(t_{j} \leq t\right)$, and then uses local polynomial smoothers to propose the c.d.f. estimator:

$$
\hat{\beta}_{p}(t)=\arg \min _{\mathbf{b} \in \mathbb{R}^{p+1}} \sum_{i=1}^{n}\left(\tilde{F}_{i}\left(t_{i}\right)-\mathbf{r}_{p}\left(t_{i}-t\right)^{\prime} \mathbf{b}\right) K_{h}\left(t_{i}-t\right),
$$

where $\tilde{F}_{i}\left(t_{i}\right)$ is the leave-one-out empirical c.d.f. estimator, $\mathbf{r}_{p}(u)=\left(1, u, u^{2}, \ldots, u^{p}\right)^{\prime} \in$ $\mathbb{R}^{p+1}, K_{h}(u)=\frac{K(u / h)}{h}, K($.$) is a kernel function, and h_{n}$ is a positive vanishing bandwidth sequence. The estimator for the density function then takes the form $\hat{f}_{p}(t)=\mathbf{e}_{1}^{\prime} \hat{\beta}_{p}(t)$, where $\mathbf{e}_{v}$ is the conformable $(v+1)$-th unit vector.

To bring this framework to the density break test, we define the control group sample $\left(t_{i}<t_{0}\right)$ as $N_{0}$ and the treated sample $\left(t_{i} \geq t_{0}\right)$ as $N_{1}$ so that $N_{0}+N_{1}=n$ by construction. Let the group indicator $g \in\{0,1\}$ take value 0 for the control group and value 1 for the treated group respectively. The density estimator for each group is computed separately at the threshold $t_{0}$, yielding the estimators $\hat{f}_{g, p}\left(t_{0}\right)=\mathbf{e}_{1}^{\prime} \hat{\beta}_{g, p}\left(t_{0}\right)$ for $g \in\{0,1\}$ and $p \geq 1$. The test statistic of interest is then:

$$
T_{p}\left(h_{n}\right)=\frac{\frac{N_{1}-1}{n-1} \hat{f}_{1, p}\left(t_{0}\right)-\frac{N_{0}-1}{n-1} \hat{f}_{0, p}\left(t_{0}\right)}{\sqrt{\left(\frac{N_{1}-1}{n-1}\right)^{2} \hat{\sigma}_{1, p}^{2}\left(t_{0}\right)+\left(\frac{N_{0}-1}{n-1}\right)^{2} \hat{\sigma}_{0, p}^{2}\left(t_{0}\right)}}
$$

where $\hat{\sigma}_{1, p}^{2}\left(t_{0}\right)$ and $\hat{\sigma}_{0, p}^{2}\left(t_{0}\right)$ are jackknife standard error estimators computed for the treated and control groups respectively. We report results from setting $p=2$, but the results are also robust to setting $p=3$ or higher.

We also perform a density break test as outlined in McCrary (2008), which estimates the density of $Y$ as a function of the running variable $t$, and then tests for a discontinuity in the density estimator at the cut-off $t_{0}$. To create the estimator for the density of $Y$, a histogram $g\left(t_{i}\right)$ of $Y$ by calendar month $t$ is built, where the total number of live births in the sample is denoted by $n$, and $t_{i}$ indicates the calendar month of live birth $i$. The histogram is created by dividing the frequency table of $Y$ into an equi-spaced grid $X_{1}, X_{2}, \ldots, X_{J}$ of width $b$ covering all the calendar months $t$ in the sample. Define the normalized cell-size for the $j$ th bin as $Y_{j}=\frac{1}{n b} \sum_{i=1}^{n} \mathbf{1}\left(g\left(t_{i}\right)=X_{j}\right)$. The triangular 
kernel function $K(v)=\max \{0,1-|v|\}$ is then used to smooth this histogram, yielding the density estimator of $Y$. Let the number of live births $Y$ in calendar month $r$ be denoted by $Y_{r}$, and the density estimator of $Y$ in calendar month $r$ be given by $\hat{f}(r)$. The parameter of interest $\theta$ is the log-difference in the height of the density at the cut-off $t_{0}$. 


\section{A Model}

We consider a small, open economy whose supply side is similar to the structure outlined in Coşar and Fajgelbaum (2016) but whose demand side features non-homothetic preferences. Specifically, we focus on non-homothetic preferences that emphasize a role for necessary goods in household welfare, a relevant case for the developing country context we explore in the empirics. We first develop the spatial equilibrium and then, in our comparative statics exercise, we consider a short-run adjustment to a trade shock in the absence of worker mobility across regions. Formally, the economy has $I$ regions, indexed by $i$, and two industries, $j \in\{C, H\}$. Only certain regions, which we will refer to as "ports", have access to international markets - e.g., they may have border crossings or international airports. We allow the index $i$ to be ordered so as to reflect the distance of a region from its nearest port, such that regions with ports are indexed $i=0$.

International trade costs take the iceberg form and are industry-specific, such that for each unit of goods shipped from a port $\tau_{0}^{j}$ units arrive in the foreign port. Similarly, internal trade costs between regions within the country take the iceberg form per unit of distance and are given by $\tau_{1}^{j}$, so that for each unit of goods shipped from some region $i$ a total of $\tau_{0}^{j} \tau_{1}^{j} i$ units arrive in the foreign port.

There are two factors of production, labour and land. Labour is mobile across industries and locations while land is assumed to be industry- and location-specific. The specificity of land therefore generates a congestion force (via decreasing returns to scale) in each region. The quantity of land and labour in an industry and region are denoted $T_{j}(i)$ and $L_{j}(i)$, respectively. The total amount of labour in the economy is $L$.

\section{D.1 Preferences}

The preferences of households located in region $i$ take the Stone-Geary form and depend on their consumption of a manufactured good $C(i)$ and their consumption of a household good $H(i) .{ }^{52}$ The indirect utility of the household is therefore given by:

$$
v\left(m(i), P_{H}(i), P_{C}(i)\right)=\phi\left(\frac{M(i)}{P_{H}(i)}-\gamma\right)\left(\frac{P_{H}(i)}{P_{C}(i)}\right)^{\alpha}, \quad \gamma \geq 0
$$

where $\phi \equiv \alpha^{\alpha}(1-\alpha)^{1-\alpha}, \alpha \in[0,1] ; \gamma>0$ indicates positive subsistence consumption of household goods, $H ; M(i)$ is total income in region $i$; and $P_{C}(i), P_{H}(i)$ are the prices of the manufactured and household goods in region $i$, respectively. Here we assume that land owners are immobile and do not work, such that total income in region $i$ is

$$
M(i)=w(i) L(i)+r(i) T(i)
$$

where $L(i)$ and $T(i)$ are labour and land in region $i$ and $w(i), r(i)$ are the returns to labour and land, respectively. Given these preferences, the share of income spent on each $\operatorname{good}, \chi_{C}(i), \chi_{H}(i)$, is

$$
\begin{aligned}
& \chi_{C}(i)=\frac{\alpha\left(M(i)-\gamma P_{H}(i)\right)}{M(i)} \\
& \chi_{H}(i)=(1-\alpha)+\frac{\gamma P_{H}(i)}{M(i)}
\end{aligned}
$$

\footnotetext{
${ }^{52}$ The utility function is $U=C(i)^{\alpha}(H(i)-\gamma)^{1-\alpha}$.
} 
where we see that richer households are less reliant on (consume proportionately less of) the subsistence good, $H$, while consuming proportionately more of the manufactured good, $C$.

\section{D.2 Production}

The aggregate production function is Cobb-Douglas in labour and land, such that the production technology for manufactured or household goods in region $i$ is

$$
Y_{j}\left[L_{j}(i), T_{j}(i)\right]=A_{j}(i) T_{j}(i)^{\eta_{j}} L_{j}(i)^{1-\eta_{j}} \quad \text { for } j=C, H
$$

where $A_{j}(i)$ is the technology level in industry $j$ and region $i$. In what follows we will assume that $\eta_{C}=\eta_{H}=\eta$ for simplicity and in order to focus on our key predictions of interest.

While the level of technology may vary across regions it is constrained such that the relative level of technology is constant across regions - i.e., $\frac{A_{C}(i)}{A_{H}(i)}=a, \forall i \in[0, I]$. This simplifying assumption ensures that the country's comparative advantage in the world economy is determined at the national, rather than regional, level. We further assume that $a$ differs across countries, providing a Ricardian motive for international trade.

Since the country is small in world markets it takes international prices as given. Defining $p^{A} \equiv P_{C}^{A} / P_{H}^{A}$ as the relative autarky price in all regions, region $i$ will be fully specialized in (and will export) good $C$ when the relative price $p(i) \equiv P_{C}(i) / P_{H}(i)>p^{A}$ and will specialize in (and export) good $H$ when $p(i)<p^{A}$. Only when $p(i)=p^{A}$ can a region be incompletely specialized, in which case the region is indifferent between autarky or trade.

An important implication of this economy is that there potentially exists some threshold region, $\bar{i}$, beyond which all regions are in autarky. To see this, first denote the boundary region within the country that is furthest from a port as $i_{b}$. We next note that when a country exports, for instance, good $C$ then all trading regions must specialize in $C$. The delivered (foreign) relative price of $C$, which we denote $p^{*} \equiv P_{C}^{*} / P_{H}^{*}$, is then

$$
p^{*}=p(i) \tau_{0}^{C} \tau_{1}^{C} \tau_{0}^{H} \tau_{1}^{H} i^{2}
$$

where we have used the fact that $P_{C}(i)=P_{C}^{*} / \tau_{0}^{C} \tau_{1}^{C} i$ and $P_{H}(i)=P_{H}^{*} \tau_{0}^{H} \tau_{1}^{H} i$. Condition (9) therefore defines the dispersion in prices across regions in this economy. Most critically, it implies that the local relative price of the export good, $p(i)$, is decreasing in the distance to a port, as more of each unit price gets absorbed in trade costs (recall $p^{*}$ is fixed). Thus, as long as $\bar{i}<i_{b}$, regions beyond some threshold $\bar{i}$ would prefer to specialize in and export $H$, as the price of $C$ will be too low ${ }^{53}$ since this is ruled out, those regions, and all those for which $i \geq \bar{i}$, must be in autarky and are consequently incompletely specialized. ${ }^{54}$

\section{D.3 Production Problem}

From (8), profits in industry $j$ within region $i$ are

\footnotetext{
${ }^{53}$ Regions exactly at distance $\bar{i}$ are indifferent.

${ }^{54}$ Another implication of this economy is that a no arbitrage condition implies that there is no domestic trade. Specifically, for any regions $i$ and $i^{\prime}$ separated by distance $d$ we know that $p_{j}\left(i^{\prime}\right) \leq p_{j}(i) \tau_{1}^{j} d$, where the condition binds when $i$ sells to $i^{\prime}$. In other words, the ratio of the prices between any two regions will be exactly equal to the transport costs between them, such that there are no gains from domestic trade.
} 


$$
\pi_{j}(i)=\max _{L_{j}(i)}\left\{P_{j}(i) Y_{j}\left[T_{j}(i), L_{j}(i)\right]-w(i) L_{j}(i)-r(i) T_{j}(i)\right\}
$$

the solution to which indicates that the demand for labour in region $i$ and industry $j$ is

$$
L_{j}(i)=\frac{1-\alpha}{\alpha}\left(\frac{A_{j}(i) P_{j}(i)}{w(i)}\right)^{1 / \eta} \text { for } j=C, H
$$

\section{D.4 Equilibrium}

The general equilibrium consists of a set of local equilibria in combination with the requirement that welfare is equalized across regions and the national labour market clears.

Definition 1 General equilibrium in region $i$ takes international prices $\left\{P_{C}^{*}, P_{H}^{*}\right\}$ as given and consists of local labour demand $\left\{L_{j}(i)\right\}_{j=C, H}$, local land use $\left\{T_{j}(i)\right\}_{j=C, H}$ and factor prices $\{w(i), r(i)\}$ such that

1. A local equilibrium holds for each region. Formally, taking prices $\left\{P_{C}(i), P_{H}(i)\right\}$ and welfare $\bar{v}$ as given,

A. Workers maximize utility, given by (4), where

$$
v(i) \leq \bar{v}, \text { for } L(i)>0
$$

B. firms (regions) maximize profits, as in (10);

C. trade is balanced across regions; and

D. land and labour markets clear locally:

$$
\sum_{j=C, H} T_{j}(i)=T(i) ; \quad \sum_{j=C, H} L_{j}(i)=L(i)
$$

2. The labour market adjusts such that indirect utility is constant across regions,

$$
\int_{0}^{i_{b}} L(i) d i=L
$$

We first note that the local wage is set by the combination of (11) and the local labour supply condition (12), which leads to the following local labour demand condition:

$$
L(i)= \begin{cases}\psi\left(\frac{A_{C}(i) p(i)}{\frac{p(i)^{\alpha}}{\phi} v(i)+\gamma}\right)^{\frac{1}{\eta-1}} & \text { if } p(i) \geq p^{A} \\ \psi\left(\frac{A_{H}(i)}{\frac{p(i) \alpha}{\phi} v(i)+\gamma}\right)^{\frac{1}{\eta-1}} & \text { if } p(i)<p^{A}\end{cases}
$$

where $\psi \equiv\left(\frac{1-\alpha}{\alpha}\right)^{\frac{\eta}{\eta-1}}$. These two cases reflect specialization and export of either $C$ or $H$, depending on the prevailing relative international price.

The general equilibrium then follows from combining (15) with the local and aggregate labour market clearing conditions (13) and (14) while setting regional welfare equal to 
an economy-wide constant, $\bar{v}^{55}$

\section{D.5 Comparative Statics}

We focus on the short-run regional welfare response to rising international trade costs. It is important to note that, though we are ultimately interested in a country's sudden shift from being relatively open to nearly completely closed, we do not compare a trading regime with an autarky regime; rather, we consider the effects of rising trade costs within the context of the trading regime. The reason is that a move to autarky in the model leads to incomplete specialization, such that both goods are produced in all regions. However, the suddenness and short-run nature of the episode we are interested in rules out a transition away from specialization. In other words, there simply was not enough time for the country to, for instance, ramp up its kerosene and pharmaceutical industries in order to forestall shortages of these goods. As a result, the relevant case is the shortrun case where specialization was maintained, but international trade costs rose to levels that effectively prohibited international trade.

We are interested in the differential regional welfare response to a trade shock, and so we apply our comparative statics to the local equilibrium, (15), since in the general equilibrium welfare is equalized across regions. In doing so, we implicitly assume that workers are unable (do not have time) to migrate in response to the shock. In this case, a shock to international trade costs affects regional welfare through its impact on the region-specific prices of the export and and import goods. Taking the case in which $C$ is the export good, we can solve (15) for $v(i)$ and calculate the effect on regional welfare of a change in international trade costs, given by $d v(i) / d \tau_{0}^{C}$ and $d v(i) / d \tau_{0}^{H}$ :

$$
\begin{aligned}
& d v(i) / d \tau_{0}^{C}=\frac{\phi}{\tau_{0}^{C}}\left[-\theta A_{C}(i) L(i)^{1-\eta} p(i)^{1-\alpha}-\gamma \alpha p(i)^{-\alpha}\right]<0 \\
& d v(i) / d \tau_{0}^{H}=\frac{\phi}{\tau_{0}^{H}}\left[-\theta A_{C}(i) L(i)^{1-\eta} p(i)^{1-\alpha}-\gamma \alpha p(i)^{-\alpha}\right]<0
\end{aligned}
$$

where $\theta \equiv \frac{(1-\alpha)^{\eta+1 / \eta}}{\alpha^{1 / \eta}}$. The only difference in the impact on welfare between a change in $\tau_{0}^{C}$ versus $\tau_{0}^{H}$ is that their magnitudes are each inversely proportional to the initial size of the trade barrier in the sector. In both cases, the overall effect on welfare is unambiguously negative for $i<\bar{i}$ (and zero beyond this point). There are three primary channels through which welfare is impacted by rising international trade costs. The first term in brackets nests two effects: first, a reduction in the local price of the export good (due to the rise in $\tau_{0}^{C}$ ) reduces the demand for labour in region $i$, which reduces household income - a negative "export effect". Second, a rise in the local price of the import good directly reduces local consumption of that good - a negative "consumption effect" - while a fall in the local price of the export good directly increases its local consumption - a positive "consumption effect". The second term in brackets then reflects the fact that the rise in $\tau_{0}^{C}$ and $\tau_{0}^{H}$ forces households to increase expenditure on the subsistence good, $H$, at the

\footnotetext{
${ }^{55}$ It follows that general equilibrium regional welfare $(\bar{v})$ is given by the following implicit functions:
}

$$
\begin{cases}\psi \int_{0}^{i_{b}}\left(\frac{A_{C}(i) p(i)}{\frac{p(i)^{\alpha}}{\phi} \bar{v}+\gamma}\right)^{\frac{1}{\eta-1}} d i-L=0 & \text { if } p(i) \geq p^{A} \\ \psi \int_{0}^{i_{b}}\left(\frac{A_{H}(i)}{\frac{p(i) \alpha}{\phi} \bar{v}+\gamma}\right)^{\frac{1}{\eta-1}} d i-L=0 & \text { if } p(i)<p^{A}\end{cases}
$$


expense of the manufactured good, $C$ - a negative "subsistence effect". In fact, individuals will cease consuming the manufactured good $C$ entirely beyond some threshold price of the subsistence (import) good - i.e., the budget share of the subsistence good may go to one. Beyond this price the desired expenditure on subsistence goods will exceed the household budget constraint, such that households must do without some amount of subsistence consumption. It is above this point that the most deleterious effects of the embargo will be incurred, as households do without subsistence levels of fuel or other necessary imports.

The move to autarky therefore reduces household incomes via a deterioration in the price of the country's export good, while also hitting households on the consumption side as imported goods become more expensive. This then forces households to spend an increasing share of their dwindling incomes on subsistence goods in lieu of other goods. Importantly, the magnitude of these effects differs systematically across regions within the country, in the manner captured in the following proposition:

Proposition 1 The welfare impact due to rising international trade costs, while always negative for $i<\bar{i}$, becomes less negative with the distance from a port as long as the subsistence parameter $\gamma$ is sufficiently small. Formally, conditions (16) are increasing in $i$ as long as

$$
\gamma<\chi A_{C}(i) L(i)^{1-\eta} \frac{p(i) i}{\tau_{0}^{C}}\left[\frac{A_{C}^{\prime}(i)}{A_{C}(i)}+(1-\eta) \frac{L^{\prime}(i)}{L(i)}-2 \frac{(1-\alpha)}{i}\right]
$$

where $\chi \equiv \alpha^{\alpha-1 / \eta}(1-\alpha)^{\eta-\alpha+1 / \eta+1}$.

Proof: Taking the first comparative static result from equation (16), we simply determine for the conditions under which $\frac{d v(i)}{d \tau_{0}^{C} d i}<0$. It is straightforward to show that:

$$
\frac{d v(i)}{d \tau_{0}^{C} d i}=\chi A_{C}(i) L(i)^{1-\eta} p(i)^{1-\alpha}\left[-\frac{A_{C}^{\prime}(i)}{A_{C}(i)}-(1-\eta) \frac{L^{\prime}(i)}{L(i)}+2 \frac{(1-\alpha)}{i}\right]-\gamma p(i)^{-\alpha} \frac{2 \alpha^{2}}{i}
$$

where $\chi \equiv \alpha^{\alpha-1 / \eta}(1-\alpha)^{\eta-\alpha+1 / \eta+1}$. Setting $\frac{d v(i)}{d \tau_{0}^{C} d i}<0$ and rearranging produces the condition in Proposition 1.

Stated in the opposite way, when the necessary household expenditure on the subsistence $\operatorname{good}(\gamma)$ is high (enough), the overall welfare loss for remote regions will exceed the loss for less-remote regions. This is due to the relative poverty of these regions, such that subsistence imports are a relatively large share of total expenditure, as well as the fact that a given rise in external (international) trade costs raises import prices relatively more for more distant regions. This proposition represents our main result: on the one hand, when the condition in Proposition 1 holds, a region that is distant from international gateways is insulated from trade shocks due to the fact that local income is relatively unaffected by those shocks. On the other hand, if the region is relatively reliant on imported necessities then remoteness will be detrimental, an effect operating via heterogeneity in income as well as heterogeneity in the domestic transport costs faced by different regions. ${ }^{56}$

\footnotetext{
${ }^{56}$ To be clear about the mechanism we have in mind, in the empirics we assume that fetal $(F)$ health in period $t, h_{t}^{F}$, is some function of the mother's $(M)$ welfare in $t$-i.e., $h_{t}^{F}=G\left(v_{t}^{M}(i)\right)$. Since fetal health is increasing in the mother's welfare - i.e., $G^{\prime}(\cdot)>0$ - the probability of miscarriage will be declining in her welfare. In this way the comparative statics with respect to welfare described above are linked to
} 
Finally, we note again that at some threshold distance from a port, $\bar{i}$, internal transport costs become too large, and regions beyond this distance are fully isolated from international markets.

fetal health and the probability of miscarriage. 